Pontifícia Universidade Católica $_{\text {do Rio de Janeiro }}$

Leandro Guedes Carvalho

Modelagem Analítica da Geração de Bandas de Deformação em Reservatórios Areníticos

Dissertação de Mestrado

Dissertação apresentada como requisito parcial para obtenção do grau de Mestre pelo Programa de Pósgraduação em Engenharia Civil do Departamento de Engenharia Civil e Ambiental da PUC-Rio.

Orientador: Profa. Dra. Raquel Quadros Velloso. Co-orientador: Dr. Anderson Moraes.

Rio de Janeiro

julho de 2020 
Pontifícia Universidade Católica

DO RIO DE JANEIRO

Leandro Guedes Carvalho

\section{Modelagem Analítica da Geração de Bandas de Deformação em Reservatórios Areníticos}

Dissertação apresentada como requisito parcial para obtenção do grau de Mestre pelo Programa de Pósgraduação em Engenharia Civil do Departamento de Engenharia Civil e Ambiental da PUC-Rio. Aprovada pela Comissão Examinadora abaixo.

Profa. Raquel Quadros Velloso

Orientador

Departamento de Engenharia Civil e Ambiental - PUC-Rio

Dr. Anderson Moraes

Co-orientador

Petróleo Brasileiro SA - Petrobras

Prof. Eurípedes do Amaral Vargas Jr. Departamento de Engenharia Civil e Ambiental - PUC-Rio

Dr. Marcos Roberto Fetter Lopes

Petróleo Brasileiro SA - Petrobras

Rio de Janeiro, 22 de julho de 2020 
Todos os direitos reservados. É proibida a reprodução total ou parcial do trabalho sem autorização da Universidade, do autor e do orientador.

\section{Leandro Guedes Carvalho}

Graduou-se em Ciência da Computação pela UFG (Universidade Federal de Goiás) em 2000. Especializou-se em Sistemas de Informação pela PUC-Rio em 2008. Ocupa o cargo de Analista de Sistemas na Petrobras desde 2008, onde trabalha com o desenvolvimento de softwares científicos com aplicações em geomecânica do petróleo.

Ficha Catalográfica

Carvalho, Leandro Guedes

Modelagem analítica da geração de bandas de deformação em reservatórios areníticos / Leandro Guedes Carvalho ; orientador: Raquel Quadros Velloso ; co-orientador: Anderson Moraes. - 2020.

78 f. : il. color. ; $30 \mathrm{~cm}$

Dissertação (mestrado)-Pontifícia Universidade Católica do Rio de Janeiro, Departamento de Engenharia Civil e Ambiental, 2020. Inclui bibliografia

1. Engenharia Civil e Ambiental - Teses. 2. Bandas de deformação. 3. Modelo Cam Clay Modificado. 4. Trajetória de tensões. 5. Paleomodelo geomecânico. 6. Permeabilidade. I. Velloso, Raquel Quadros. II. Moraes, Anderson. III. Pontifícia Universidade Católica do Rio de Janeiro. Departamento de Engenharia Civil e Ambiental. IV. Título. 
À minha esposa Luciana e ao meu filho Isaac. 


\section{Agradecimentos}

Em primeiro lugar agradeço a Deus por me dar resiliência nesse período de muita dedicação e "porque dele e por ele, e para ele, são todas as coisas" [Rm 11:36].

À minha esposa e amiga Luciana, ao meu filho Isaac e aos meus pais Eustáquio e Roseni pelo apoio e incentivo nos momentos difíceis e pela compreensão nas horas ausentes.

À Profa. Dra. Raquel Velloso por suas valiosas orientações e contribuições.

Ao Dr. Anderson Moraes pelo tema proposto, pelos ensinamentos e paciência dispensados.

À Petrobras e aos gestores Sebastião César Assis Pereira, Silmara Campos e Alvaro Arouca pela oportunidade concedida.

Aos colegas de mestrado Felipe Tajá, Tatiana Alice e Guilherme Bispo por compartilharem seus conhecimentos e me ajudarem no cumprimento dos créditos.

Aos revisores da dissertação Felipe Tajá e Guilherme Bispo.

Aos colegas Aline Theophilo, Bruno Catto, Daniel Dargan, Gustavo Garcia, Eujana Coelho, Felipe Tajá, Guilherme Bispo, Jorge André Braz, Jorge Campos, Krishna Milani, Marcus Santini, Raphael Hatushika, Richard Ney, Romulo Stohler, Thiago Conceição, Thiago Falcão, Victor Hugo Guimaraes e Vitor Gorne por ajudarem na realização do trabalho.

À colega Solange Cunha pela edição das figuras.

O presente trabalho foi realizado com apoio da Coordenação de Aperfeiçoamento de Pessoal de Nível Superior - Brasil (CAPES) - Código de Financiamento 001. Por isso meu agradecimento a essa entidade. 


\section{Resumo}

Carvalho, Leandro Guedes; Velloso, Raquel Quadros; Moraes, Anderson. Modelagem Analítica da Geração de Bandas de Deformação em Reservatórios Areníticos. Rio de Janeiro, 2020. 78 p. Dissertação de Mestrado - Departamento de Engenharia Civil e Ambiental, Pontifícia Universidade Católica do Rio de Janeiro.

A predição da permeabilidade é uma etapa crítica no fluxo de caracterização e modelagem geológica de reservatórios e essencial para o desenvolvimento de projetos de produção. Estruturas subsísmicas denominadas bandas de deformação (BD) podem diminuir a permeabilidade em até seis ordens de grandeza em relação à rocha matriz de reservatórios areníticos e podem, dessa forma, atuar como barreiras totais ou parciais ao fluxo de fluidos.

O presente trabalho pretende contribuir na determinação do comportamento hidráulico de reservatórios propondo um modelo geomecânico analítico para a predição de $\mathrm{BD}$ em reservatórios de arenitos. Em termos práticos, o objetivo é prever se em uma determinada porção de um depósito siliciclástico de hidrocarboneto foram atingidas condições para a formação de $\mathrm{BD}$, ou quão próximo se está de uma possível geração dessa feição a fim de se sugerir uma análise da redução de permeabilidade. A proposta se estende na implementação computacional do método e sua aplicação em um estudo de caso de um reservatório arenítico pouco consolidado da margem continental brasileira rico em BD.

Os resultados confirmaram a viabilidade do método mostrando que a porção do reservatório analisada atingiu as condições mecânicas para a gênese de BD a partir da idade geológica intitulada de Oligoceno ( 23 a $35 \mathrm{Ma}$ ) para os cenários estabelecidos.

\section{Palavras-chave}

bandas de deformação; Modelo Cam Clay Modificado; trajetória de tensões; paleomodelo geomecânico; permeabilidade. 


\section{Abstract}

Carvalho, Leandro Guedes; Velloso, Raquel Quadros (Advisor); Moraes, Anderson (Co-Advisor). Analytical Modeling of Deformation Bands Generation in Sandstone Reservoirs. Rio de Janeiro, 2020. 78 p. Dissertação de Mestrado - Departamento de Engenharia Civil e Ambiental, Pontifícia Universidade Católica do Rio de Janeiro.

The permeability prediction is a critical step in the flow of geological modeling and reservoir characterization and is essential for the development of production projects. Sub-seismic structures called deformation bands (BD) can reduce permeability up to six orders of magnitude in relation to the host reservoir sandstone and can thus act as total or partial barriers to the fluid flow.

The present work intends to contribute in the determination of the hydraulic behavior of reservoirs proposing an analytical geomechanical model for BD's prediction in sandstone reservoirs. In practical terms, the objective is to predict whether the conditions in a given portion of a siliciclastic hydrocarbon deposit have been reached for the localization of $\mathrm{BD}$ or how close it is to a possible generation of this feature in order to suggest an analysis of the permeability reduction. The proposal extends to the computational implementation of the method and its application in a case study of a poorly consolidated sandstone reservoir on the brazilian continental margin, rich in BD.

The results confirmed the viability of the method by showing that the portion of the analyzed reservoir reached the mechanical conditions for the genesis of BD from the geological age entitled Oligocene ( 23 to $35 \mathrm{Ma}$ ) for the established scenarios.

\section{Key-words}

deformation bands; Modified Cam Clay Model; stress path; geomechanics paleomodel; permeability. 


\section{Sumário}

1 Introdução 19

1.1. Motivação 19

1.2. Objetivos 19

1.3. Estruturação do Trabalho 20

2 Revisão Bibliográfica $\quad 21$

2.1. Zona de Falha e Bandas de Deformação 21

2.2. Tipos de Bandas de Deformação 24

2.3. Fatores que controlam a permeabilidade em bandas de deformação $\begin{array}{ll}\text { cataclásticas } & 27\end{array}$

2.4. Geometria das zonas de falhas 28

2.5. Mecânica da gênese de bandas de deformação 29

2.6. Backstripping 39

2.7. Permeabilidade $\quad 40$

2.8. Paleotensões por Inversão de Descontinuidades 43

3 Metodologia $\quad 45$

3.1. Procedimento para a Simulação 46

4 Estudo de caso $\quad 49$

4.1. Descrição da rocha reservatório $\quad 50$

4.2. Modelo Geomecânico 1D Atual 51

4.2.1. Tensão Vertical Total ou Sobrecarga 51

4.2.2. Tensão Horizontal Mínima 52

4.2.3. Tensão Horizontal Máxima 53

4.2.4. Pressão de Fluidos $\quad 56$

4.2.5. Propriedades Mecânicas da Rocha 56

4.3. Geo-História

4.3.1. Inversão de descontinuidades $\quad 61$

4.4. Trajetória de Tensões e Plastificação 64

4.5. Simulação e Resultados $\quad 65$

5 Considerações Finais $\quad 71$ 
5.1. Conclusões

71

5.2. Sugestões para Trabalhos Futuros 72

6 Referências Bibliográficas 


\section{Lista de Figuras}

Figura 1 - Diferentes arquiteturas de zona de falha. a) rochas cristalinas com núcleo de falha (FC - fault core) composto por brecha e gouge de falha e zona de dano (DZ - damage zone) com aumento na densidade de fraturas; b) arenitos porosos com FC composto de argila e DZ composta por BD. Uma terceira parte entre o FC e a DZ denominada zona mista ( $\mathrm{MZ}$ - mixed zone) com sedimentos deformados e misturados é estabelecida e; c) sedimentos não litificados a pouco litificados com FC estruturado em uma parte central (CFC - central fault core) com membranas argilosas e lentes de fragmentos da rocha matriz e a parte distal (DFC - distal fault core) composta de uma mistura de areia e argila ou lentes de argila em uma matriz composta de areia. A DZ inclui BD únicas ou em clusters. [Adaptado de Bauer et al. (2015)] . 22

Figura 2 - Exemplos de BD em regime extensional. (a) Banda de cisalhamento com compactação associada (CSB) mostrando a variação de suas espessuras em relação ao tamanho do grão. Arenito Navajo, Utah. (b) Cluster de CSB e sua transição para superfície de falha na parte inferior da imagem. (c) Cluster de CSB espessa. (d) BD conjugadas. (b-d) Arenito Entrada, San Rafael Desert, Utah [Adaptado de Fossen et al. (2017)] 23

Figura 3 - Afloramento com rede de BD. Bacia do Rio do Peixe, PB - Brasil.....24 Figura 4 - Detalhe de Zona de Dano, com BD, de uma falha com rejeito centimétrico $(\sim 20 \mathrm{~cm})$ em um arenito pouco consolidado. Bacia do Rio do Peixe, PB - Brasil 24

Figura 5 - Espectro cinemático de BD entre os end-members compactação, cisalhamento e dilatação. [Adaptado de Fossen et al. (2017)] 26

Figura 6 - Modelo conceitual mostrando a influência da intensidade de catáclase no contraste da permeabilidade induzido por BD e falhas em reservatórios areníticos. (a) Bandas de compactação pura e bandas de compactação reforçada por cisalhamento. (b) Bandas cataclásticas. (c) Clusters de BD. (d) Bandas cataclásticas com deslocamento. (e) Núcleo de falha com catáclase. A cor azul representa a porosidade. [Adaptado de Ballas et al. (2015)] .....27

Figura 7 - Resumo esquemático dos fatores que influenciam o grau de catáclase em BD. [Adaptado de Fossen et al. (2017)]. 28

Figura 8 - Relação empírica entre o rejeito da superfície da falha e a espessura da zona de dano. [Adaptado de Fossen et al. (2017)] 29 
Figura 9 - Critérios de plastificação Cam Clay e Cam Clay Modificado no espaço p x q. [Adaptado de Borja (2013)] 30

Figura 10 - (a) Dilatância induzida por cisalhamento e (b) compactação do arenito Adamswiller. As curvas sólidas mostram a tensão média efetiva em função da mudança de porosidade em ensaios triaxiais com pressões efetivas fixas como indicado. Para referência, o ensaio hidrostático é mostrado por curvas pontilhadas. [Adaptado de Wong et al. 1997] 32

Figura 11 - Séries de fotografias ilustrando os diferentes modos de falhamento em amostras do arenito Bleurswiller deformadas sob diferentes pressões de confinamento. O diâmetro da amostra intacta (2) era $40 \mathrm{~mm}$ e o comprimento de $80 \mathrm{~mm}$. A amostra (1) foi deformada sob condições hidrostáticas. [Wong e Baud (2012)] 32

Figura 12 - Estado de tensão $C^{\star}$ no início da compactação induzida por cisalhamento (símbolos abertos) e tensão de pico para fratura rúptil (símbolos sólidos) são mostrados no espaço $p \times q$ normalizado. A maior parte das magnitudes de $C^{*}$ está localizada entre dois caps elípticos (curvas pontilhadas) correspondentes a eq.(5). As tensões de pico são ajustadas com uma envoltória de ruptura parabólica (curva sólida). [Adaptado de Wong et al. (1997)]

Figura 13 - Pressões de colapso do grão $\left(P^{*}\right)$ reportados por Wong et al. (1997) somados a três arenitos distintos. [Adaptado de Nguyen et al. (2014)] ......34

Figura 14 - Diagrama $p$ x $q$ aplicado a rochas porosas [após Schultz e Siddharthan (2005)]. Envoltória de deformação inelástica de rocha matriz (curva em negrito) produz bandas de dilatação (1), bandas de cisalhamento com dilatação (2), bandas de cisalhamento (3), bandas de compactação com cisalhamento (4) e bandas de compactação (5). [Fossen et al. (2007)]......37

Figura 15 - Modelo de localização ou distribuição de deformações como bandas dominadas por cisalhamento ou compactação respectivamente, em função das tensões média e diferencial, tamanho do grão, porosidade, pressão de poros e deformação hardening. [Adaptado de Soliva et al. (2013)] 38

Figura 16 - Diagrama $p$ x $q$ mostrando a trajetória de tensões aplicadas em um arenito durante o soterramento que, após atingir o ponto (1) é exposto a extensão, aumentando $q$ e reduzindo $p$ até tocar na envoltória no ponto onde a localização de banda de cisalhamento (CSB) é prevista (2). Se exposto a compressão após o ponto (1), cria um caminho que intercepta o cap onde bandas do tipo SECB e PCB são esperadas (3). [Adaptado de Fossen et al. (2017)] 
Figura 17 - Gráfico mostrando valores de permeabilidade para vários tipos de BD cataclásticas em função da permeabilidade da rocha matriz (arenito). [Adaptado de Ballas et al. (2015)] 42

Figura 18 - Melhor ajuste de $\sigma \varnothing$ aos dados de estrias de falhas (pontos) frente ao critério de Mohr-Coulomb. [Moraes (2018)] 44

Figura 19: Metodologia para obtenção do paleomodelo geomecânico [Moraes (2018)] 45

Figura 20 - Representação conceitual da metodologia 46

Figura 21 - Janela de configuração dos parâmetros do simulador desenvolvido neste projeto

Figura 22 - (A) Testemunho 9 do poço A $(3 \cdot 337,00 \mathrm{~m}$ a $3 \cdot 353,50 \mathrm{~m})$. (B) Testemunho 10 do poço $A(3.353,50 \mathrm{~m}$ a $3.371,50 \mathrm{~m})$ mostrando um cluster de BD. 49

Figura 23 - Interpretação de BD em perfil imagem do poço A e suas atitudes ...50 Figura 24 - Regressão linear representando a tendência da magnitude do $\sigma \mathrm{h}$ em relação às profundidades do poco $A$ 53

Figura 25 - Representação de feições de breakout na parede de um poço vertical [Zoback (2016)]. .54

Figura 26 - Polígono de Tensões .55

Figura 27 - Correlações empíricas por litologia adotadas no cálculo da curva de UCS no poço $A$ 57

Figura 28 - Visão geral dos dados do poço A. .58

Figura 29 - Distribuição granulométrica da profundidade 3.355,00 m do Poço A59 Figura 30 - Evolução cronoestratigráfica pelo método Backstripping. A curva em vermelho representa a subsidência tectônica do embasamento nas idades geológicas. 61

Figura 31 - Evolução cronoestratigráfica pelo método Backstripping 61

Figura 32 - Superfícies de falhas próximas ao poço A utilizadas para a inversão de descontinuidades 62

Figura 33 - Regressão linear para o fator de proporcionalidade (Kp) para estimativa da pressão de colapso $\left(P^{*}\right)$ 65

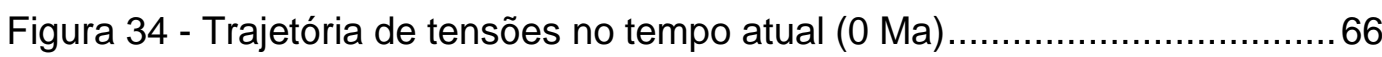

Figura 35 - Trajetória de tensões no tempo 70 Ma (Maastrichtiano)................66 67

Figura 36 - Trajetória de tensões no tempo $\sim 65 \mathrm{Ma}$ (Maastrichtiano) ................66 67

Figura 37 - Trajetória de tensões no tempo 60 Ma (Paleoceno).......................68 68

Figura 38 - Trajetória de tensões no tempo 50 Ma (Eoceno) .........................68

Figura 39 - Trajetória de tensões no tempo 35 Ma (Oligoceno Médio/Inferior) . 69 
Figura 40 - Trajetória de tensões no tempo 25 Ma (Oligoceno Superior) .........69

Figura 41 - Trajetória de tensões no tempo atual ......................................... 70 


\section{Lista de Tabelas}

Tabela 1: Compilação de dados experimentais de pressão crítica efetiva no início do colapso dos grãos sob carga hidrostática $\left(P^{*}\right)$ de Wong et al. (1997) e

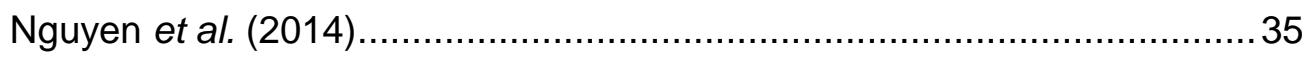

Tabela 2: Pressões de absorção obtidos de teste de absorção (LOT) no poço A 53

Tabela 3: $\sigma_{\mathrm{H}}$ e $\mathrm{K}_{\mathrm{H}}$ calculados a partir de breakouts ......................................55

Tabela 4: Modelo geomecânico 1D atual na profundidade 3.355,22 m ..............57

Tabela 5 - Análise granulométrica da profundidade 3.355,00 m do Poço A .......5 59

Tabela 6: Parâmetros de entrada do Backstripping 1D por intervalo cronoestratigráfico do poço $A$............................................................6 60

Tabela 7 - Cenários para as tensões horizontais e regimes de falhamento........63

Tabela 8: Compilação dos resultados .........................................................66 


\section{Lista de Símbolos}

Alfabeto Latino:

a Constante empírica ajustável na relação de Gardner.

$b \quad$ Expoente empírico ajustável na relação de Gardner.

C Coeficiente de decaimento da compactação.

C' Tensão de início de dilatância induzida por cisalhamento em ensaio triaxial.

$C^{*} \quad$ Tensão de início de compactação induzida por cisalhamento em ensaio triaxial.

$d_{g} \quad$ Diâmetro do grão assumindo geometria esférica (equação de KozenyCarman).

g Aceleração devido à gravidade.

$k \quad$ Permeabilidade.

$k_{i} \quad$ Permeabilidade inicial.

$k_{0} \quad$ Fator de correção introduzido para contabilizar a forma real do poro na equação de Kozeny-Carman.

$k_{p} \quad$ Fator de proporcionalidade da relação de Zhang et al. (1990b) para a estimativa da pressão crítica de colapso $\left(P^{*}\right)$.

M Inclinação da linha de estado crítico do modelo Cam-Clay Modificado no gráfico $p^{\prime} \times q$.

$p^{\prime} \quad$ Tensão média efetiva.

$P^{*} \quad$ Pressão efetiva de colapso do meio poroso com o esmagamento e o faturamento em escala do grão, na qual ocorre compactação com ausência de cisalhamento.

$P_{b d t} \quad$ Pressão efetiva de transição entre falhamento rúptil e fluxo cataclástico em ensaio triaxial.

$P_{c} \quad$ Pressão de pré-adensamento, parâmetro do modelo Cam-Clay Modificado no gráfico $p$ ' x $q$ para solos.

$P_{c f} \quad$ Pressão de confinamento.

$P_{p} \quad$ Pressão de fluido ou pressão de poros.

$q \quad$ Tensão diferencial.

$R \quad$ Raio do grão. 
$s \quad$ Vetor unitário na direção da estria de uma descontinuidade.

W Paleobatimetria.

$W_{b o} \quad$ Ângulo de abertura de breakout.

$V \quad$ Velocidade do som.

$X \quad$ Fator de proporcionalidade entre porosidade e permeabilidade.

z Profundidade vertical.

$z_{a} \quad$ Lâmina d'água.

Alfabeto Grego:

$\alpha \quad$ Coeficiente de Biot.

$\Delta \quad$ Variação eustática do nível do mar.

$\Delta t \quad$ Tempo de trânsito ou perfil sônico compressional.

$\varepsilon \quad$ Erro de aceitação.

$\mu \quad$ Coeficiente de atrito interno da rocha.

$\rho_{a} \quad$ Massa específica ou densidade da água.

$\rho_{b} \quad$ Massa específica ou densidade da rocha.

$\rho_{\text {grão }}$ Massa específica ou densidade do grão.

$\rho_{m} \quad$ Massa específica ou densidade do manto.

$\sigma_{c}^{u} \quad$ Vetor unitário na direção da maior tensão cisalhante projetada na superfície de uma falha.

$\sigma_{\varnothing} \quad$ Tensor de tensões reduzido.

$\sigma_{1} \quad$ Maior tensão principal.

$\sigma_{2} \quad$ Tensão principal intermediária.

$\sigma_{3} \quad$ Menor tensão principal.

$\sigma_{v} \quad$ Tensão vertical total.

$\sigma_{H} \quad$ Tensão horizontal máxima total.

$\sigma_{h} \quad$ Tensão horizontal mínima total.

$\sigma_{\theta \theta} \quad$ Tensão tangencial.

$\varphi \quad$ Ângulo de atrito interno da rocha. 
$\phi \quad$ Porosidade.

$\phi_{0} \quad$ Porosidade inicial da camada desconfinada.

$\phi_{i} \quad$ Porosidade inicial.

$\emptyset \quad$ Razão de tensões.

Abreviaturas:

$\mathrm{BD}$

Bandas de deformação.

CCM

Cam Clay Model.

CFC Parte central do núcleo da falha (central fault core).

CSB Banda de cisalhamento com compactação associada.

CSL Linha de estado crítico.

DFC Parte distal do núcleo de uma falha (distal fault core).

DSB Banda de cisalhamento com dilatação associada.

DZ Zona de dano (damage zone).

FC núcleo da falha (fault core).

Ma Milhões de anos.

MCCM Modified Cam Clay Model.

MZ Zona mista de uma falha (mixed zone).

PCB Banda de compactação pura.

PDB Banda de dilatação pura.

SECB Banda de compactação reforçada por cisalhamento.

SEDB Banda de dilatação reforçada por cisalhamento.

SSB Banda de cisalhamento puro.

UCS Resistência a compressão uniaxial da rocha. 
"Ó profundidade das riquezas, tanto da sabedoria, como da ciência de Deus! Quão insondáveis são os seus juízos, e quão inescrutáveis os seus caminhos!'

(Paulo de Tarso) 


\section{1 \\ Introdução}

\section{1. Motivação}

A predição da permeabilidade é uma etapa crítica no fluxograma de caracterização e de modelagem geológica de reservatórios e essencial para o desenvolvimento de projetos de produção de óleo e gás. Uma das principais incertezas no processo de modelagem envolve a determinação do comportamento hidráulico de zonas de falhas, que podem atuar como condutos ou barreiras ao fluxo de fluidos no espaço e no tempo [Rotevatn e Fossen (2011), Tueckmantel et al. (2012)].

Alguns fatores contribuem para a dificuldade na caracterização dos reservatórios. Entre eles, destacam-se: a complexa e heterogênea área influenciada por falhas e por estruturas subsísmicas (bandas de deformação ou fraturas); a tecnologia utilizada para simulação de fluxo que, por sua complexidade computacional, ainda utiliza malhas grossas com células em torno de 50 metros de espessura, resultando em representações pobres das falhas; e a dificuldade e custo na obtenção de amostras de rochas em águas profundas para a descrição de suas propriedades mecânicas e petrofísicas.

Por serem subsísmicas, as bandas de deformação (BD) são feições de difícil mapeamento, porém, são comuns em reservatórios siliciclásticos com alta porosidade e podem reduzir consideravelmente a permeabilidade do sistema em relação à permeabilidade da rocha original.

\section{2.}

\section{Objetivos}

O presente trabalho propõe a elaboração e implementação computacional de um modelo geomecânico analítico para a predição de BD em reservatórios de arenitos porosos. A ferramenta desenvolvida é capaz de auxiliar os profissionais de geo-engenharia em análises de sensibilidade para estimarem qualitativamente o potencial de formação de BD e seus efeitos na qualidade dos reservatórios. 
O modelo proposto fundamenta-se nos conhecimentos adquiridos nos últimos anos sobre o impacto das BD na redução de permeabilidade em arenitos, nos fatores que controlam a intensidade de catáclase ${ }^{1}$, na mecânica de geração dessas estruturas, e na teoria do estado crítico da mecânica dos solos, amplamente utilizada no entendimento do desenvolvimento de BD [Ballas et al. (2015), Fossen et al. (2017)]. Tal abordagem baseia-se também no estudo da geohistória da unidade estratigráfica em questão, com a finalidade de se obter os paleomodelos geomecânicos, indispensáveis para traçar a trajetória de tensões de um ponto ou determinada porção do reservatório desde a deposição até a posição atual.

A proposta se estende na aplicação do método via estudo de caso de um reservatório arenítico de petróleo de uma bacia sedimentar da Margem Continental Brasileira.

\section{3.}

\section{Estruturação do Trabalho}

Esta dissertação está dividida em cinco capítulos. O capítulo 1 apresenta esta introdução que contextualiza o tema abordado e explica o objetivo do trabalho. O capítulo 2 constitui uma ampla revisão bibliográfica que abrange toda a fundamentação teórica necessária para o desenvolvimento do modelo proposto. O capítulo 3 descreve de forma sucinta a metodologia aplicada. O capítulo 4 elucida com detalhes o estudo de caso realizado para avaliação do modelo, incluindo parâmetros, premissas e resultados. Em seguida, o capítulo 5 são as considerações finais com as conclusões do trabalho e sugestões para trabalhos futuros.

${ }^{1}$ Catáclase: deformação tectônica acompanhada da trituração ou cominuição generalizada, por microfraturamento, dos grãos. A resultante redução em granulometria pode ser extrema e formar um material extremamente fino nos núcleos denominado gouge de falha. 


\section{2 \\ Revisão Bibliográfica}

\section{1. \\ Zona de Falha e Bandas de Deformação}

Como as falhas geológicas têm grande influência no comportamento hidráulico e mecânico de maciços rochosos, o conhecimento de sua arquitetura é bastante relevante para atividades econômicas em subsuperfície tais como a exploração e produção de óleo e gás, o gerenciamento de recursos hídricos, os estudos geotécnicos e hidrológicos para grandes projetos de engenharia e o armazenamento de produtos residuais como rejeito atômico e $\mathrm{CO}_{2}$.

Exemplos de aplicações práticas são o planejamento de explotação econômica de um aquífero ou de um campo de petróleo ao prever se uma ou mais zonas de falha atuam como barreiras ou facilitadoras do fluxo de fluidos, a locação de poços exploratórios ao definir a trajetória dos poços e estimar a altura máxima de retenção de hidrocarbonetos de uma falha, e estudos geotécnicos e hidrológicos de barragens, dentre outros. Essas estruturas também são fundamentais para a sismologia, uma vez que os terremotos são resultado da energia liberada no processo evolutivo de uma falha geológica.

Uma zona de falha (Figura 1) é formada por uma ou múltiplas falhas-núcleo rodeadas por uma zona de dano composta por fraturas e/ou, muitas vezes, BD [e.g. Caine et al. (1996), Faulkner et al. (2010), Bense et al. (2013)].

Diversos estudos e medições de permeabilidade em falhas naturais e sintéticas em siliciclásticos indicam redução de sua magnitude no núcleo da falha, enquanto a zona de dano apresenta grande variabilidade pois depende da distribuição espacial e tipo das estruturas que a compõem, tais como BD e fraturas, que podem potencializar ou dificultar o fluxo de fluidos [Matsumoto e Shigematsu (2018)]. Por serem feições que comumente reduzem a permeabilidade em relação a rocha matriz, as $\mathrm{BD}$ se tornaram tema de muitas pesquisas nos últimos anos. 


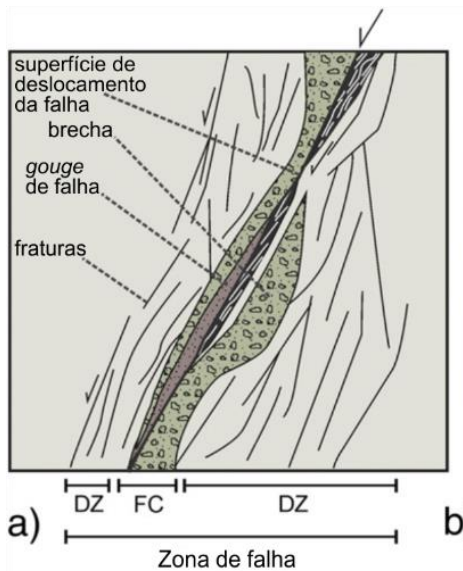

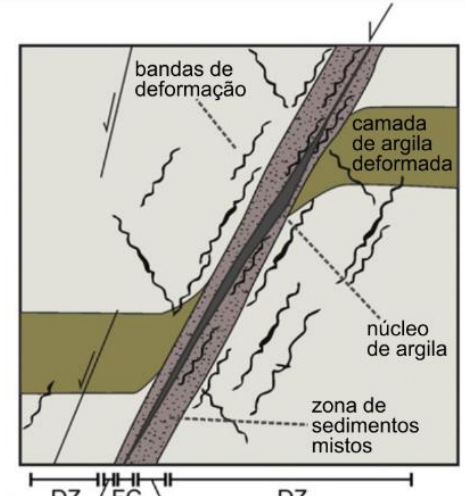

b)

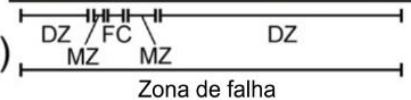

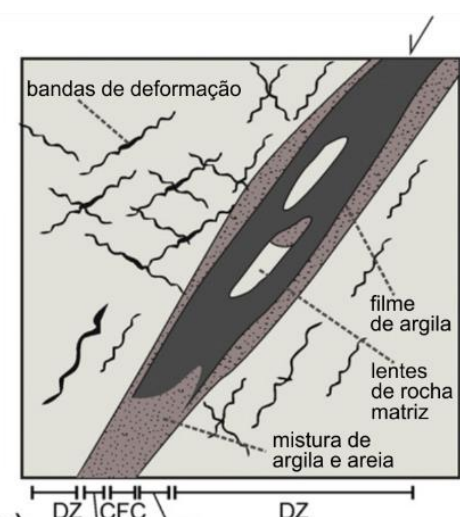

c) ${ }_{D F C}^{D Z} C_{D F C}$

Zona de falha

Figura 1 - Diferentes arquiteturas de zona de falha. a) rochas cristalinas com núcleo de falha (FC - fault core) composto por brecha e gouge de falha e zona de dano (DZ - damage zone) com aumento na densidade de fraturas; b) arenitos porosos com FC composto de argila e DZ composta por BD. Uma terceira parte entre o FC e a DZ denominada zona mista (MZ - mixed zone) com sedimentos deformados e misturados é estabelecida e; c) sedimentos não litificados a pouco litificados com FC estruturado em uma parte central (CFC - central fault core) com membranas argilosas e lentes de fragmentos da rocha matriz e a parte distal (DFC - distal fault core) composta de uma mistura de areia e argila ou lentes de argila em uma matriz composta de areia. A DZ inclui BD únicas ou em clusters. [Adaptado de Bauer et al. (2015)]

As BD são estruturas planares subsísmicas de deformação localizadas em uma dimensão finita de rocha, comuns em arenitos porosos e que variam em relação a mecanismos de deformação, geometria e distribuição. Essas deformações podem reduzir a permeabilidade em até seis ordens de grandeza em relação a rocha matriz [Ballas et al. (2015)]. Exemplos de afloramentos com essas estruturas podem ser visualizados na Figura 2, Figura 3 e Figura 4. A magnitude da catáclase envolvida na deformação determina, em grande parte, como as BD afetam o fluxo de fluido. Catáclase pode ser definida como uma deformação tectônica acompanhada da trituração ou cominuição generalizada por microfraturamento dos grãos. A resultante redução em granulometria pode ser extrema e formar um material extremamente fino nos núcleos denominado gouge de falha. Normalmente, quanto mais intenso for esse processo uma maior redução de permeabilidade se verifica. A cominuição dos grãos é geralmente facilitada pela presença de grãos grossos e bem selecionados, elevada porosidade (geralmente maior que $15 \%$ ) e por soterramentos mais profundos (geralmente maiores que $500 \mathrm{~m}$ a $1000 \mathrm{~m}$ ) no momento da plastificação. Além do processo de catáclase, o desenvolvimento das $\mathrm{BD}$ envolve outros mecanismos em microescala como o 
esmagamento, atrito, rotação e deslizamento dos grãos, além de dissolução e cimentação (Fossen et al., 2017).
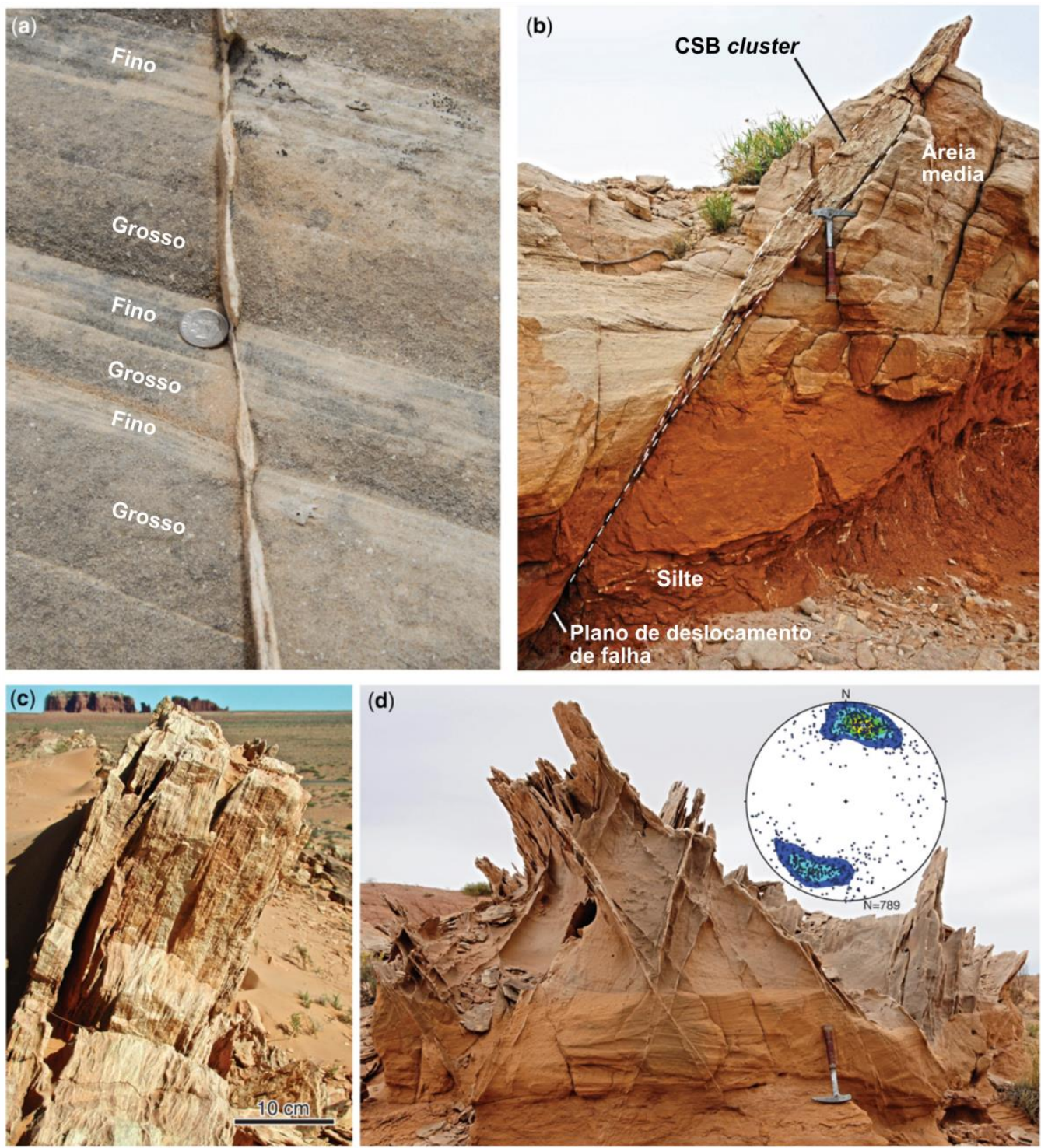

Figura 2 - Exemplos de BD em regime extensional. (a) Banda de cisalhamento com compactação associada (CSB) mostrando a variação de suas espessuras em relação ao tamanho do grão. Arenito Navajo, Utah. (b) Cluster de CSB e sua transição para superfície de falha na parte inferior da imagem. (c) Cluster de CSB espessa. (d) BD conjugadas. (b-d) Arenito Entrada, San Rafael Desert, Utah [Adaptado de Fossen et al. (2017)] 


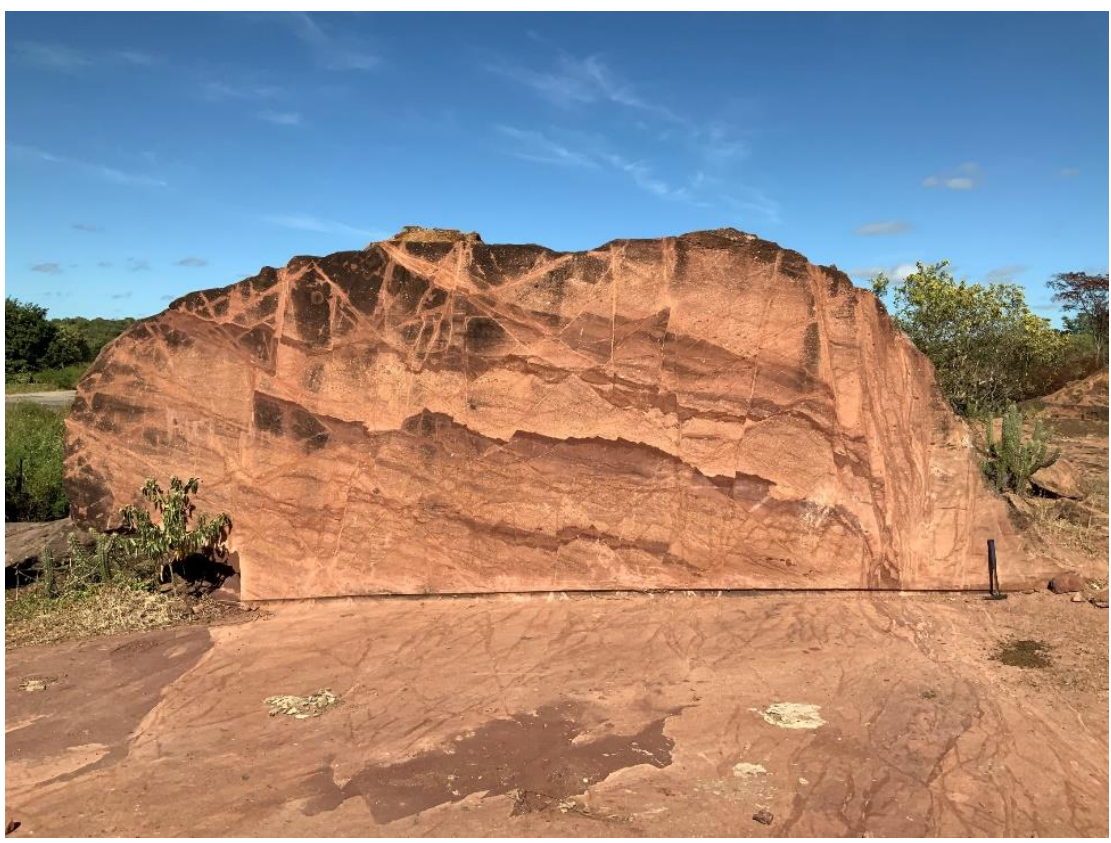

Figura 3 - Afloramento com rede de BD. Bacia do Rio do Peixe, PB - Brasil

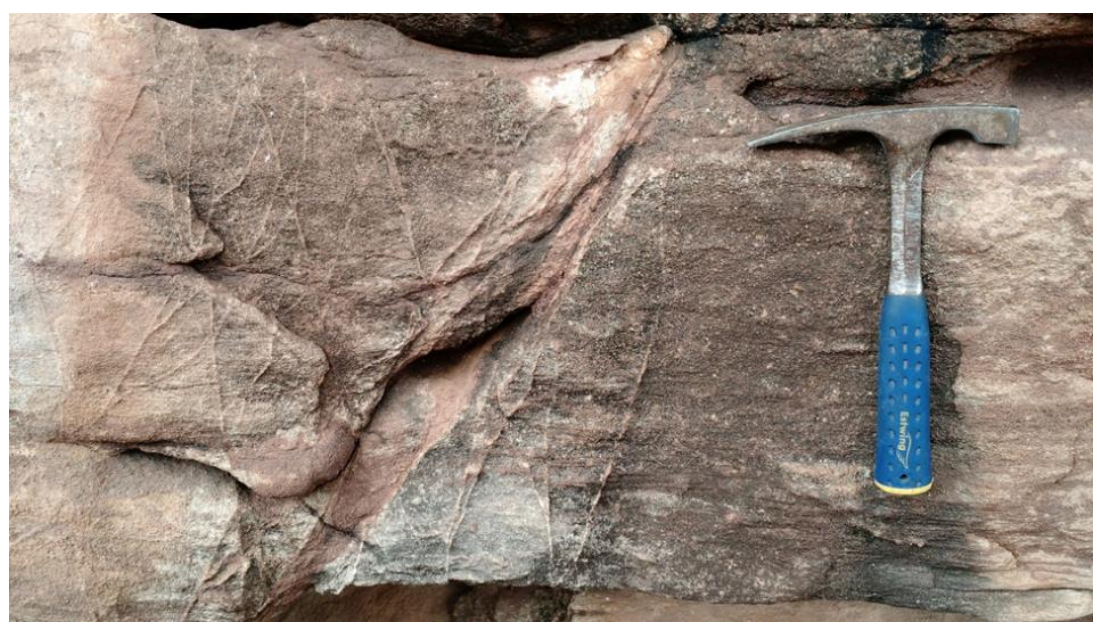

Figura 4 - Detalhe de Zona de Dano, com BD, de uma falha com rejeito centimétrico ( 20 $\mathrm{cm}$ ) em um arenito pouco consolidado. Bacia do Rio do Peixe, PB - Brasil

\section{2.}

\section{Tipos de Bandas de Deformação}

O fator mais relevante para classificar as bandas de deformação é a quantidade de catáclase envolvida, que com alguma dissolução e cimentação, normalmente gera uma rocha mecanicamente resistente, envolvendo 
compactação com redução da porosidade e da permeabilidade em relação ao protólito [Ballas et al. (2014)].

As BD foram primeiramente descritas por Aydin (1978) como estruturas em que os grãos foram quebrados significativamente.

Antonellini et al. (1994) classificaram as BD em três principais grupos:

(i) bandas de deformação sem catáclase: caracterizadas pela quase ausência de quebra de grãos. Elas podem exibir variações de volume positivas ou negativas;

(ii) bandas de deformação com catáclase: caracterizadas por uma redução intensa no tamanho dos grãos e no volume;

(iii) bandas de deformação com filme de argila ou localização de zonas de cisalhamento.

Fossen et al. (2007) classificaram as BD de acordo com o mecanismo de deformação dominante durante sua formação e pelo comportamento cinemático.

A classificação baseada na mecânica deformacional seria a seguinte:

(i) fluxo granular (ruptura da cimentação e rotação do grão);

(ii) catáclase (fraturamento de grãos);

(iii) presença de membrana de filossilicatos;

(iv) dissolução e cimentação.

Como a compreensão dos aspectos cinemáticos das bandas de deformação evoluiu ao longo dos últimos anos e o processo de catáclase está, até certo ponto, relacionado à cinemática e ao mecanismo de deformação, Fossen et al. (2007) classificaram cinematicamente as bandas de deformação em:

(i) bandas de compactação;

(ii) bandas de cisalhamento com compactação associada;

(iii) bandas de cisalhamento isocórico;

(iv) bandas de cisalhamento com dilatação associada;

(v) bandas de dilatação.

Posteriormente, Fossen et al. (2017) revisaram essa classificação em um espectro entre três end-members, que é listado abaixo e esquematizado na Figura 5.

(i) PCB: banda de compactação pura;

(ii) SECB: banda de compactação reforçada por cisalhamento;

(iii) CSB: banda de cisalhamento com compactação associada;

(iv) SSB: banda de cisalhamento isocórico;

(v) DSB: banda de cisalhamento com dilatação associada;

(vi) SEDB: banda de dilatação reforçada por cisalhamento; 
(vii) PDB: banda de dilatação pura.

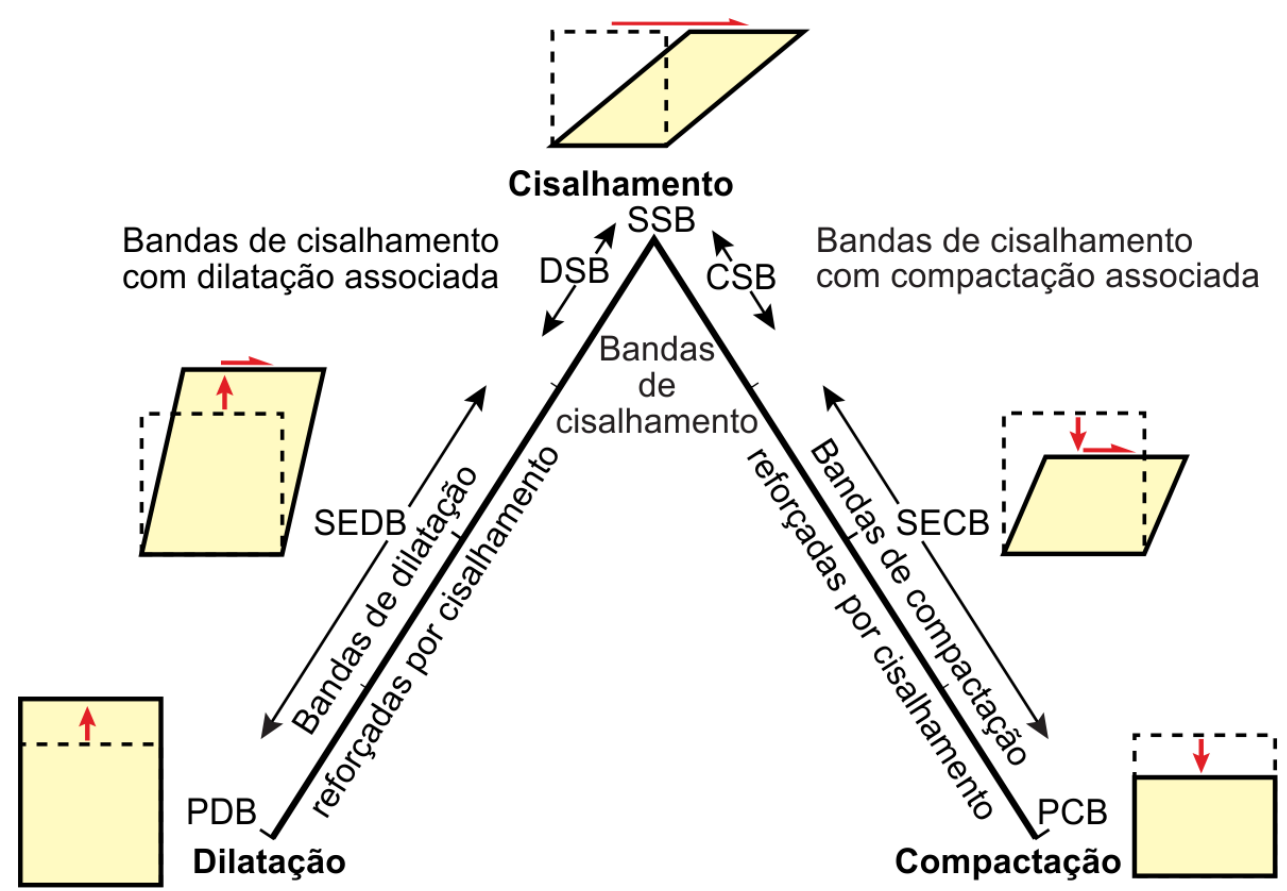

Figura 5 - Espectro cinemático de BD entre os end-members compactação, cisalhamento e dilatação. [Adaptado de Fossen et al. (2017)]

Ballas et al. (2015) classificaram as bandas de deformação conforme a intensidade de catáclase envolvida, esquematizadas na Figura 6 e listadas a seguir:

(i) banda de compactação pura (PCB) e banda de compactação reforçada por cisalhamento (SECB);

(ii) banda cataclástica;

(iii) cluster de bandas de deformação;

(iv) cluster de bandas de deformação cataclásticas com deslocamento;

(v) núcleo de falha. 


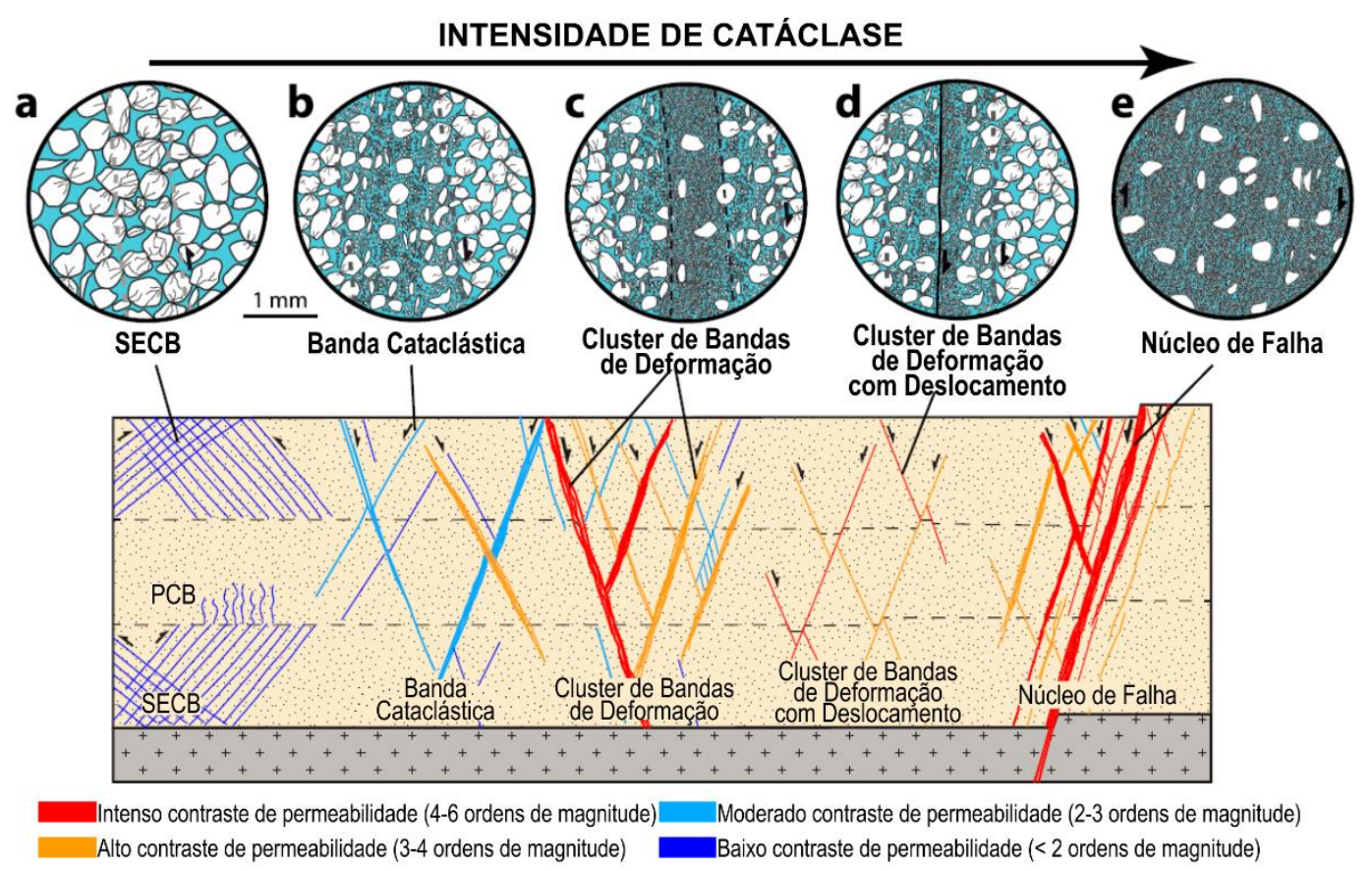

Figura 6 - Modelo conceitual mostrando a influência da intensidade de catáclase no contraste da permeabilidade induzido por BD e falhas em reservatórios areníticos. (a) Bandas de compactação pura e bandas de compactação reforçada por cisalhamento. (b) Bandas cataclásticas. (c) Clusters de BD. (d) Bandas cataclásticas com deslocamento. (e) Núcleo de falha com catáclase. A cor azul representa a porosidade. [Adaptado de Ballas et al. (2015)]

\section{3. \\ Fatores que controlam a permeabilidade em bandas de deformação cataclásticas}

Os diferentes tipos de BD se originam de acordo com o estado de tensões in situ e variações nas propriedades e características da rocha, relacionadas direta ou indiretamente à profundidade de soterramento [Fossen et al. (2017)].

Fatores como porosidade, mineralogia, tamanho e forma dos grãos, litificação, estado de tensões e profundidade de soterramento controlam o tipo da estrutura formada. Dos diferentes tipos, as bandas de filossilicatos e as bandas cataclásticas apresentam uma maior redução na permeabilidade e, portanto, têm o maior potencial para influenciar o fluxo de fluidos. As bandas de desagregação, onde o fluxo granular não cataclástico é o mecanismo dominante, mostram pouca influência no fluxo de fluidos, a menos que auxiliado por compactação química ou cimentação [Fossen et al. (2007)]. 
Um resumo esquemático dos fatores que influenciam o grau de catáclase em BD pode ser visto na Figura 7.

\begin{tabular}{|l|l|}
\multicolumn{1}{c}{ Variável } & Fluxo Granular $\longrightarrow$ Catáclase \\
\hline Soterramento (tensões confinantes) & Raso $\longrightarrow$ Profundo \\
\hline Litificação & Inconsolidado $\longrightarrow$ Bem litificado \\
\hline Sobrepressão de fluido & Alta $\longrightarrow$ Baixa \\
\hline Cimentação & $\begin{array}{l}\text { FeO(OH) } \\
\left(\text { baixo) } \longrightarrow \mathrm{CaCO}_{3} \longrightarrow \text { (alto) }\right.\end{array}$ \\
\hline Forma do grão & Angular $\longrightarrow$ Arredondado \\
\hline Seleção do grão & Pobre $\longrightarrow$ Boa \\
\hline Mineralogia (resistência do grão) & Forte $\longrightarrow$ Fraco \\
\hline Conteúdo de filossilicatos & Alto $\longrightarrow$ Nenhum \\
\hline Regime tectônico & Extensão \\
\hline
\end{tabular}

Figura 7 - Resumo esquemático dos fatores que influenciam o grau de catáclase em BD. [Adaptado de Fossen et al. (2017)]

\section{4.}

\section{Geometria das zonas de falhas}

Diversos autores publicaram relações empíricas derivadas de estudos de campo de geologia estrutural. A partir do rejeito de uma falha é possível fazer algumas estimativas, como exemplo, as espessuras dos núcleos das falhas e as espessuras das zonas de dano, informações que podem auxiliar na modelagem da permeabilidade ou transmissibilidade em zonas de falhas.

A relação empírica entre a magnitude do rejeito da falha e a espessura da zona de dano é usualmente modelada por uma regressão exponencial

$$
T=a D^{b}
$$

onde $T$ é a espessura da zona de dano, $D$ é o rejeito da falha, $a$ e $b$ são parâmetros ajustáveis [Fossen et al. (2017)]. Essa aproximação é exemplificada na Figura 8.

Muitos trabalhos como por exemplo Scholz (1987), Sperrevik et al. (2002), Childs et al. (2009) e Torabi e Berg (2011) também apontam relações empíricas entre a espessura do núcleo da falha e o seu deslocamento. 


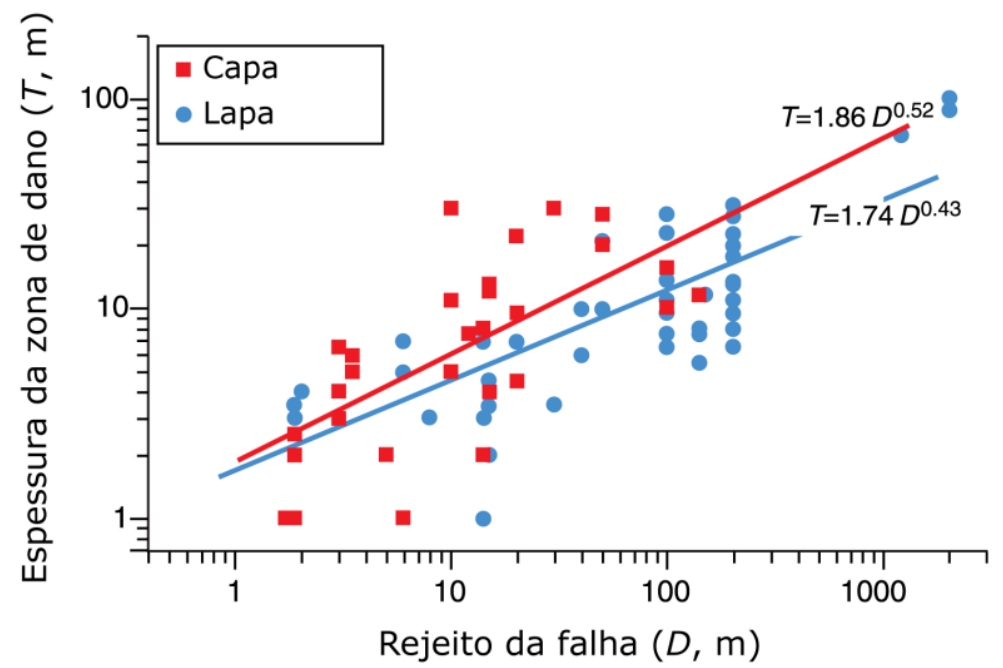

Figura 8 - Relação empírica entre o rejeito da superfície da falha e a espessura da zona de dano. [Adaptado de Fossen et al. (2017)]

Outra informação derivada da magnitude do rejeito de uma falha é a intensidade de fragmentação dos grãos dentro do núcleo da falha. Cataclasitos foliados formados por grãos finos são formados em falhas com poucos metros de rejeito enquanto gouges ultracataclásticos se desenvolvem em falhas com deslocamentos que excedem $15 \mathrm{~m}$ a 20 m [Balsamo e Storti (2010)].

\section{5 . \\ Mecânica da gênese de bandas de deformação}

Uma abordagem largamente aplicada para o entendimento da nucleação de $\mathrm{BD}$ em rocha porosa é a teoria do estado crítico, que fornece uma estrutura para descrever o comportamento inelástico de compactação e dilatância. Essa teoria é representada, no diagrama $p \times q$ (tensão média $x$ tensão diferencial), por uma envoltória limite de plastificação composta pela linha de estado crítico (CSL) e um cap (semi-elipse). A CSL separa os regimes de compressão e dilatância na superfície de plastificação (Figura 9) [Borja, 2013].

Os modelos tipo cap são derivados da aplicação dos conceitos da mecânica dos solos aos processos de deformação inelástica observados em rochas porosas [Schultz e Siddharthan (2005)]. O trabalho original para fluxo em solos ricos em argila foi proposto por Roscoe e Schofield (1963) e nomeado Cam Clay Model (CCM) devido ao local donde foi retirado o material para os experimentos - Rio Cam, em Cambridge, Inglaterra. Posteriormente, foi modificado por Roscoe e Burland (1968), evoluindo para o Modified Cam Clay Model (MCCM) e se tornando o modelo do estado crítico mais amplamente utilizado. 


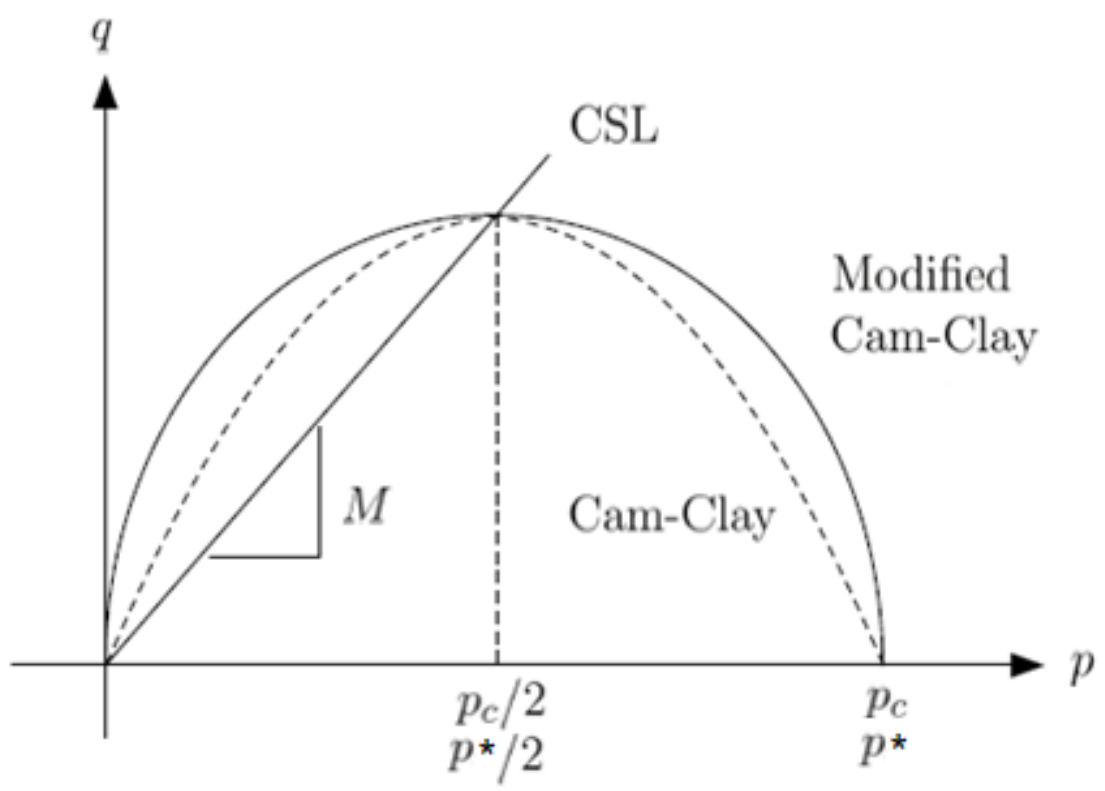

Figura 9 - Critérios de plastificação Cam Clay e Cam Clay Modificado no espaço $p$ x q. [Adaptado de Borja (2013)]

A geometria da envoltória de plastificação depende das características físicas da rocha em deformação. O centro da semi-elipse é a metade da pressão de pré-adensamento $(P C)$ para solos e a metade da pressão de colapso $\left(P^{*}\right)$ para rochas porosas. A função de plastificação para o MCCM é dada por:

$$
\frac{q^{2}}{M^{2}}+p\left(p-p_{c}\right)=0
$$

A inclinação $M$ da linha do estado crítico no espaço de tensões $p \times q$ se relaciona ao ângulo de atrito interno em solos e rochas sensíveis à tensão confinante pela relação:

$$
M=\frac{6 \sin \varphi}{3-\sin \varphi}
$$

onde $\varphi$ é o ângulo de atrito interno e $\mu=\tan \varphi$.

A CSL assume a forma:

$$
q=M p
$$

Esse modelo abrange os tipos cinemáticos end-members de deformação cisalhamento e compactação, além de suas variantes como por exemplo compactação associada com cisalhamento e dilatação.

O aparecimento de cada tipo cinemático depende do caminho de tensões e das tensões confinantes. [Issen e Rudnicki (2000); Issen e Rudnicki (2001)].

Nguyen et al. (2014) confirmaram por ensaios hidrostáticos e triaxiais que, apesar do MCCM ter sido formulado para solos finos de profundidades rasas a 
moderadas, tal modelo pode ser usado para caracterizar o comportamento elastoplástico de arenitos inconsolidados ou pouco consolidados.

Com a finalidade de elaborar modelos constitutivos mais completos e analisar a evolução da porosidade e permeabilidade em relação aos diferentes tipos de deformação, laboratórios de mecânica de rochas têm estudado a zona de transição entre a deformação rúptil e fluxo cataclástico, caracterizada pela existência de compactação induzida por cisalhamento. Esses experimentos, normalmente, definem envoltórias de deformação inelástica para o material estudado e buscam dar resposta a uma grande questão no caso de deformação com componente de compactação: o estado de tensão ou os parâmetros que indiquem o início do colapso dos grãos e dos poros.

Uma informação indispensável na modelagem da gênese de uma BD é a pressão de colapso $\left(P^{*}\right)$, pressão efetiva na qual ocorre compactação com ausência de cisalhamento $(q=0)$. Essa pressão crítica estabelece o limite elástico máximo para a tensão média efetiva em uma envoltória tipo cap. Fisicamente, representa o início de colapso do meio poroso com o esmagamento e o fraturamento em escala de grão.

Wong et al. (1997) conduziram uma série de ensaios triaxiais compressivos em amostras de seis arenitos com porosidades variando de $15 \%$ a $35 \%$, com a pressão de poros $\left(P_{p}\right)$ constante em $10 \mathrm{MPa}$ e pressão de confinamento variando de $13 \mathrm{MPa}$ a $550 \mathrm{MPa}$ (Figura 10). Em regime rúptil, a dilatância induzida por cisalhamento iniciou em estágio prepeak no nível de tensão $C^{\prime}$, que aumentou com o incremento da tensão média efetiva. Sob elevadas pressões efetivas, as amostras falharam por fluxo cataclástico. As deformações hardening e de compactação induzidas por cisalhamento iniciaram no nível de tensão $C^{*}$, que diminuíram com o aumento da tensão média efetiva. $O$ tipo de deformação e o estado de tensão foram eminentemente determinados pelas medições de porosidade e emissão de ondas acústicas.

Em síntese, a partir de carregamentos não hidrostáticos, a ruptura e plastificação da amostra são caracterizadas por alguns parâmetros críticos de tensão: (i) tensão de início de dilatância induzida por cisalhamento $(C)$, (ii) tensão de pico para fratura rúptil, (iii) tensão de início de compactação induzida por cisalhamento $\left(C^{\star}\right)$ e (iv) pressão efetiva de transição entre falhamento rúptil e fluxo cataclástico $\left(P_{b d t} \approx 0,15 P^{*}\right)$.

Esse tipo de experimento pode ser ilustrado por uma série de fotografias de amostras ensaiadas sob diferentes pressões de confinamento (Figura 11). 

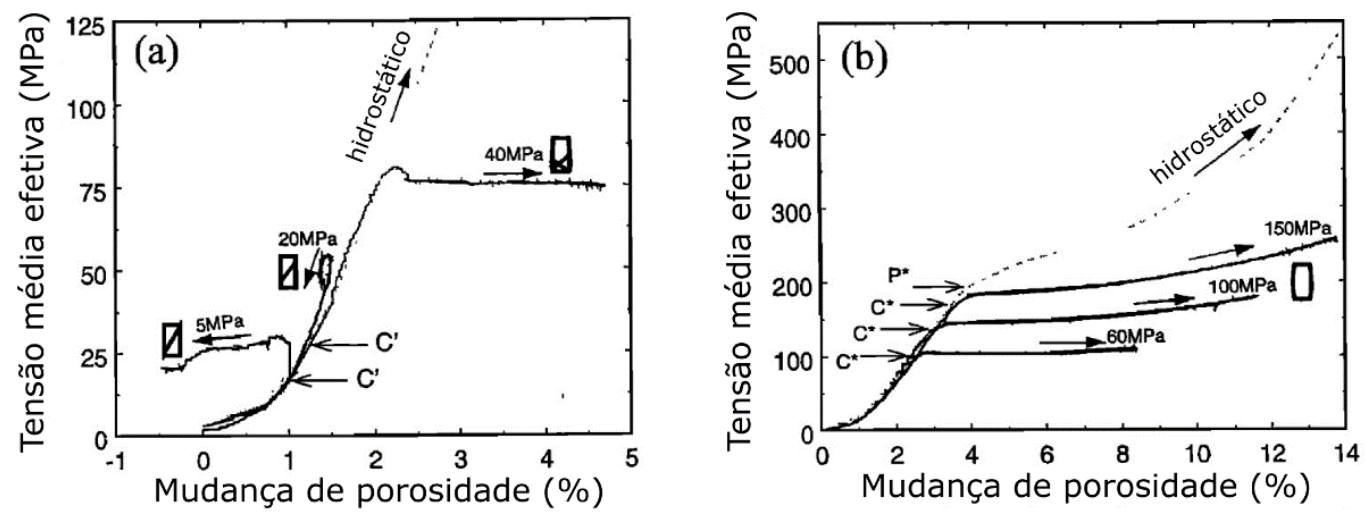

Figura 10 - (a) Dilatância induzida por cisalhamento e (b) compactação do arenito Adamswiller. As curvas sólidas mostram a tensão média efetiva em função da mudança de porosidade em ensaios triaxiais com pressões efetivas fixas como indicado. Para referência, o ensaio hidrostático é mostrado por curvas pontilhadas. [Adaptado de Wong et al. 1997]

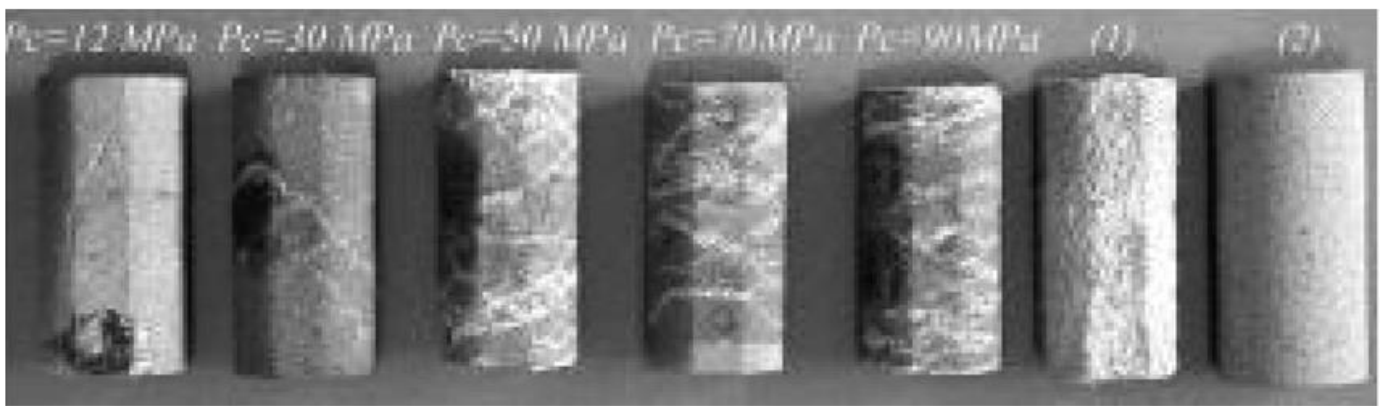

Figura 11 - Séries de fotografias ilustrando os diferentes modos de falhamento em amostras do arenito Bleurswiller deformadas sob diferentes pressões de confinamento. $O$ diâmetro da amostra intacta (2) era $40 \mathrm{~mm}$ e o comprimento de $80 \mathrm{~mm}$. A amostra (1) foi deformada sob condições hidrostáticas. [Wong e Baud (2012)]

No espaço de tensões normalizadas $\left(p / p^{*}\right) \times\left(q / p^{*}\right)$, as magnitudes de $C^{*}$ ajustaram uma envoltória de plastificação aproximadamente elíptica (Figura 12), em concordância com o estado crítico da mecânica dos solos e com os modelos tipo cap. Sua equação é dada por:

$$
\frac{\left(p / p^{*}-\gamma\right)^{2}}{(1-\gamma)^{2}}+\frac{\left(q / p^{*}\right)^{2}}{\delta^{2}}=1
$$

com $\gamma \approx 0,5 ; \delta$ entre 0,5 e 0,$7 ; p=\frac{\left(\sigma_{1}+2 \sigma_{3}\right)}{3}-P_{p}$ e $q=\sigma_{1}-\sigma_{3}$. 


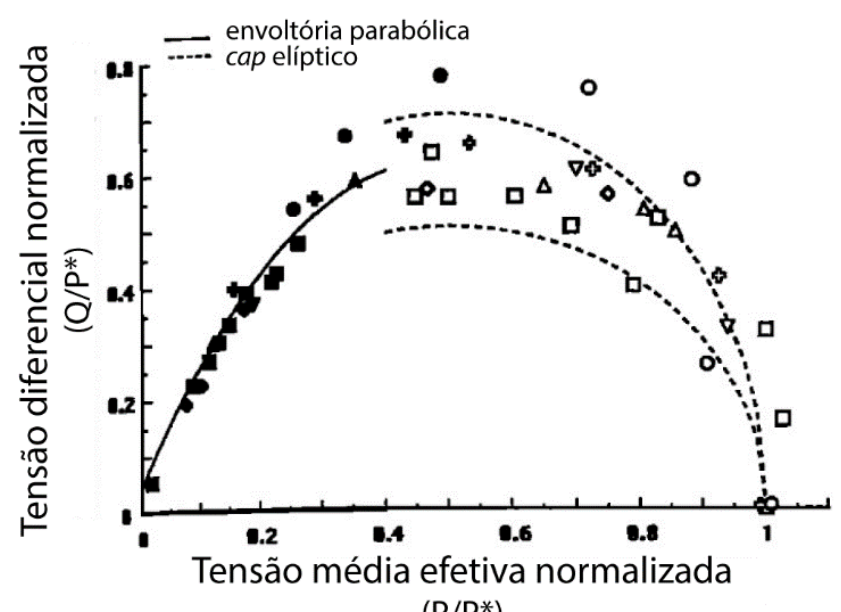

$\left(P / P^{*}\right)$

Figura 12 - Estado de tensão $C^{\star}$ no início da compactação induzida por cisalhamento (símbolos abertos) e tensão de pico para fratura rúptil (símbolos sólidos) são mostrados no espaço $p \times q$ normalizado. A maior parte das magnitudes de $C^{*}$ está localizada entre dois caps elípticos (curvas pontilhadas) correspondentes a eq.(5). As tensões de pico são ajustadas com uma envoltória de ruptura parabólica (curva sólida). [Adaptado de Wong et al. (1997)]

Há uma importante diferença entre carregamento hidrostático e não hidrostático. O microfraturamento em uma amostra a partir de $C^{*}$ tem uma orientação preferencial subparalela à $\sigma_{1}$, enquanto o fraturamento em uma amostra carregada hidrostaticamente e que compactou a partir de $P^{*}$ é relativamente isotrópico. [Wong et al. (1997)].

Zhang et al. (1990) discutem a importância do fraturamento em escala de grão para a compactação em rochas porosas e a relação com o estabelecimento da transição rúptil-dúctil nessas rochas. $O$ autor vale-se de experimentos triaxiais em diversos arenitos com diversas porosidades e do modelo hertziano de microfratura [Hertz (1882)] para explicar o quebramento dos grãos em rochas porosas. De acordo com a teoria hertziana tem-se uma relação entre a tensão de início de colapso $P_{c r}$, a porosidade $\phi$ e o raio dos grãos $R$ na forma:

$$
P_{c r}=2,2 \frac{\left(1-v_{g}^{2}\right)^{2}}{\left(1-2 v_{g}\right)^{3}} \frac{\mathrm{K}_{I c}^{3}}{E_{g}^{2}} \frac{1}{\sqrt{\alpha \phi R}^{3}}
$$

onde $v_{g}$ é o coeficiente de Poisson dos grãos, $E_{g}$ é o módulo de Young dos grãos, $\alpha=\frac{c}{R}$ é a relação entre o comprimento inicial da microfratura e o raio dos grãos e $K_{I c}$ é o fator de intensidade de tensão para fraturas de tração nas extremidades da microfratura (que se iguala à tenacidade na iminência do faturamento) [Moraes (2004)]. 
Zhang et al. (1990b) mostraram que, para compactação hidrostática, existe um estado de tensão crítico correspondente à pressão de colapso $\left(P^{*}\right)$ que é controlado principalmente pela porosidade e pelo tamanho dos grãos. Portanto, este valor poderia ser dimensionado aproximadamente com o produto do tamanho do grão $R$ pela porosidade $\Phi$, ou seja:

$$
P^{*} \propto(\Phi R)^{-1.5}
$$

A relação empírica de Zhang et al. (1990b), proveniente de um ajuste por regressão não linear, pode ser melhor entendida pelo diagrama mostrado na Figura 13.

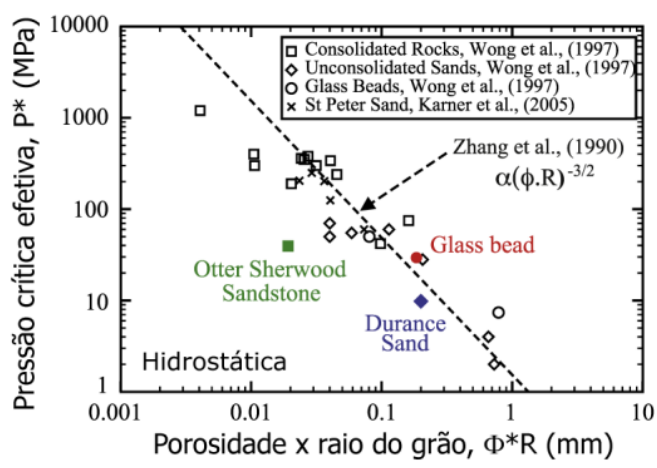

Figura 13 - Pressões de colapso do grão $\left(P^{*}\right)$ reportados por Wong et al. (1997) somados a três arenitos distintos. [Adaptado de Nguyen et al. (2014)]

Ensaios experimentais [e.g. Cuss et al. (2003), Rutter e Glover (2012), Wong e Baud (2012), Nguyen et al. (2014)] confirmaram que a pressão de colapso $P^{*}$ para rochas clásticas pode ser estimada pelos simples parâmetros de porosidade e tamanho do grão.

Boutéca et al. (2000) mostraram que para amostras de arenitos com porosidade entre $15 \%$ a $25 \%$ a tensão hidrostática de plastificação é de 6 a 7 vezes a magnitude de UCS.

Como a pressão crítica ou pressão de colapso (grain crushing pressure, $P^{*}$ ) é uma informação pouco disponível, é comum adotar dados da literatura. Uma opção é usar a relação empírica da porosidade e o raio do grão, eq. (7). Entretanto, a proporcionalidade entre o produto da porosidade e raio do grão em relação a pressão crítica, simbolizado aqui de $K_{p}$, varia bastante para uma mesma litologia. Nos dados da Tabela 1, essa constante varia entre 0,035 a 4,845 para arenitos. 
Tabela 1: Compilação de dados experimentais de pressão crítica efetiva no início do colapso dos grãos sob carga hidrostática $\left(P^{*}\right)$ de Wong et al. (1997) e Nguyen et al. (2014)

\begin{tabular}{|c|c|c|c|c|c|c|c|}
\hline ID & Material & Referência & Raio do Grão - R (mm) & $\phi$ & $\mathrm{P}^{*}$ (Mpa) & $\mathrm{K}_{\mathrm{p}}=\mathrm{P}^{*} /\left(\phi^{*} \mathrm{R}\right)^{-1,5}$ & $\phi * R$ \\
\hline \multicolumn{8}{|c|}{ Arenitos inconsolidados } \\
\hline 1 & Angular coarse sand & Lee and Farhoomand [1967] & 1,400 & 0,520 & 2,000 & 1,242 & 0,728 \\
\hline 2 & Subrounded coarse & Lee and Farhoomand [1967] & 1,400 & 0,470 & 4,000 & 2,135 & 0,658 \\
\hline 3 & Ottawa sand & Lambe and Whitman [1969] & 0,550 & 0,375 & 28,000 & 2,623 & 0,206 \\
\hline 4 & Ottawa sand $(200 \varnothing \mathrm{C})$ & Dewars and Hajash [1995] & 0,100 & 0,400 & 50,000 & 0,400 & 0,040 \\
\hline 5 & Ottawa sand & Zoback [1975] & 0,190 & 0,310 & 55,000 & 0,786 & 0,059 \\
\hline 6 & Coarse sand & Talwani et al. [1973] & 0,325 & 0,350 & 60,000 & 2,302 & 0,114 \\
\hline 7 & Ottawa sand $(150 \varnothing \mathrm{C})$ & Dewars and Hajash [1995] & 0,100 & 0,400 & 70,000 & 0,560 & 0,040 \\
\hline 8 & Durance Sand & Nguyen et al [2014] & 0,060 & 0,390 & 9,800 & 0,035 & 0,023 \\
\hline \multirow[t]{2}{*}{9} & Otter Sherwood sandstone & Nguyen et al [2014] & 0,060 & 0,330 & 39,500 & 0,110 & 0,020 \\
\hline & \multicolumn{7}{|c|}{ Rochas consolidadas } \\
\hline 10 & Boise sandstone II & Wong et al. [1997] & 0,280 & 0,350 & 42,000 & 1,289 & 0,098 \\
\hline 11 & Boise sandstone I & Zhang et al. [1990b] & 0,460 & 0,350 & 75,000 & 4,845 & 0,161 \\
\hline 12 & Adamswiller & David et al. [1994] & 0,090 & 0,226 & 190,000 & 0,551 & 0,020 \\
\hline 13 & Rothbach sandstone & David et al. [1994] & 0,228 & 0,199 & 240,000 & 2,319 & 0,045 \\
\hline 14 & Lance sandstone & Schock et al. [1973] & 0,125 & 0,085 & 300,000 & 0,329 & 0,011 \\
\hline 15 & Kayenta sandstone & Zhang et al. [1990b] & 0,150 & 0,210 & 300,000 & 1,677 & 0,032 \\
\hline 16 & St Peter sandstone & Zhang et al. [1990b] & 0,140 & 0,290 & 340,000 & 2,781 & 0,041 \\
\hline 17 & Fontainebleau & David et al. [1994] & 0,188 & 0,136 & 350,000 & 1,431 & 0,026 \\
\hline 18 & Darley Dale sandstone & Wong et al. [1997] & 0,167 & 0,145 & 360,000 & 1,357 & 0,024 \\
\hline 19 & Berea sandstone & Zhang et al. [1990b] & 0,130 & 0,210 & 380,000 & 1,714 & 0,027 \\
\hline
\end{tabular}

A maneira com que a rocha se deforma e quais tipos de feições são formados dependem da porosidade da rocha matriz, da geometria dos grãos, da pressão de fluído, da profundidade de soterramento (isto é, pressão de confinamento), da tensão diferencial que gera a deformação e da trajetória de tensões que levou o protólito ao estado de deformação. [e.g., Wong et al. (1997), Schultz e Siddharthan (2005), Ballas et al. (2015), Fossen et al. (2017)].

Os estudos mencionados anteriormente permitem a aplicação direta da teoria do estado crítico às rochas naturalmente deformadas. Porém, é necessário conhecer a trajetória de tensões, o que remete ao passado geológico dessas rochas.

Apesar da difícil avaliação do caminho das tensões aplicadas em rochas naturalmente deformadas, algumas observações gerais podem ser obtidas desses modelos:

- à medida que o tamanho do grão e/ou a porosidade aumentam, a pressão crítica de colapso $\left(P^{*}\right)$ e a envoltória de deformação plástica diminuem (Figura 14). Sendo assim, areia não consolidada pode formar bandas de compactação a profundidades relativamente rasas, enquanto arenito consolidado requer pressões confinantes bem maiores [Fossen et al. (2007)];

- em fluxos cataclásticos a envoltória de plastificação expande à medida que a porosidade diminui [Wong et al. (1992)]; 
- banda de cisalhamento com dilatância (Figura 14, ponto 2) pode ser formada por qualquer trajetória de carregamento ou descarregamento enquanto o lado de dilatação da envoltória de deformação (Figura 14, sombreamento escuro) for atingido [Schultz e Siddharthan (2005)];

- banda de compactação com cisalhamento (Figura 14, ponto 4) aparentemente requer condições triaxiais ou de soterramento de valores inicialmente grandes de pressão de confinamento $\left(p_{c f}\right)$, embora uma trajetória de descarregamento íngreme com $p_{c f}$ inicialmente grande também possa interceptar o limite de plastificação [Schultz e Siddharthan (2005)];

- banda de compactação implica grandes valores de $p_{c f}$ (Figura 14, ponto 5), enquanto bandas de dilatação (Figura 14, ponto 1) implicam valores pequenos de $p_{c f}$. [Schultz e Siddharthan (2005)];

- a localização de deformação cataclástica é favorecida por uma alta tensão diferencial, o que promove a geração de bandas de cisalhamento com catáclase, enquanto uma baixa tensão diferencial associada a uma alta tensão média favorece a compactação do material em bandas distribuídas de compactação com catáclase [Soliva et al. (2013)];

- uma composição mineralógica rica em feldspato e fragmentos de rochas favorece processos cataclásticos [Ballas et al. 2015];

- depleção associada a produção de hidrocarbonetos pode induzir grandes deformações plásticas em reservatórios siliciclásticos, com sérias consequências, tais como subsidência, rupturas em poços, danos na permeabilidade e comprometimento do reservatório [Nguyen et al. (2014)]. 


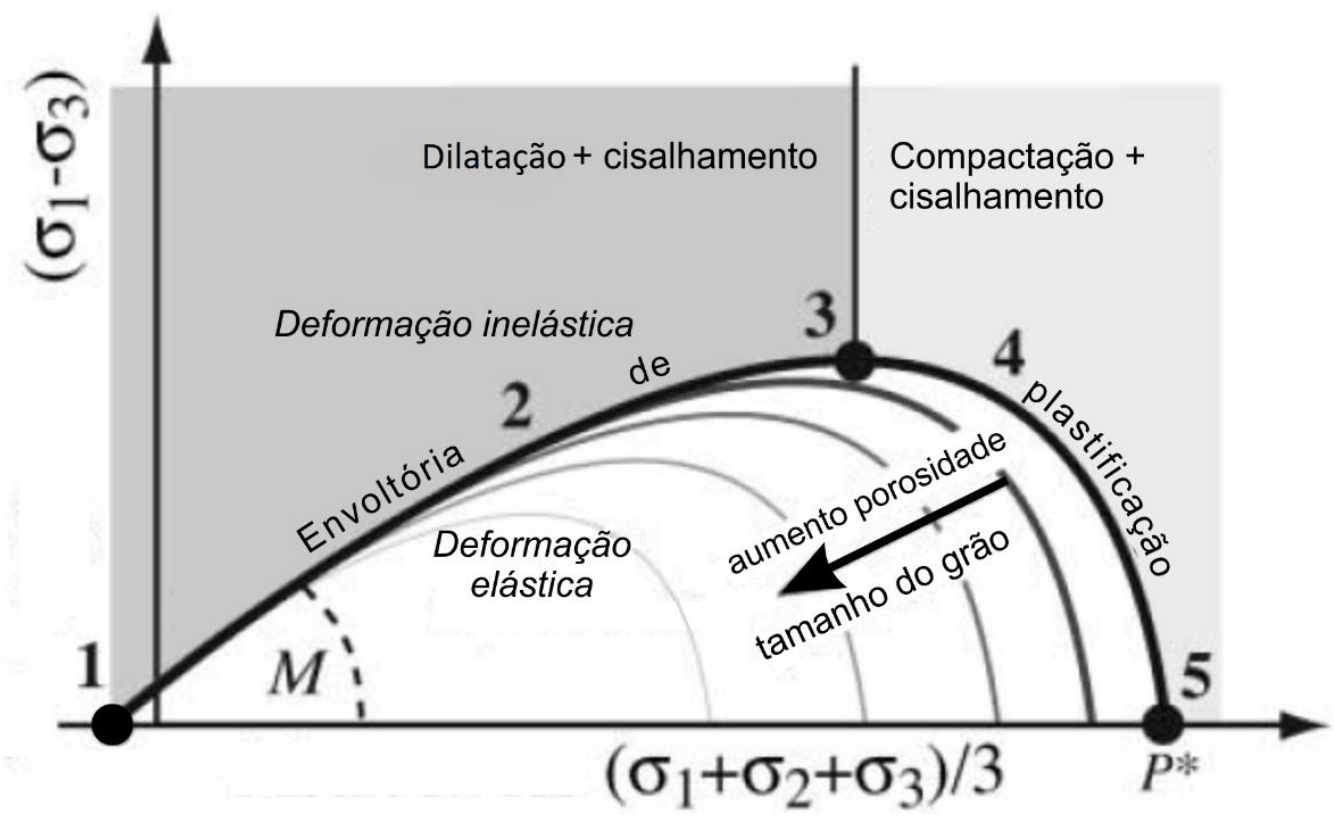

Figura 14 - Diagrama $p$ x $q$ aplicado a rochas porosas [após Schultz e Siddharthan (2005)]. Envoltória de deformação inelástica de rocha matriz (curva em negrito) produz bandas de dilatação (1), bandas de cisalhamento com dilatação (2), bandas de cisalhamento (3), bandas de compactação com cisalhamento (4) e bandas de compactação (5). [Fossen et al. (2007)]

Soliva et al. (2013) apresentaram três diferentes sistemas de bandas de deformação de duas áreas diferentes que demostraram que (1) dentro da mesma litologia, da mesma área e mesmas propriedades petrofísicas a geometria do sistema de BD diferem em função do regime tectônico; e (2) em diferentes litologias, diferentes redes de BD ocorrem sob as mesmas condições tectônicas. Baseado nessas observações e na teoria da plasticidade em arenitos porosos, eles propuseram um modelo de formação de sistemas de BD em função das tensões tectônicas, soterramento e propriedades da rocha, sintetizado nos esquemas da Figura 15 e da Figura 16. 


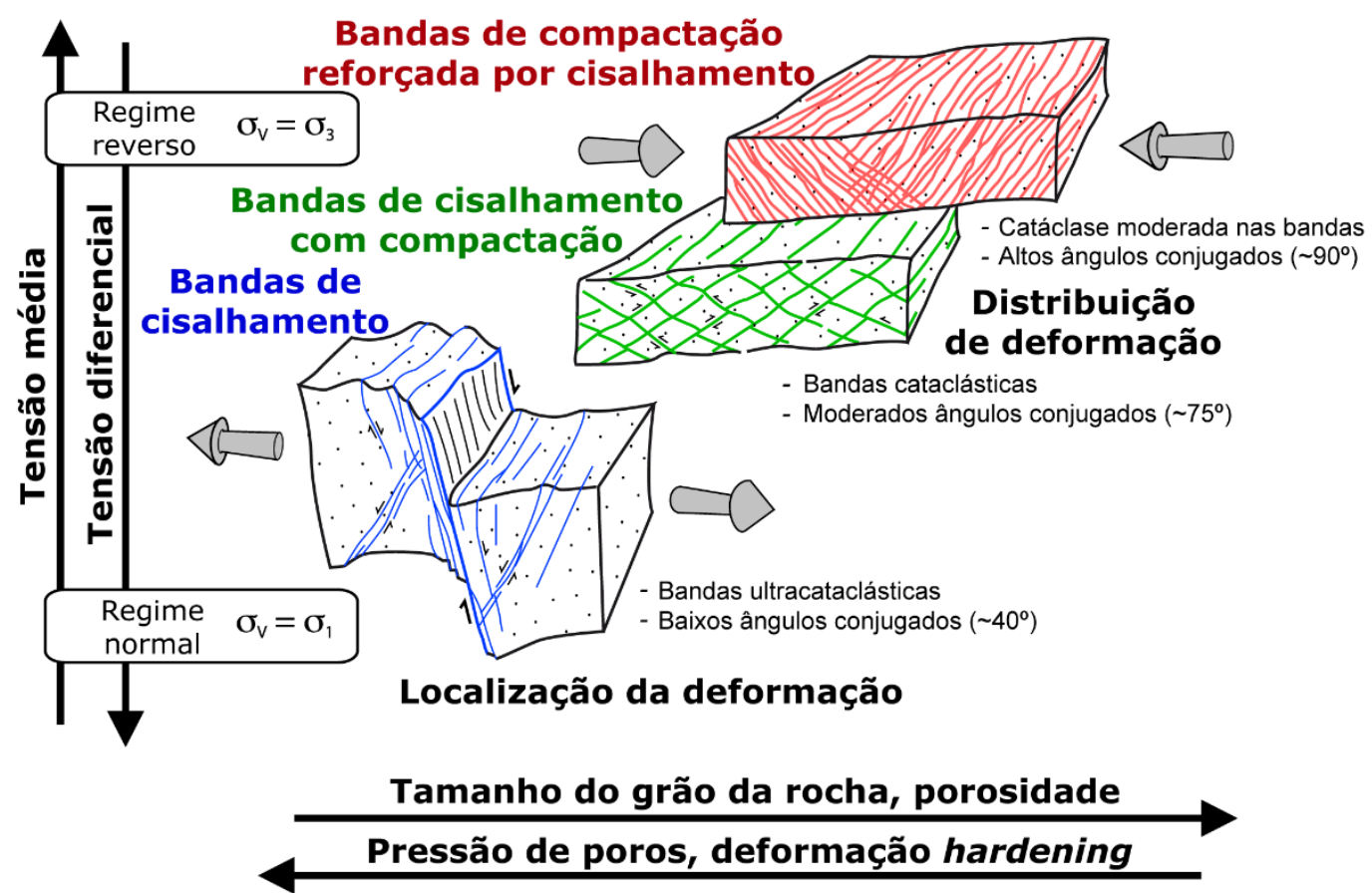

Figura 15 - Modelo de localização ou distribuição de deformações como bandas dominadas por cisalhamento ou compactação respectivamente, em função das tensões média e diferencial, tamanho do grão, porosidade, pressão de poros e deformação hardening. [Adaptado de Soliva et al. (2013)]

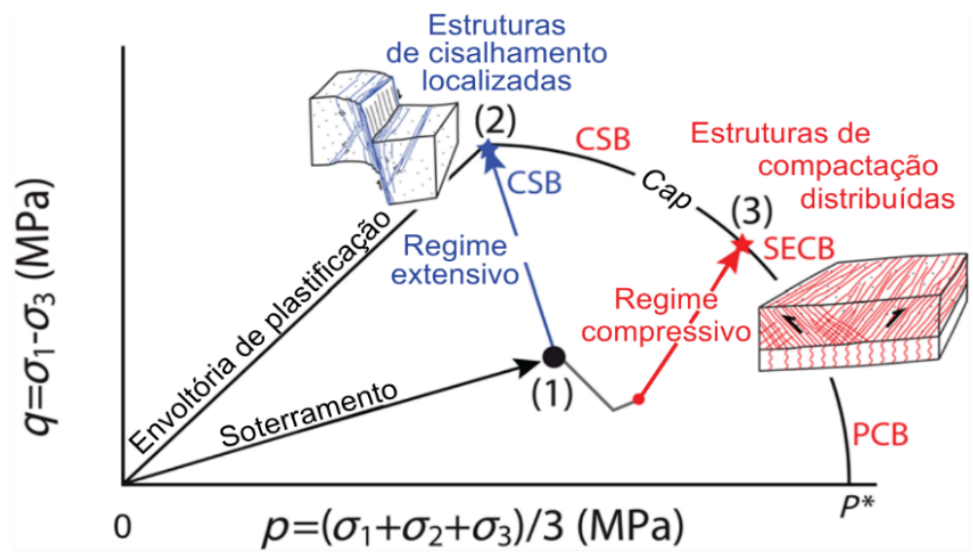

Figura 16 - Diagrama $p$ x q mostrando a trajetória de tensões aplicadas em um arenito durante o soterramento que, após atingir o ponto (1) é exposto a extensão, aumentando $q$ e reduzindo $p$ até tocar na envoltória no ponto onde a localização de banda de cisalhamento (CSB) é prevista (2). Se exposto a compressão após o ponto (1), cria um caminho que intercepta o cap onde bandas do tipo SECB e PCB são esperadas (3). [Adaptado de Fossen et al. (2017)] 


\section{6. \\ Backstripping}

A mecânica da geração de BD remete ao conhecimento do passado geológico para modelar a trajetória das tensões que atuaram na rocha reservatório. Para isso, são necessárias informações pretéritas dos estados de tensões e propriedades das rochas, ou seja, o paleomodelo geomecânico [Moraes (2018)].

De uma forma sintética 0 método de Backstripping trata-se da descompactação sequencial das camadas estratigráficas atuais prevendo como elas estariam em diferentes tempos no passado, separando a influência do carregamento dos sedimentos sobrejacentes e a influência da tectônica na subsidência do embasamento (Allen e Allen, 2005).

A descompactação sucessiva das camadas sedimentares selecionadas é feita no tempo por:

$$
Z_{2}-Z_{1}=z_{2}-z_{1}-\left(\frac{\phi_{0}}{C}\right)\left(e^{-C z_{1}}-e^{-C z_{2}}\right)+\left(\frac{\phi_{0}}{C}\right)\left(e^{-C Z_{1}}-e^{-C Z_{2}}\right)
$$

onde $Z_{1}$ e $Z_{2}$ são as paleoprofundidades equivalentes de topo e base da camada com profundidades atuais $z_{1}$ e $z_{2}, \phi_{0}$ é a porosidade inicial de cada camada desconfinada e $C$ é o coeficiente do decaimento da compactação.

A eq. (8), uma equação transcendental, tem sua solução por um procedimento computacional numérico iterativo. Durante o processamento, a porosidade média $(\phi)$ da camada é calculada pela equação

$$
\phi=\left(\frac{\phi_{0}}{C}\right)\left(\frac{e^{-C Z_{1}}-e^{-C Z_{2}}}{Z_{2}-Z_{1}}\right)
$$

A análise de subsidência tectônica dos horizontes de interesse é feita ao associar o comportamento isostático ${ }^{2}$ com a retirada de carga sedimentar, assumindo-se uma bacia preenchida por água. A subsidência tectônica $Y$ por uma compensação isostática local (Airy $\left.{ }^{3}\right)$ é dada por:

${ }^{2}$ O conceito de isostasia, a compensação das diferenças na distribuição das cargas e dos campos de tensões no espaço, principalmente em profundidade, relaciona-se diretamente com a elevação e a subsidência da litosfera. A superfície da litosfera, em uma primeira aproximação, é esculpida em função da compensação da distribuição da massa em um estado de equilíbrio, onde geralmente assume-se a astenosfera, com comportamento fluido, como sendo a profundidade de compensação isostática. Essa compensação de cargas pode ser feita localmente ou de forma distribuída regionalmente [Moraes (2016)].

${ }^{3} \mathrm{O}$ método de Airy é um modelo para a isostasia local que preconiza que blocos com mesma densidade e diferentes espessuras e profundidades de compensação gerariam topografia [Moraes (2016)]. 


$$
Y=S\left(\frac{\rho_{m}-\rho_{b}}{\rho_{m}-\rho_{a}}\right)-\Delta\left(\frac{\rho_{a}}{\rho_{m}-\rho_{a}}\right)+(W-\Delta)
$$

onde $S$ é a espessura do pacote sedimentar descompactado, $\rho_{b}$ é a densidade média do pacote sedimentar descompactado, $\rho_{a}$ é a densidade da água, $\rho_{m}$ é a densidade do manto, $W$ é a paleobatimetria e $\Delta$ é a variação eustática do nível do mar.

Essa técnica é utilizada no modelo proposto para estimar a tensão vertical total, a pressão de poros hidrostática e a porosidade com suas derivações em diferentes tempos geológicos.

Com a geo-história da bacia sedimentar e os dados petrofísicos atuais, pode-se aplicar a teoria do estado crítico pelo modelo de deformação inelástica MCCM, inferindo-se o potencial de nucleação de BD.

\section{7. \\ Permeabilidade}

O índice de produtividade de um reservatório é fortemente controlado pela permeabilidade da rocha reservatório. Um dos fatores que faz a permeabilidade ter uma grande variação é a presença de estruturas como fraturas, falhas e BD, que podem resultar em barreiras, canais de fluxo e compartimentalização de corpos rochosos no reservatório. Essa variabilidade controla como o fluído é drenado [Fjaer et al. (2008)].

$\mathrm{Na}$ indústria do petróleo a estimativa da permeabilidade em reservatórios é uma tarefa de alta complexidade, pois muitas feições na rocha são subsísmicas.

Do ponto de vista microscópico, a permeabilidade é controlada pelos seguintes parâmetros: (i) porosidade $(\phi)$, (ii) tamanho do poro / tamanho do grão, (iii) geometria do poro / geometria do grão e (iv) tortuosidade (T) [Fjaer et al. (2008)].

Uma forma de estimar a permeabilidade $(k)$ em meios porosos bastante conhecida é a equação de Kozeny-Carman, que é baseada em um modelo de rede, onde os poros são considerados condutos [Fjaer et al. (2008)] e é dada pela equação

$$
k=\frac{d_{g}^{2}}{k_{0} T^{2}} \frac{\phi^{3}}{(1-\phi)^{2}}
$$

onde $d_{g}$ é o diâmetro do grão, assumindo geometria esférica e $k_{0}$ é um fator de correção introduzido para contabilizar a forma real do poro. É importante ressaltar que essa relação não se aplica à arenitos deformados. 
Flornes (2005) realizou diversos ensaios hidrostáticos em amostras de arenitos de alta porosidade e concluiu, em concordância com a relação permeabilidade-porosidade tal qual a equação de Kozeny-Carman, uma mudança de permeabilidade proporcional a mudança de porosidade dada por:

$$
\frac{\Delta k}{k}=-X \frac{\Delta \phi}{\phi}
$$

onde o fator de proporcionalidade $X$ encontra-se na faixa entre 4 e 10 para as diferentes rochas estudadas, com um valor médio em torno de 7 .

Uma outra relação entre a permeabilidade e a porosidade resultante de medições diretas de amostras porosas durante o processo de deformação foi descrita por Nikolaevskiy (1996) na forma:

$$
\frac{k}{k_{i}}=\left(\frac{\phi}{\phi_{i}}\right)^{n}
$$

onde $k_{i}$ é a permeabilidade inicial, $\phi_{i}$ é a porosidade inicial e o expoente $n=10$ corresponde à arenitos reais.

Zhu et al. (1997) observaram através de ensaios triaxiais que a evolução da permeabilidade durante a localização de fluxo cataclástico imita a mudança de porosidade.

Uma outra observação comum é que em ensaios triaxiais a permeabilidade é sempre maior na direção de maior tensão principal [Fjaer et al. (2008)].

Crowford (2002) realizou experimentos laboratoriais e afirmou que as mudanças de permeabilidade associadas a alterações nas tensões e deformações geralmente seguem um modelo constitutivo semelhante ao da deformação. Este estudo também usou isolinhas de isopermeabilidade para mapear a redução da permeabilidade e concluiu que a redução da permeabilidade é mapeada tão somente na região de compactação, limitando-se à linha de estado crítico.

Ballas et al. (2015) realizaram uma extensa compilação com 766 dados de permeabilidade de BD e falhas cataclásticas da literatura e de novos campos, confirmando que a permeabilidade decresce em função da intensidade de catáclase em $\mathrm{BD}$, com baixa redução da permeabilidade em crush microbreccia de PCB e SECB e alta redução em cataclasitos/ultracataclasitos de clusters de $\mathrm{BD}$, de bandas com deslocamento e de núcleos de falhas. Essa síntese mostra que a permeabilidade pode ser reduzida em até seis ordens de grandeza devido à presença dessas estruturas (Figura 17). $O$ trabalho enfatiza que a catáclase e a redução da permeabilidade são controladas por:

- regime tectônico e a presença de falha: regime de falha normal e a presença de uma descontinuidade ou falha (tanto de regime normal 
quanto de regime reverso) tipicamente leva a formação de bandas cisalhantes cataclásticas mostrando intensa catáclase e alta redução de permeabilidade enquanto reduções moderadas são geralmente registradas em bandas formadas em regime reverso e em áreas sem falhas localizadas;

- profundidades de soterramento entre $1 \mathrm{~km}$ e $3 \mathrm{~km}$ favorecem a formação de bandas cataclásticas mostrando intensa catáclase e alta redução de permeabilidade, enquanto menor redução de permeabilidade é geralmente observada em bandas formadas em soterramentos menores que um quilômetro e maiores que três quilômetros.
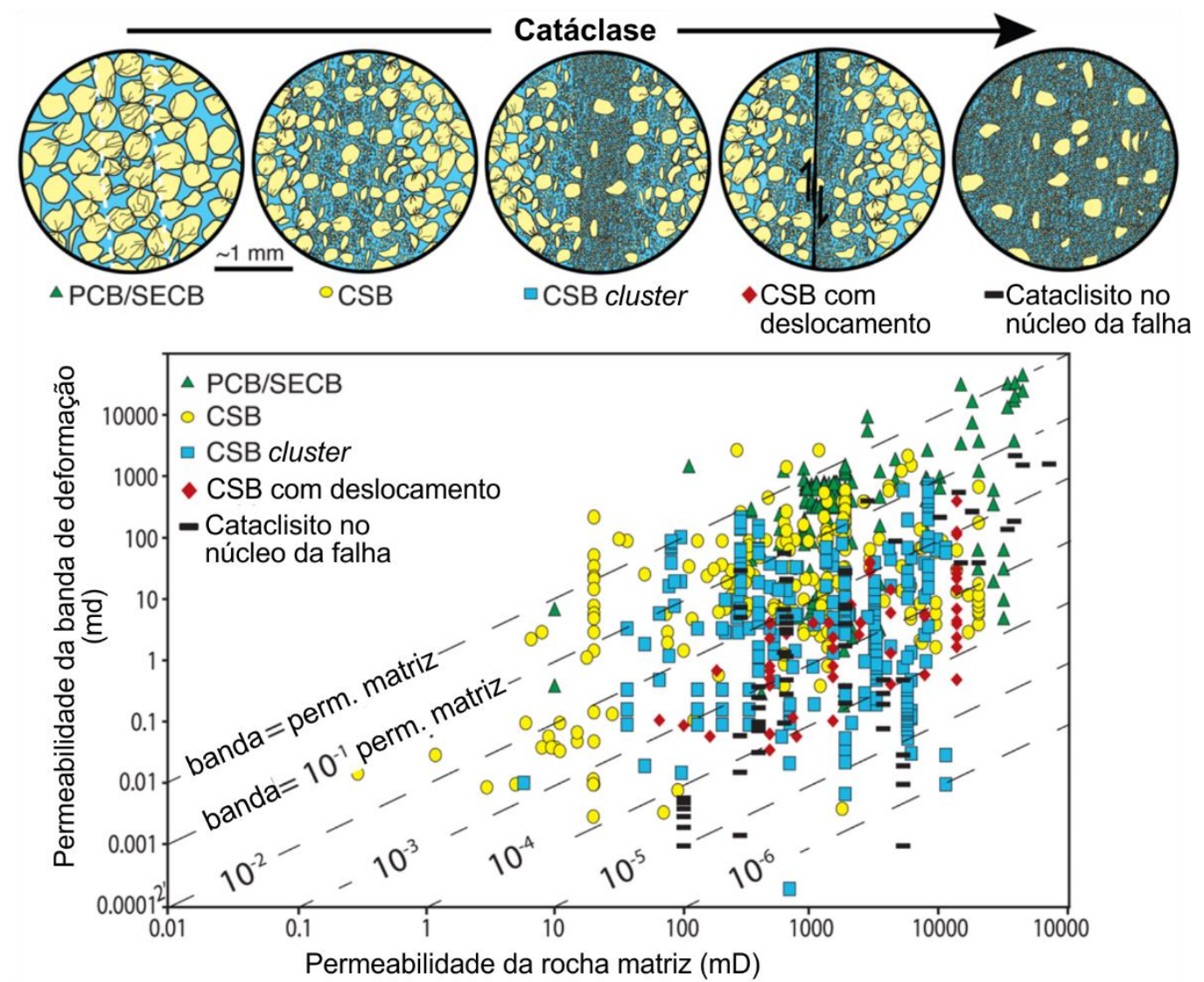

Figura 17 - Gráfico mostrando valores de permeabilidade para vários tipos de BD cataclásticas em função da permeabilidade da rocha matriz (arenito). [Adaptado de Ballas et al. (2015)] 


\section{8. Paleotensões por Inversão de Descontinuidades}

A observação de algumas propriedades cinemáticas de descontinuidades como azimute, mergulho e estrias de planos de falhas fornece insumos para a interpretação e análise de paleotensões. Quando se tem dados de um conjunto de descontinuidades, é possível estimar a orientação das tensões principais $\left(\sigma_{1}\right.$, $\sigma_{2}$ e $\sigma_{3}$ ). $O$ método de paleotensões se apoia em algumas premissas: um agrupamento de falhas é formado pelo mesmo estado de tensões, as rochas são razoavelmente homogêneas, as deformações são relativamente baixas e as estruturas não sofreram rotações significantes desde sua gênese [Fossen (2010)].

Uma outra suposição bastante conhecida e essencial para a inversão de descontinuidades é a hipótese de Wallace-Bott [sintetizada de Wallace (1951) e Bott (1959)]. Esta afirma que a direção de deslizamento em uma descontinuidade cisalhante é paralela à maior tensão cisalhante que se dispôs na superfície da falha. Nesse sentido, deve-se minimizar o ângulo de desvio entre a direção de deslizamento real e a teórica através do produto escalar

$$
s \cdot \sigma_{c}^{u} \leq \varepsilon+1
$$

onde $s$ é o vetor unitário na direção da estria, $\sigma_{c}^{u}$ é o vetor unitário na direção da maior tensão cisalhante projetada na falha e $\varepsilon$ é o erro de aceitação.

Enquanto os valores absolutos são praticamente inatingíveis em muitos casos, suas magnitudes relativas, isto é, a forma do elipsoide de tensões, pode ser estimada a partir dos dados das falhas. Para esse propósito é usado a relação denominada de razão de tensões

$$
\varnothing=\frac{\left(\sigma_{2}-\sigma_{3}\right)}{\left(\sigma_{1}-\sigma_{3}\right)}
$$

onde $0 \leq \emptyset \leq 1$.

A razão de tensões $(\varnothing)$ é usada para se obter um tensor de tensões que contem a forma e a orientação do elipsoide de tensões. Esse tensor é chamado de tensor de tensões reduzido $\left(\sigma_{\emptyset}\right)$.

$$
\sigma_{\emptyset}=\left[\begin{array}{lll}
1 & 0 & 0 \\
0 & \varnothing & 0 \\
0 & 0 & 0
\end{array}\right]
$$

Em conseguinte se tem uma quantificação relativa das tensões principais, representada na Figura 18. 


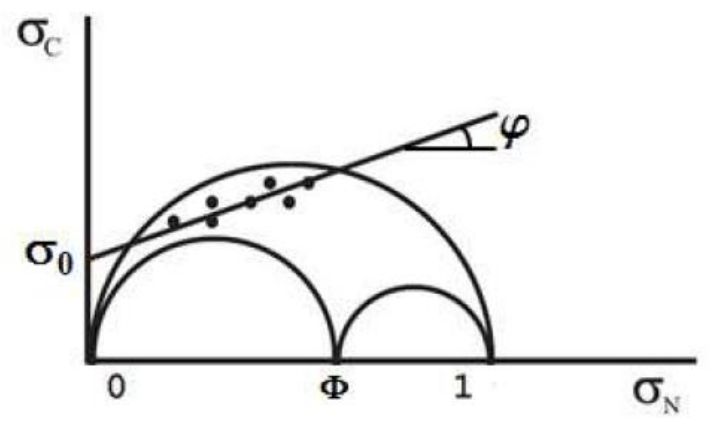

Figura 18 - Melhor ajuste de $\sigma_{\emptyset}$ aos dados de estrias de falhas (pontos) frente ao critério de Mohr-Coulomb. [Moraes (2018)]

Em síntese, a inversão de descontinuidades possibilita a obtenção das direções das tensões principais e uma quantificação imediata de seus valores relativos.

Essa técnica na indústria do petróleo esbarra na quase total ausência de dados de estrias. Moraes e Riccomini (2014) desenvolveram um procedimento por condicionantes e premissas da geomecânica do petróleo e através de análise estatística elementar. O método foi calibrado e confrontado, valendo-se de dez conjuntos de dados de descontinuidades com estrias. Basicamente, buscou-se o melhor ajuste dos dados tão somente de atitude das falhas e fraturas para a eq. (14) frente a critérios de ruptura adequados, levando a determinação das direções das tensões horizontais e da $\emptyset$, obtendo-se assim, as tensões relativas, a coesão, o ângulo de atrito interno da rocha de falha e o regime de falhamento. 


\section{3 \\ Metodologia}

O objetivo do trabalho é prever se em uma determinada porção de um reservatório siliciclástico de hidrocarboneto foram atingidas condições para a formação de BD ou quão próximo se está de uma possível geração dessa feição a fim de se sugerir uma análise da redução de permeabilidade.

Em termos práticos, objetiva-se traçar a trajetória de tensões atuantes em uma porção do reservatório durante a formação e história de soterramento da bacia sedimentar na qual ele pertence. Para isso, é necessário:

(i) o modelo geomecânico 1D atual a partir de dados do poço na profundidade alvo do estudo;

(ii) as paleotensões pela geo-história, por backstripping, e pela inversão de descontinuidades, metodologia apresentada por Moraes (2018) (Figura 19);

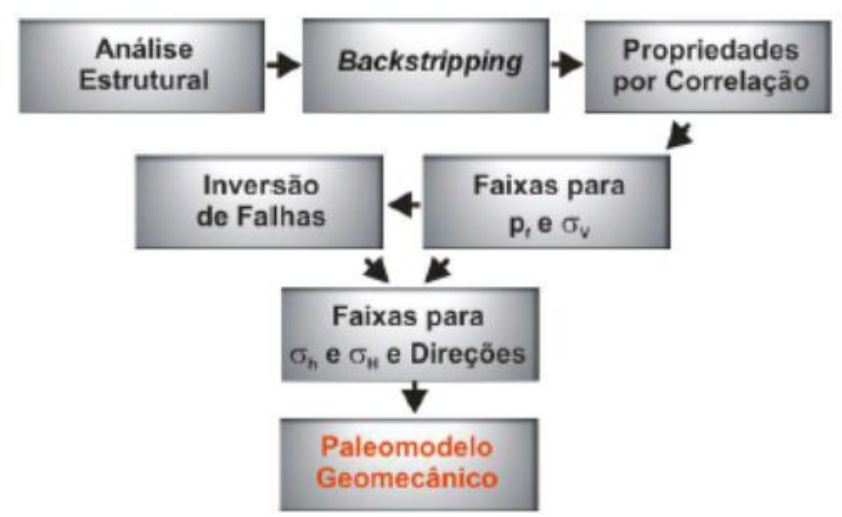

Figura 19: Metodologia para obtenção do paleomodelo geomecânico [Moraes (2018)]

(iii) as propriedades petrofísicas e mecânicas da rocha reservatório ao longo do tempo;

(iv) a implementação de um simulador analítico com a envoltória do MCCM (eq. (2), (3) e (4)) e o caminho das tensões no tempo geológico.

O modelo proposto é representado pela Figura 20. 


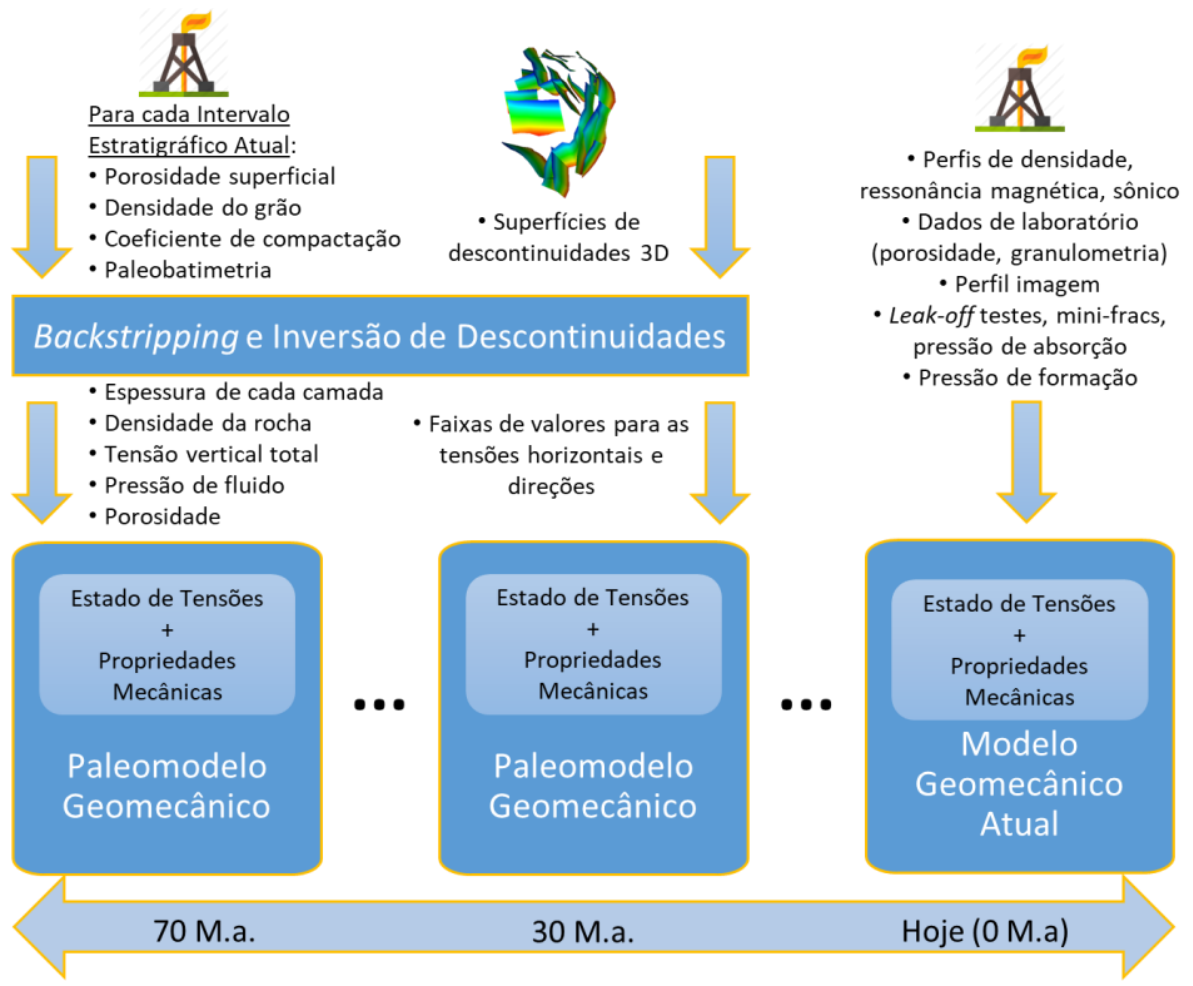

Figura 20 - Representação conceitual da metodologia

As implementações foram realizadas em linguagem de programação Python versão 3.7.4 conjuntamente com os seguintes módulos: Qt 5.9.7, PyQt 5.9.2, NumPy 1.16.5, Matplotlib 3.1.1 e Pandas 0.25.1. Para simplificar o gerenciamento e a instalação dos pacotes utilizou-se a plataforma "Anaconda Individual Edition 3", de distribuição gratuita e de código aberto das linguagens de programação Python e R para computação científica. O simulador desenvolvido pode ser executado nos sistemas operacionais Windows, Linux e macOS.

O software "Sigeo 3" foi utilizado para a modelagem geomecânica 1D atual e o programa "Gopaleog" [Moraes e Ricomini (2014)] foi usado para a inversão de descontinuidades. O algoritmo de Backstripping foi implementado tendo como base o script "Gobassub" - Programa para Análise de Subsidência em Bacias Sedimentares em 1D - escrito no Matlab e fornecido pelo co-orientador deste trabalho, o geólogo Dr. Anderson Moraes.

\section{1.}

\section{Procedimento para a Simulação}

A simulação se inicia com a inserção dos parâmetros de entrada do algoritmo de Backstripping (Figura 21-1) para cada intervalo cronoestratigráfico que corta a trajetória do Poço (Porosidade inicial da camada desconfinada, 
coeficiente de decaimento da compactação, variação do nível do mar, densidade do grão, paleobatimetria, densidade do manto e densidade da água), bem como a descrição da própria formação (Figura 21-2) (profundidades de soterramento de topo e base, descrição e idade cronoestratigráfica). Após o preenchimento dessas informações, deve-se clicar no botão "Adicionar Intervalo" (Figura 21-3) para salvar em memória e continuar com a entrada para os demais intervalos.

Com a estratigrafia atual configurada, o passo seguinte é executar o algoritmo do Backstripping clicando no botão "Backstripping" (Figura 21-4). Esse procedimento vai resultar no passado geológico (profundidades de topo e base em cada idade geológica modelada), bem como algumas "paleoinformações" necessárias para os paleomodelos geomecânicos: densidade média da coluna de rocha, porosidade, pressão de poros hidrostática e tensão vertical total.

Em seguida, deve-se configurar os dados para a definição da envoltória de plastificação (Figura 21-5) (raio do grão e ângulo de atrito) e definição das tensões horizontais pelas razões $K_{H}$ e $K_{h}$ (Figura 21-6). Essas informações são necessárias para a formação de interesse (intervalo de maior profundidade) em todos as idades geológicas do modelo. No término desse passo, tem-se a

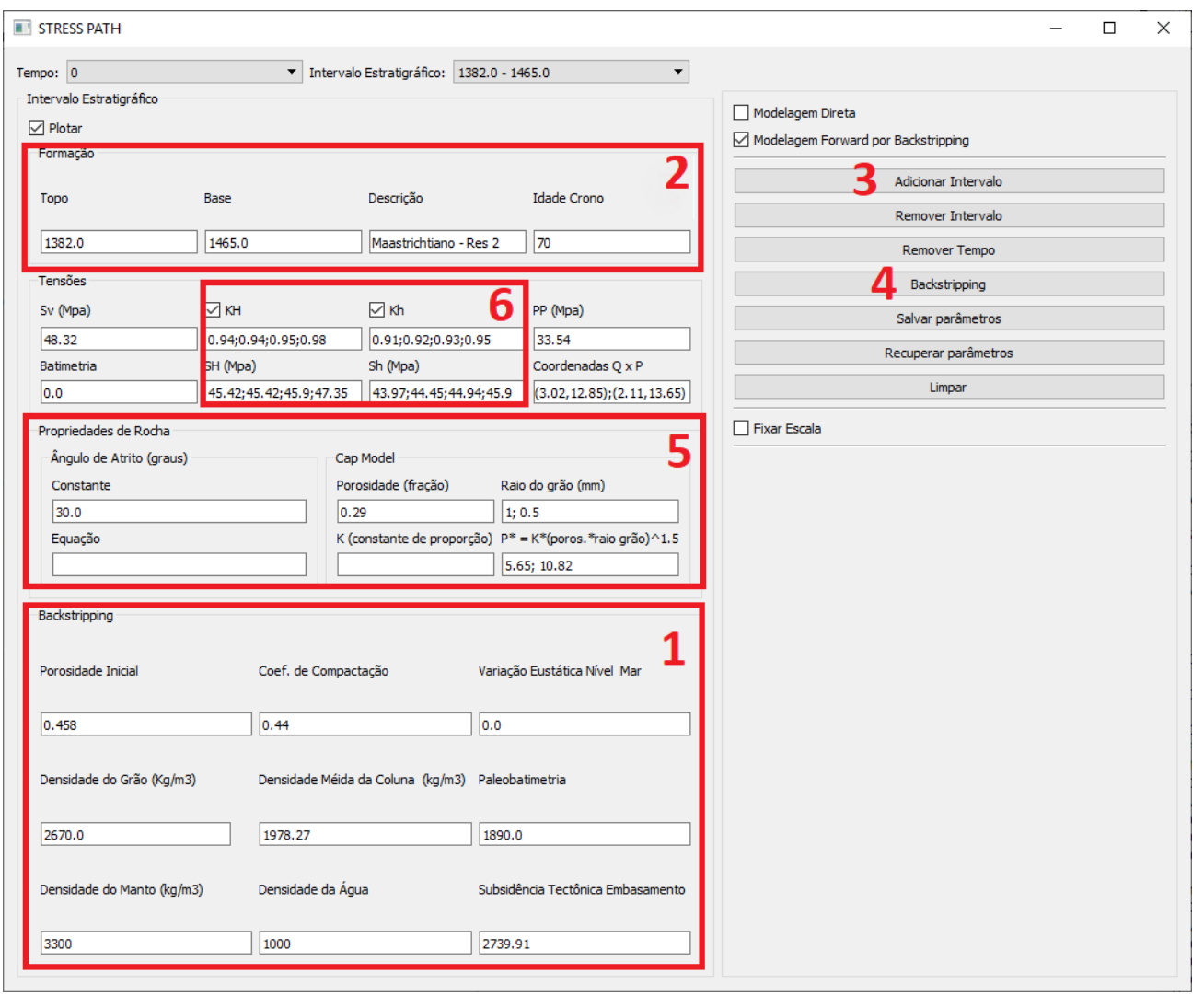

Figura 21 - Janela de configuração dos parâmetros do simulador desenvolvido neste projeto 
trajetória de tensões para a porção do reservatório objeto da análise desde o início do soterramento até os dias atuais (Figura 41). 


\section{Estudo de caso}

Muitos reservatórios descobertos no offshore do Mar do Norte, Golfo do México, Brasil e Angola são compostos por arenitos pouco consolidados que são mais propensos à compactação [Nguyen et al. (2014)]. Levando-se em conta essa informação, escolheu-se então, para uma prova de conceito, um reservatório arenítico pouco consolidado da margem continental brasileira. Para o estudo foram utilizados os dados de perfuração e de análises de laboratório de um dos poços produtores, denominado poço A. Esse poço é conhecido por apresentar feições interpretadas como BD em testemunhos (Figura 22).
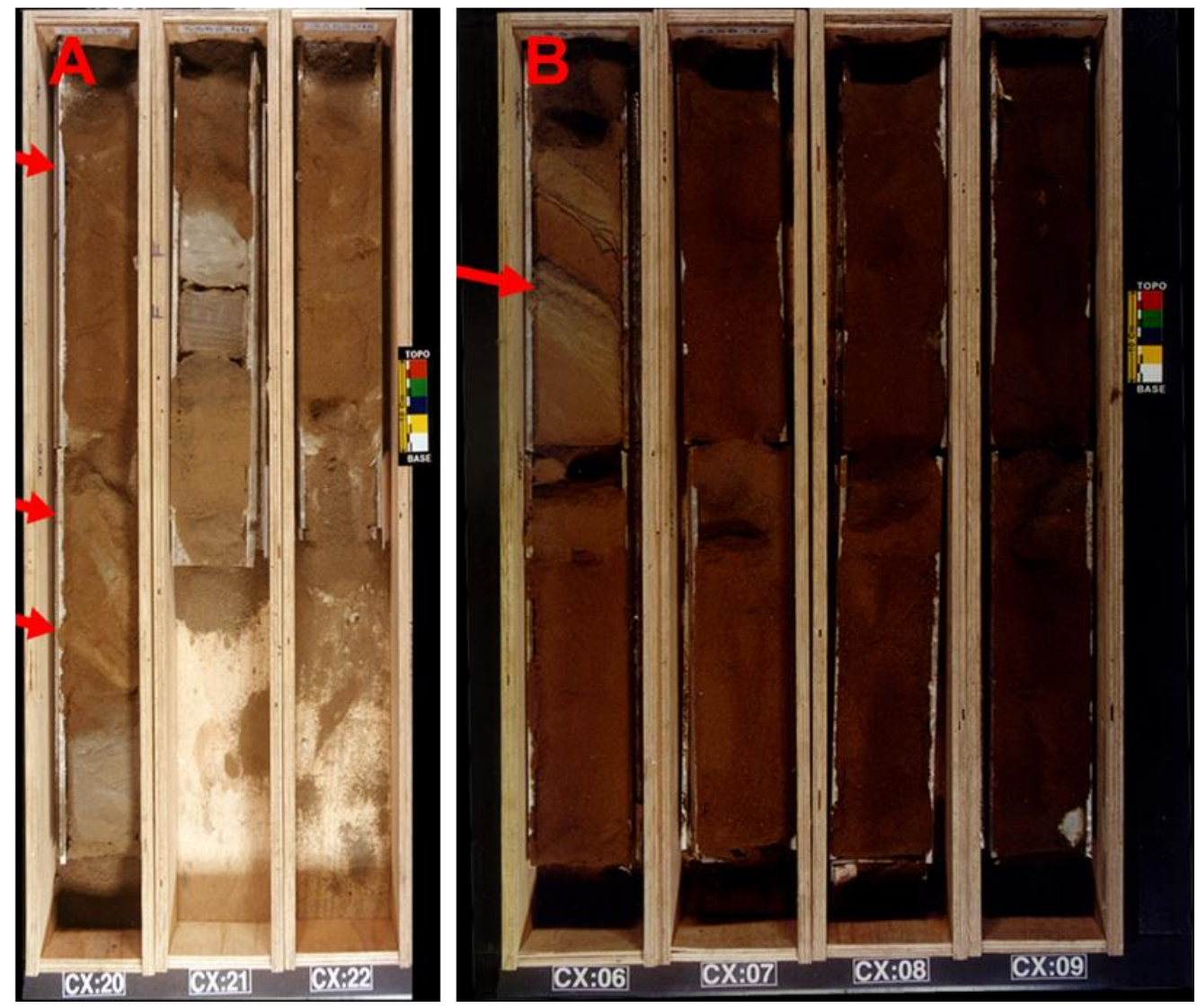

Figura 22 - (A) Testemunho 9 do poço A (3.337,00 m a 3.353,50 m). (B) Testemunho 10 do poço $A(3.353,50 \mathrm{~m}$ a $3.371,50 \mathrm{~m})$ mostrando um cluster de BD. 
As mesmas BD também podem ser visualizadas em perfil de imagem da Figura 23.

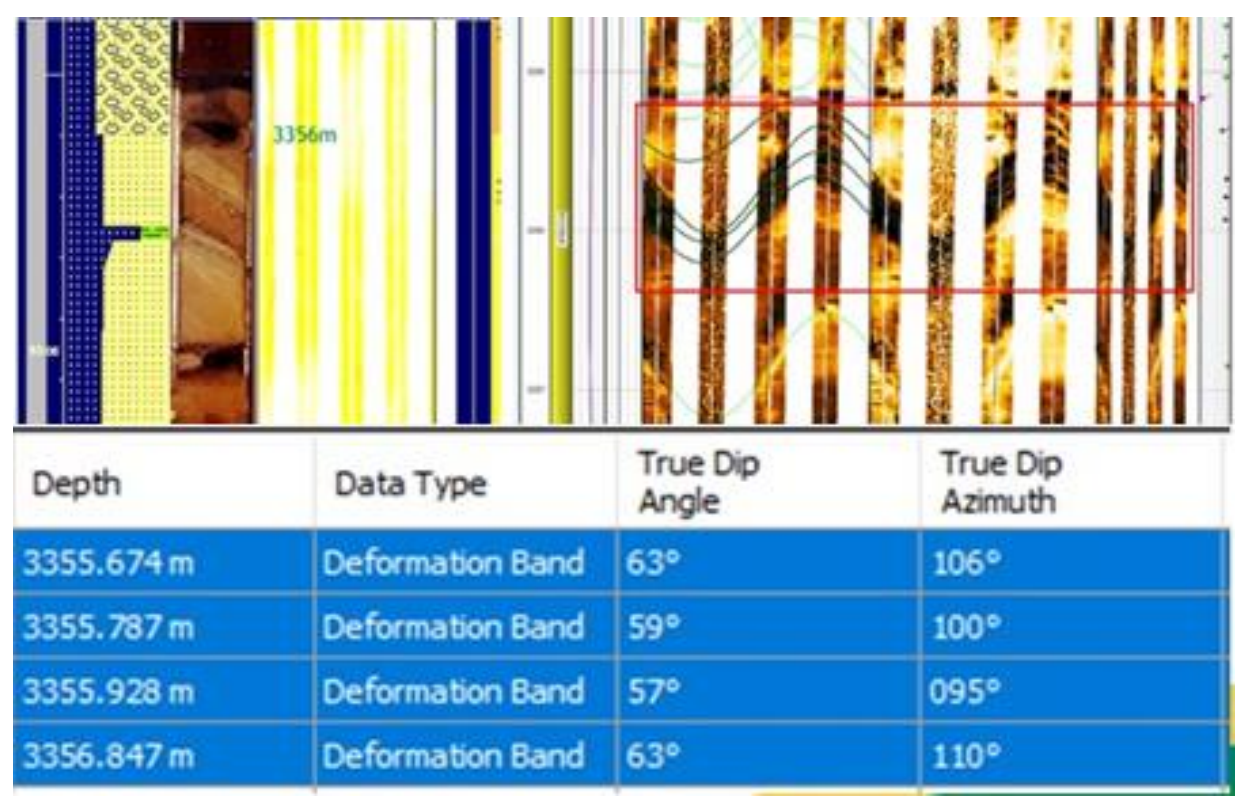

Figura 23 - Interpretação de BD em perfil imagem do poço A e suas atitudes

A profundidade $3.355,00$ metros, pertencente a zona de falhamento, foi selecionada para esta análise com o intuito de calibrar ou validar o modelo de predição de BD.

\section{1. \\ Descrição da rocha reservatório}

O reservatório cortado pelo poço A é formado por arenitos maastrichtianos classificados como arcósios líticos, rochas clásticas que contém mais de $25 \%$ de feldspato, muito quartzo, pouca argila e com fragmentos de outras rochas, nesse caso, vulcânicas. A descrição mineralógica da profundidade 3358,45 metros, do testemunho 10 (Figura 22), define a granulometria como areia fina a média, composta por grãos subangulosos/angulosos, pouco litificados, de moderadamente a bem selecionados.

No plano de deformação subsísmica, verifica-se que a rocha possui uma coloração semelhante aos fragmentos de rochas vulcânicas, mas com ausência de contornos desses grãos, sugerindo que todos eles foram esmagados e possivelmente formaram um cataclasito. Tal comportamento pode ser explicado pelo aspecto mais frágil dos fragmentos de rocha vulcânica se comparados aos grãos de quartzo e feldspatos, os quais não se apresentam quebrados na região plastificada. 


\section{2. \\ Modelo Geomecânico 1D Atual}

O modelo geomecânico atual é composto pelas magnitudes das tensões totais in-situ (vertical, horizontal máxima e horizontal mínima), pela pressão de fluidos (ou pressão de poros) e por propriedades mecânicas da rocha (UCS e ângulo de atrito interno). O procedimento de cálculo dessas variáveis é descrito a seguir.

\subsection{1.}

\section{Tensão Vertical Total ou Sobrecarga}

A tensão vertical total $\left(\sigma_{v}\right)$ é obtida pelo somatório dos pesos das camadas sobrepostas a um determinado elemento de rocha, incluindo a lâmina d'água em poços offshore, conforme a equação

$$
\sigma_{v}=\rho_{a} g z_{a}+\int_{z_{a}}^{z} \rho_{b} g d z
$$

onde $\rho_{a}$ é a massa específica ou densidade da água do mar $\left(\mathrm{g} / \mathrm{cm}^{3}\right), \rho_{b}$ é a massa específica ou densidade da rocha $\left(\mathrm{g} / \mathrm{cm}^{3}\right), z_{a}$ é a lâmina d'água $(\mathrm{m}), z$ é a profundidade $(\mathrm{m})$ e $g$ a aceleração devido à gravidade. Utiliza-se o perfil densidade prioritariamente como insumo do cálculo da sobrecarga. Nos trechos do poço onde esse perfil não é corrido, por exemplo nas profundidades iniciais, costuma-se derivar a densidade a partir de alguma correlação baseada em perfis comumente medidos no poço como o perfil sônico compressional.

Nesse trabalho foi adotado a correlação de Gardner (1974), uma equação empírica bastante simples e dada por

$$
\rho_{b}=a V^{b}=a\left(\frac{10^{6}}{\Delta t}\right)^{b}
$$

onde $\rho_{b}$ é a densidade total da formação $\left(\mathrm{g} / \mathrm{cm}^{3}\right)$, a é uma constante empírica (valor igual a 0,23 definido para o Golfo do México), $V$ é a velocidade do som (ft/s), $b$ é um expoente empírico (valor igual a 0,25 definido para o Golfo do México) e $\Delta t$ é o tempo de trânsito ou perfil sônico compressional ( $\mu \mathrm{s} / \mathrm{ft}$ ).

$\mathrm{Na}$ ausência de alguns dos perfis citados anteriormente, adota-se valores constantes de densidade para algumas litologias, como por exemplo os sais anidrita $\left(2,97 \mathrm{~g} / \mathrm{cm}^{3}\right)$ e halita $\left(2,17 \mathrm{~g} / \mathrm{cm}^{3}\right)$. Valores típicos para a densidade das rochas encontram-se na faixa entre $1,90 \mathrm{~g} / \mathrm{cm}^{3}$ a $2,50 \mathrm{~g} / \mathrm{cm}^{3}$. Porém, nos trechos mais superficiais, onde os sedimentos são mais porosos, os valores de densidade normalmente variam de $1,5 \mathrm{~g} / \mathrm{cm}^{3}$ a $1,95 \mathrm{~g} / \mathrm{cm}^{3}$. [Rocha e Azevedo (2007)]. 
A tensão vertical total (ou sobrecarga) $\left(\sigma_{v}\right)$ foi calculada pela abordagem explicada acima e sua magnitude na profundidade $3.355,00$ metros equivale aproximadamente a $7.008,81$ psi ou $48,32 \mathrm{MPa}$.

\subsection{2.}

\section{Tensão Horizontal Mínima}

Atualmente, a estimativa para a tensão horizontal mínima total $\left(\sigma_{h}\right)$ in situ passa pela medição direta dos gradientes de fraturamento da formação na parede do poço, geralmente feita através de testes em que o fluido de perfuração é pressurizado de maneira controlada dentro do poço. De acordo com os procedimentos e equipamentos utilizados, pode-se conhecer desde a pressão em que os fluidos começam a ser absorvidos pela formação até o valor da tensão in situ mínima. Dentre esses métodos podemos citar o (i) Teste de Absorção Clássico ou leak off test (LOT), (ii) Teste de Absorção Estendido (LOTX) e o (iii) Teste de Microfraturamento (minifrac).

A estimativa mais precisa da tensão horizontal mínima é a pressão de fechamento do teste de microfraturamento, pressão sob a qual a fratura fecha completamente. Essa magnitude é obtida após a leitura das pressões de absorção, de quebra e propagação da fratura.

A teoria de que a pressão de fechamento da fratura é uma boa estimativa para $\sigma_{h}$ defende que suficiente quantidade de fluido de perfuração foi bombeada após a absorção, a ponto de estender o comprimento da fratura para além da região perturbada próxima ao poço. Dessa forma, a pressão de fechamento não é influenciada pelos efeitos próximos ao poço, pela permeabilidade da fratura e pelo processo de crescimento da fratura, podendo ser considerada uma boa estimativa da tensão horizontal in situ mínima.

As medições de pressão utilizadas na calibração do gradiente de fratura pelas técnicas citadas apresentam, de maneira geral, a seguinte ordem decrescente de magnitude: pressão de quebra, pressão de absorção e tensão mínima. Tanto a pressão de absorção quanto a pressão de quebra são afetadas pela concentração de tensões ao redor do poço. Já a tensão mínima (pressão de fechamento) é representativa das tensões atuantes nas regiões mais distantes do poço. Para maiores detalhes consultar Rocha e Azevedo (2007) e Fjaer et al. (2008). 
No presente trabalho utilizou-se dados de Teste de Absorção (LOT) realizado no poço $A$ (Tabela 2 ) afim de estimar a tensão horizontal mínima total $\left(\sigma_{h}\right)$ via regressão linear (Figura 24).

Tabela 2: Pressões de absorção obtidos de teste de absorção (LOT) no poço A

\begin{tabular}{|c|c|}
\hline Profundidade Vertical (m) & Pressão de Absorção (psi) \\
\hline 2634.91 & 4478.83 \\
\hline 2653.91 & 4407.35 \\
\hline 3127.87 & 5859.28 \\
\hline 3137.87 & 5587.84 \\
\hline
\end{tabular}

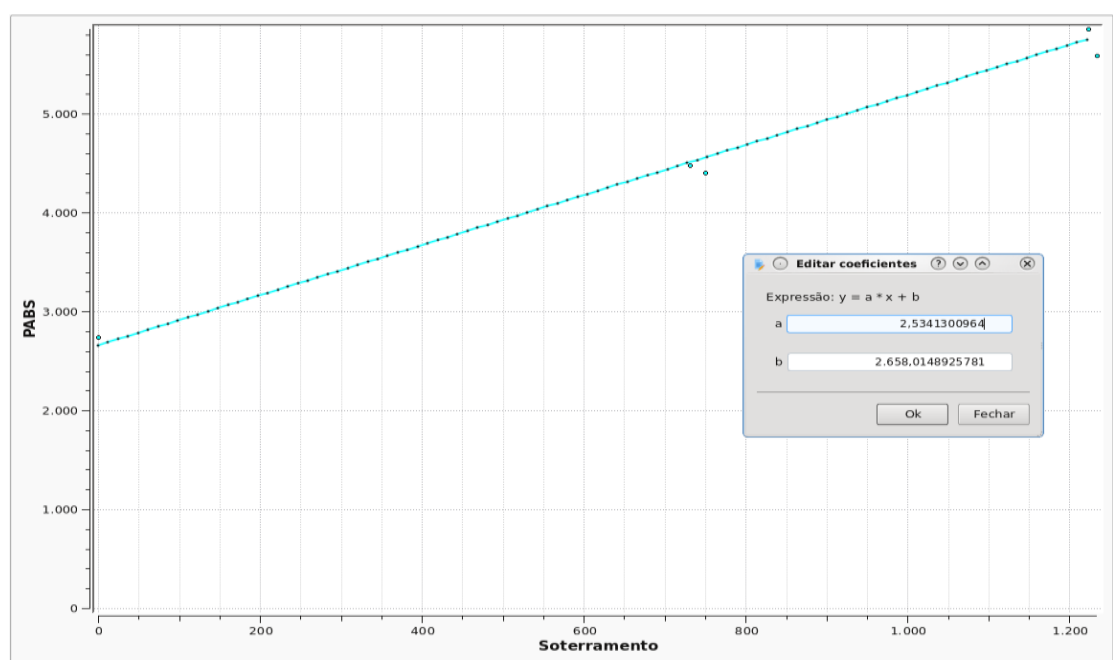

Figura 24 - Regressão linear representando a tendência da magnitude do $\sigma_{h}$ em relação às profundidades do poco $\mathrm{A}$

De acordo com os dados acima podemos afirmar então que a tensão horizontal mínima total no poço A pode ser estimada pela equação

$$
\sigma_{h}=2,534 * z_{\text {sot }}+1,4556 * z_{a}
$$

onde $z_{s o t}$ é a profundidade vertical menos a lâmina d'água $\left(z_{a}\right)$ em metros.

Para a profundidade alvo do estudo, 3.355,00 metros, a magnitude da $\sigma_{h}$ seria, então, aproximadamente $6.428,40$ psi ou $44,32 \mathrm{MPa}$.

\subsection{3.}

\section{Tensão Horizontal Máxima}

O método adotado para a estimativa da tensão horizontal máxima total $\left(\sigma_{H}\right)$ fundamenta-se na premissa de que a concentração de tensões no limite de um 
breakout (Figura 25), feição formada pelo desmoronamento de rocha na parede do poço, está em equilíbrio com a resistência da rocha [Zoback et al. (1988)].

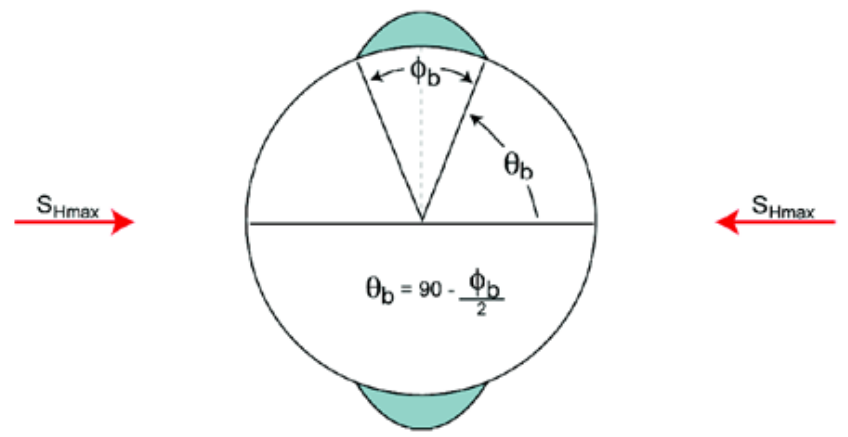

Figura 25 - Representação de feições de breakout na parede de um poço vertical [Zoback (2016)].

Assumindo-se que a tensão tangencial $\left(\sigma_{\theta \theta}\right)$ é a maior tensão principal $\left(\sigma_{1}\right)$ no elemento de rocha em questão e considerando-se o critério de ruptura de MohrCoulomb, tem-se que a tensão tangencial é dada por

$$
\sigma_{\theta \theta}=\sigma_{h}+\sigma_{H}-2\left(\sigma_{H}-\sigma_{h}\right) \cos 2 \theta_{b}-2 P_{p}-\Delta P-\sigma^{\Delta t}=C_{e f f}
$$

onde $\theta_{b}$ é o ângulo medido a partir do azimute da tensão horizontal máxima, $P_{p}$ é a pressão de poros da formação, $\Delta P$ é a diferença entre o peso de lama e a pressão de poros, $\sigma^{\Delta t}$ é a indução de tensões por variação térmica e

$$
C_{e f f}=\sigma_{1}=U C S+q \sigma_{3}
$$

onde $q=\left[\left(\mu_{i}^{2}+1\right)^{1 / 2}+\mu_{i}\right]^{2}=\tan ^{2}(\pi / 4+\varphi / 2), \varphi=\tan ^{-1}\left(\mu_{i}\right)$ e $\varphi$ é o ângulo de atrito interno.

Sabendo-se que um breakout é formado na porção de tensão tangencial $\left(\sigma_{\theta \theta}\right)$ máxima na parede do poço, das equações acima deriva-se, então, a equação

$$
\sigma_{H}=\frac{\left(C_{e f f}+2 P_{p}+\Delta P+\sigma^{\Delta t}\right)-\sigma_{h}\left(1+2 \cos 2 \theta_{b}\right)}{1-2 \cos 2 \theta_{b}}
$$

para o cálculo da tensão horizontal máxima, onde $2 \theta_{b} \equiv \pi-W_{b o}$ e $W_{b o}$ é o ângulo de abertura do breakout. É importante ressaltar que essa abordagem é válida apenas quando a tensão tangencial (hoop stress) for a maior tensão principal $\left(\sigma_{1}\right)$.

No poço A foram interpretadas quatro feições de breakout a partir do perfil de imagem, listadas na Tabela 3. Daí, a tensão horizontal máxima foi calculada e validada pelo gráfico Polígono de Tensões do Sigeo (Figura 26) para as quatro profundidades e posteriormente a magnitude média de $K_{H}\left(\sigma_{H} / \sigma_{v}\right)$ também foi determinada para a extrapolação do $\sigma_{H}$ em outras profundidades do poço. A $\sigma_{H}$ 
calculada para a profundidade $3.407,79$ metros não foi levada em consideração porque se mostrou inconsistente pelo Polígono de Tensões.

Tabela 3: $\boldsymbol{\sigma}_{\boldsymbol{H}}$ e $\boldsymbol{K}_{\boldsymbol{H}}$ calculados a partir de breakouts

\begin{tabular}{|c|c|c|c|c|}
\hline Prof. medida (m) & $\mathbf{W}_{\text {bo }}\left(\mathbf{(}^{\mathbf{0}}\right.$ & $\boldsymbol{\sigma}_{\mathbf{H}}(\mathbf{p s i})$ & $\boldsymbol{\sigma}_{\mathbf{H}}(\mathbf{M P a})$ & $\mathbf{K}_{\mathbf{H}}\left(\boldsymbol{\sigma}_{\mathbf{H}} / \boldsymbol{\sigma}_{\mathbf{v}}\right)$ \\
\hline $3.407,79$ & 75,16 & $6.286,30$ & 43,35 & 0,88 \\
\hline $3.414,70$ & 34,05 & $6.826,42$ & 47,07 & 0,95 \\
\hline $3.415,50$ & 37,98 & $6.775,11$ & 46,72 & 0,94 \\
\hline $3.418,04$ & 45,89 & $6.723,63$ & 46,35 & 0,93 \\
\hline
\end{tabular}

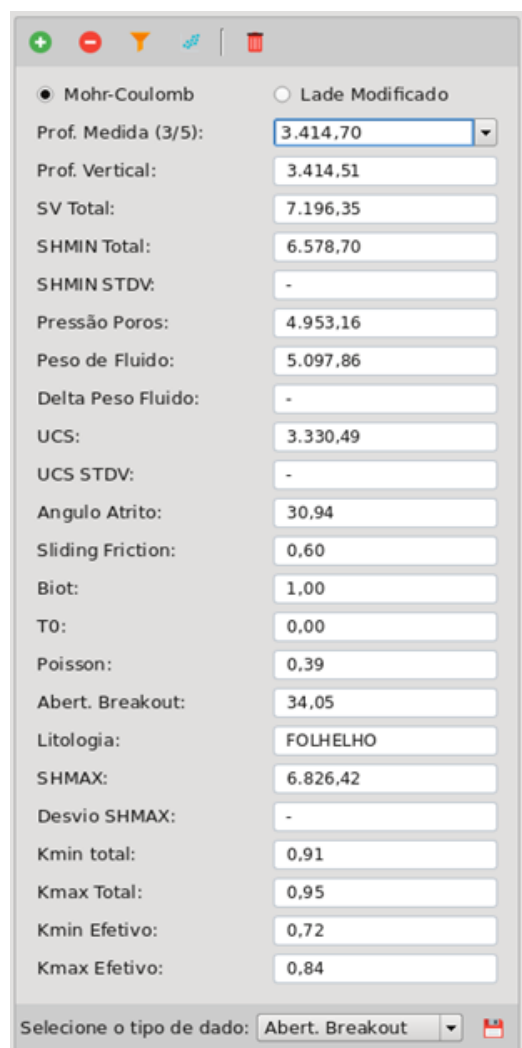

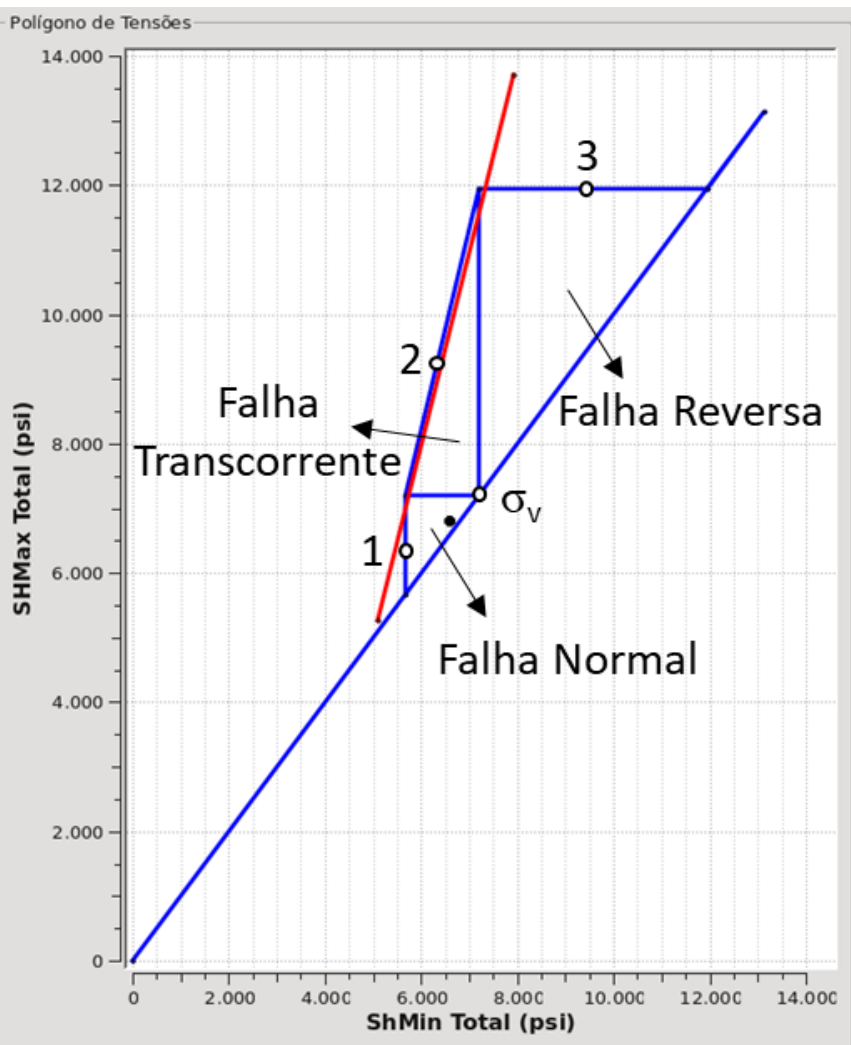

Figura 26 - Polígono de Tensões

O Polígono de Tensões tem por objetivo restringir e reduzir a incerteza na estimativa das magnitudes das tensões analisadas. Esse gráfico se apoia nas hipóteses de que os valores das tensões tectônicas na crosta terrestre são limitadas pela resistência à fricção de falhas e fraturas pré-existentes favoravelmente orientadas ao campo de tensões atual e que o coeficiente de atrito ( $\mu$ ) para grande parte de descontinuidades em subsuperfície oscila conforme um pequeno limite de valores: entre 0,6 a 1,0 [Zoback (2010)]. 
Dessa forma, se a razão entre as magnitudes das tensões principais efetivas mínima e máxima forem maiores que o valor definido pelo coeficiente de atrito das descontinuidades, uma desestabilização ocorre em falhas favoravelmente orientadas. Jaeger e Cook (1979) mostraram que a condição para o equilíbrio friccional pode ser representada na forma:

$$
\frac{\sigma_{1}^{\prime}}{\sigma_{3}^{\prime}}=\frac{\left(\sigma_{1}-P p\right)}{\left(\sigma_{3}-P p\right)}=\left[\left(\mu^{2}+1\right)^{0.5}+\mu\right]^{2}
$$

Assumindo que a tensão vertical é uma tensão principal, pode-se aplicar o modelo de classificação de Anderson (regime normal, transcorrente e reverso), definindo os limites do gráfico Polígono de Tensões (pontos 1, 2 e 3 da Figura 26) para uma determinada profundidade e pressão de poros. O interior do polígono representa os possíveis estados de tensão na crosta terrestre, fazendo distinção entre os três regimes de falhamento. Para maiores detalhes consultar Zoback (2010).

Como resultado da abordagem explicada anteriormente, a $\sigma_{H}$ foi estimada para a profundidade $3.355,00$ metros valendo-se de $K_{H}$ igual a 0,94 e $\sigma_{V}$ igual a 7.008,81 psi ou 48,32 $\mathrm{MPa}$, derivando uma magnitude de $\sigma_{H}$ aproximada de $6.588,28$ psi ou $45,42 \mathrm{MPa}$.

\subsection{4.}

\section{Pressão de Fluidos}

Adotou-se pressão de poros hidrostática, premissa confirmada por medições da pressão de formação no poço, e calculada conforme

$$
P_{p}=\rho_{a} g z_{a}+\int_{z_{a}}^{z} \rho_{a} g d z
$$

onde $\rho_{a}$ é a densidade da água do mar, $z_{a}$ é a lâmina d'água, $z$ é a profundidade e $g$ a aceleração devido à gravidade e calibrada por dados medidos de pressão de formação.

A pressão de poros foi calculada para a profundidade $3.355,00$ metros com o resultado equivalente a 4.864,62 psi ou $33,54 \mathrm{MPa}$.

\subsection{5.}

\section{Propriedades Mecânicas da Rocha}

As principais propriedades mecânicas da rocha para a aplicação de algum critério de ruptura ou deformação são a resistência à compressão uniaxial da rocha (UCS), o ângulo de atrito interno $(\varphi)$ e coesão (c). Em geral elas são 
calculadas por correlações empíricas da literatura e calibradas com resultados de ensaios de laboratório, se existirem. Em alguns casos, pode-se optar por utilizar magnitudes constantes para as propriedades ângulo de atrito e coesão. Observase que o valor do ângulo de atrito igual a $30^{\circ}$ é considerado uma boa aproximação para arenitos, sendo que esta propriedade varia, tipicamente, entre $20^{\circ}$ e $40^{\circ}$ para rochas sedimentares em geral. Por outro lado, a coesão pode variar significativamente para as rochas sedimentares em função do grau de cimentação/consolidação do material, resultante do processo de litificação [Fjaer et al. (2008)].

As propriedades ângulo de atrito interno $(\varphi)$ e UCS (Figura 27) foram estimadas a partir de correlações empíricas por litologia gerando um perfil calculado no poço.

\begin{tabular}{|c|c|c|c|c|c|c|}
\hline & Rocha & Zona & Nome Equação & Equação & Unidade & Tipo \\
\hline$\square$ & $\because$ ARENITO & Poço inteiro & ARENITOS CHANG $2006 \mathrm{~A}$ & $1.4138 \mathrm{E}+7 * \mathrm{DT} *-3$ if $(\mathrm{DT}>0)$ ) else nulo & $\mathrm{MPa}$ & uCS \\
\hline$\square$ & 正 CALCILUTITO & Poço inteiro & CARBONATOS MILITZER E STOLL 1973 & $(7682 / D T) * * 1.82 / 145$ if $(\mathrm{DT}>0)$ else nulo & $\mathrm{MPa}$ & ucs \\
\hline$\square$ & E= FOLHELHO & Poço inteiro & FOLHELHOS CHANG $2006 \mathrm{C}$ & $1.35 *(304.8 / D T) * 2.6$ if $(D T>0)$ else nulo & $\mathrm{MPa}$ & uCs \\
\hline$\square$ & 1 MARGA & Poço inteiro & CARBONATOS MILITZER E STOLL 1973 & $(7682 / D T) * * 1.82 / 145$ if $(\mathrm{DT}>0)$ else nulo & $\mathrm{MPa}$ & uCs \\
\hline
\end{tabular}

Figura 27 - Correlações empíricas por litologia adotadas no cálculo da curva de UCS no poço $A$

Outras propriedades fundamentais nesse estudo de caso são a porosidade $(\phi)$ e o raio do grão $(R)$.

Os procedimentos de laboratório "Ensaio de Velocidade Elástica com Petrofísica" e "Análise de Petrofísica Básica" indicam uma porosidade para a profundidade 3.355,00 m do Poço A de 29 \% e o perfil de Ressonância Magnética (Porosidade Efetiva) informa uma porosidade de $27 \%$.

O modelo geomecânico 1D na profundidade 3.355,00 m é descrito na Tabela 4 e uma visão geral dos dados do poço pode ser visualizado na Figura 28.

Pode-se observar nesse modelo que as magnitudes das tensões totais são similares, se aproximando de um regime hidrostático.

Tabela 4: Modelo geomecânico 1D atual na profundidade 3.355,22 m

\begin{tabular}{ccccccccc}
\hline PROF. (m) & $\sigma_{\mathrm{V}}(\mathrm{MPa})$ & $\mathrm{P}_{\mathrm{P}}$ (MPa) & peso lama (MPa) & $\sigma \mathrm{h}(\mathrm{MPa})$ & $\sigma \mathrm{H}(\mathrm{MPa})$ & UCS (MPa) & $\boldsymbol{\varphi}\left({ }^{\circ}\right)$ & $\boldsymbol{\phi}(\%)$ \\
\hline 3355,22 & 48,32 & 33,54 & 34.53 & 44,32 & 45,420 & 14,75 & 30,51 & 29
\end{tabular}




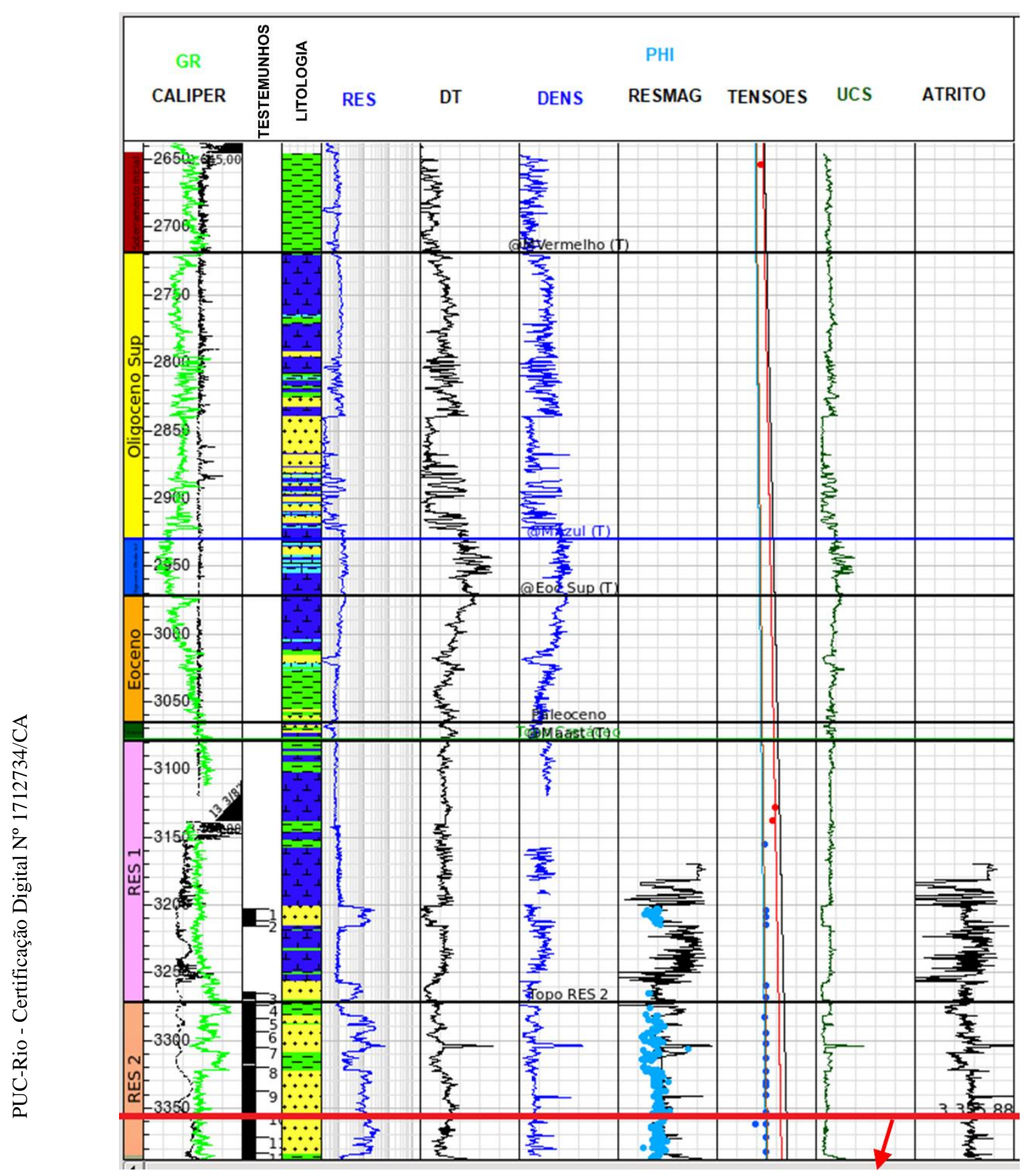

PROFUNDIDADE DAS BANDAS DE DEFORMAÇÃO INTERPRETADAS: $\sim 3.355,00 \mathrm{~m}$

Figura 28 - Visão geral dos dados do poço $\mathrm{A}$

A análise granulométrica realizada em testemunhos do poço $A$ mostra uma variação do diâmetro do grão entre areia média a areia fina na maior parte do reservatório. Para a profundidade alvo temos a distribuição descrita na Tabela 5 e Figura 29. 
Tabela 5 - Análise granulométrica da profundidade $3.355,00 \mathrm{~m}$ do Poço A

\begin{tabular}{lcc}
\hline \multicolumn{1}{c}{ Tamanho Grão } & D $(\mathbf{m m})$ & Proporção $(\%)$ \\
\hline GRÂNULO & 2,000 & 1,37 \\
\hline AREIA MUITO GROSSA INFERIOF & 1,000 & 5,93 \\
\hline AREIA GROSSA INFERIOR & 0,500 & 17,91 \\
\hline AREIA MÉDIA INFERIOR & 0,250 & 35,38 \\
AREIA FINA INFERIOR & 0,125 & 22,17 \\
AREIA MUITO FINA INFERIOR & 0,063 & 9,93 \\
\hline SILTE GROSSO & 0,044 & 2,44 \\
SILTE GROSSO & 0,037 & 1,28 \\
SILTE FINO & 0,020 & 1,11 \\
SILTE FINO & 0,015 & 0,95 \\
ARGILA & 0,010 & 1,56
\end{tabular}

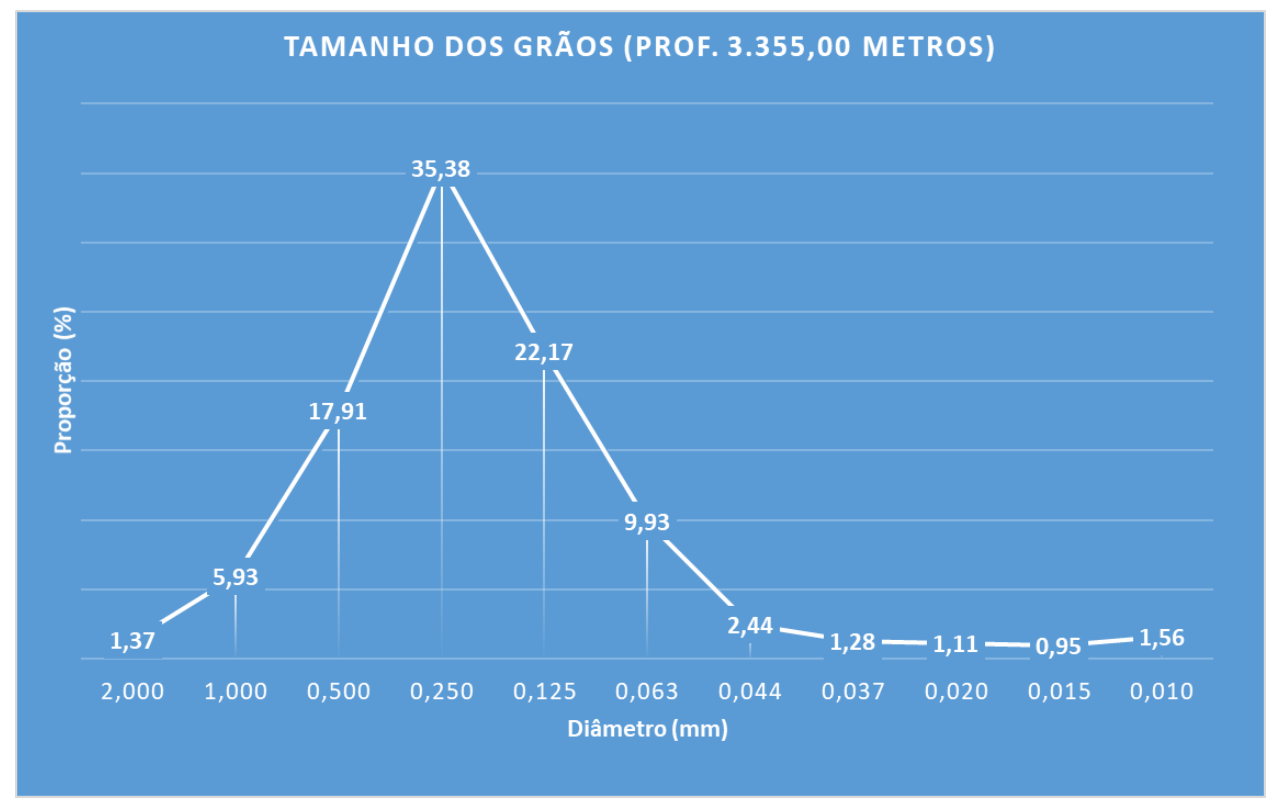

Figura 29 - Distribuição granulométrica da profundidade $3.355,00 \mathrm{~m}$ do Poço A

\section{3.}

\section{Geo-História}

Com o propósito de reconstruir o passado geológico do reservatório adotouse uma modelagem forward 1D por Backstripping, lançando mão do conhecimento presente através da análise dos dados do poço $A$ e de correlações empíricas de análogos disponíveis na literatura.

O primeiro passo nessa abordagem é definir as unidades cronoestratigráficas ou formações que cortam a trajetória do poço, com seus respectivos tempos deposicionais. Nesse método, cada camada é descompactada à medida que se caminha em direção ao passado geológico. No 
caso, a profundidade alvo está contida no reservatório 2 cujo os sedimentos foram depositados durante o período denominado Maastrichtiano. O objetivo então, é voltar no tempo até esse período, aproximadamente 65 a 74 milhões de anos. Esse objetivo é alcançado pelas equações (8), (9) e (10), sendo que muitas informações são requeridas tais como as profundidades dos intervalos atuais, a porosidade inicial de cada camada desconfinada $\left(\phi_{0}\right)$, o coeficiente de decaimento da compactação $(C)$, a densidade do grão $\left(\rho_{\text {grão }}\right)$, a densidade do manto $\left(\rho_{m}\right)$, a paleobatimetria $(W)$, a batimetria atual $\left(z_{a}\right)$ e a variação eustática do nível do mar $(\Delta)$. A maioria delas é de difícil inferência e carrega grande incerteza.

Estimou-se os parâmetros $\phi_{0}, C$ e $\rho_{\text {grão }}$ de cada intervalo cronoestratigráfico fazendo uso de análises laboratoriais, de dados da literatura e da proporção de fácies de cada camada do poço $A$. As profundidades de lâmina d'água referentes à paleobatimetria foram obtida por informação verbal de colegas geólogos não publicadas. A compilação dos parâmetros utilizados para o processamento do algoritmo de Backstripping 1D pode ser visualizada na Tabela 6.

Tabela 6: Parâmetros de entrada do Backstripping 1D por intervalo cronoestratigráfico do poço $\mathrm{A}$

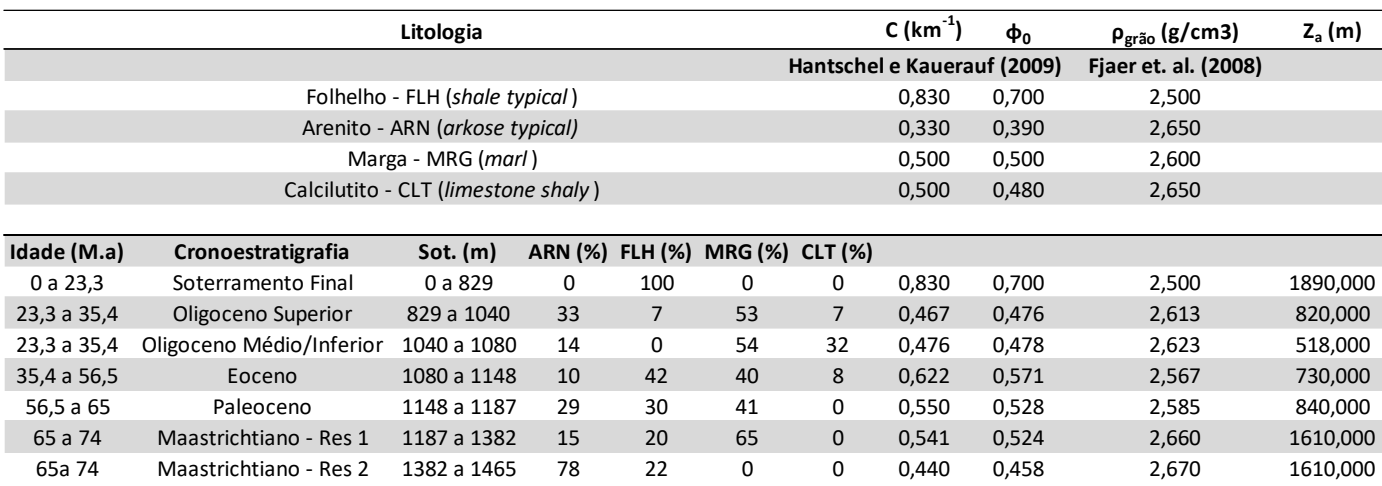

Os parâmetros não específicos por intervalo cronoestratigráfico são a densidade do manto $\left(3,330 \mathrm{~g} / \mathrm{cm}^{3}\right)$ e densidade da água $\left(10 \mathrm{~g} / \mathrm{cm}^{3}\right)$. Por simplificação, definimos a variação eustática do nível do mar como nula.

Os resultados da evolução cronoestratigráfica do Maastrichtiano até os dias atuais são mostrados na Figura 30 e na Figura 31. 


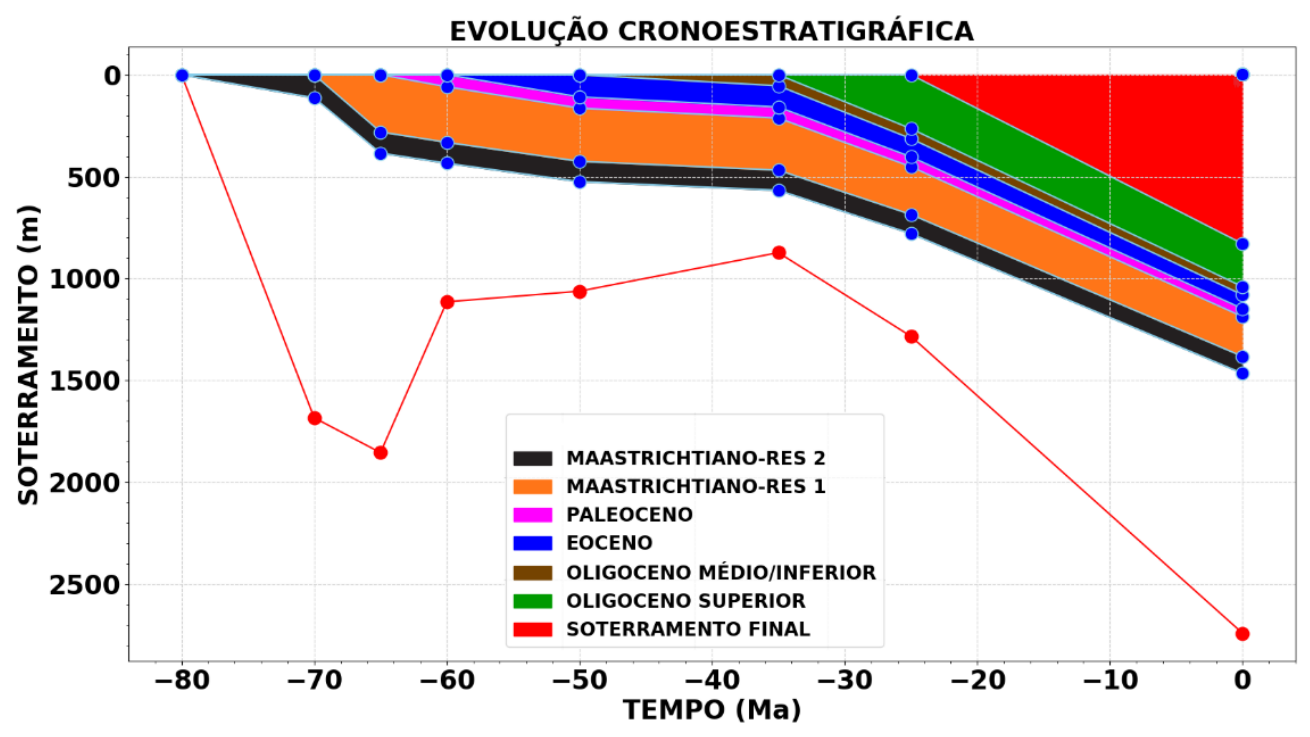

Figura 30 - Evolução cronoestratigráfica pelo método Backstripping. A curva em vermelho representa a subsidência tectônica do embasamento nas idades geológicas.

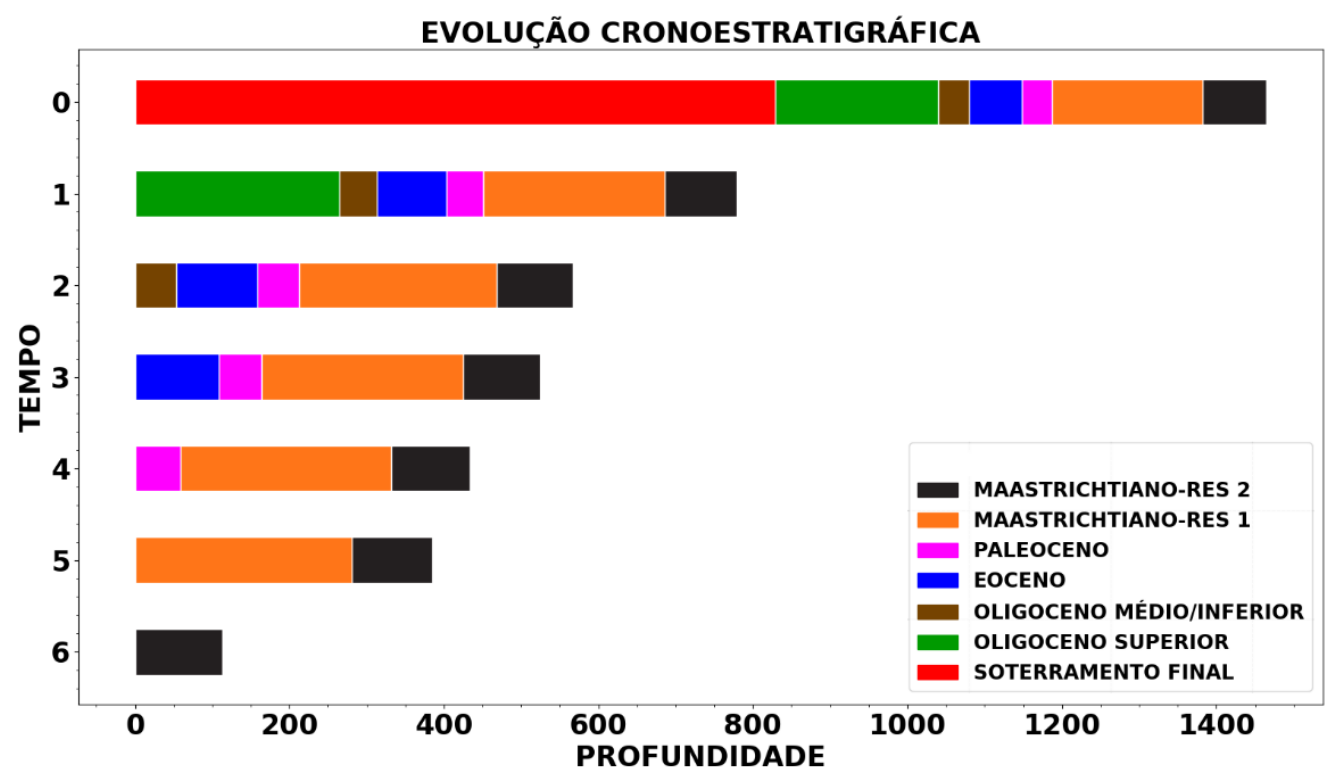

Figura 31 - Evolução cronoestratigráfica pelo método Backstripping

\subsection{1.}

\section{Inversão de descontinuidades}

Diante da grande incerteza relacionada ao regime de falhamento nos diferentes tempos geológicos a técnica de inversão de descontinuidades (de fraturas, de falhas) para tensões foi utilizada em algumas falhas (Figura 32), mapeadas por interpretação sísmica e localizada nas proximidades do poço $A$, 
com a finalidade de estabelecer ou restringir os possíveis regimes de tensões. Porém, devido à inexistência de dados de estrias foi adotada a abordagem de Moraes e Riccomini (2014), uma alternativa ao método tradicional.

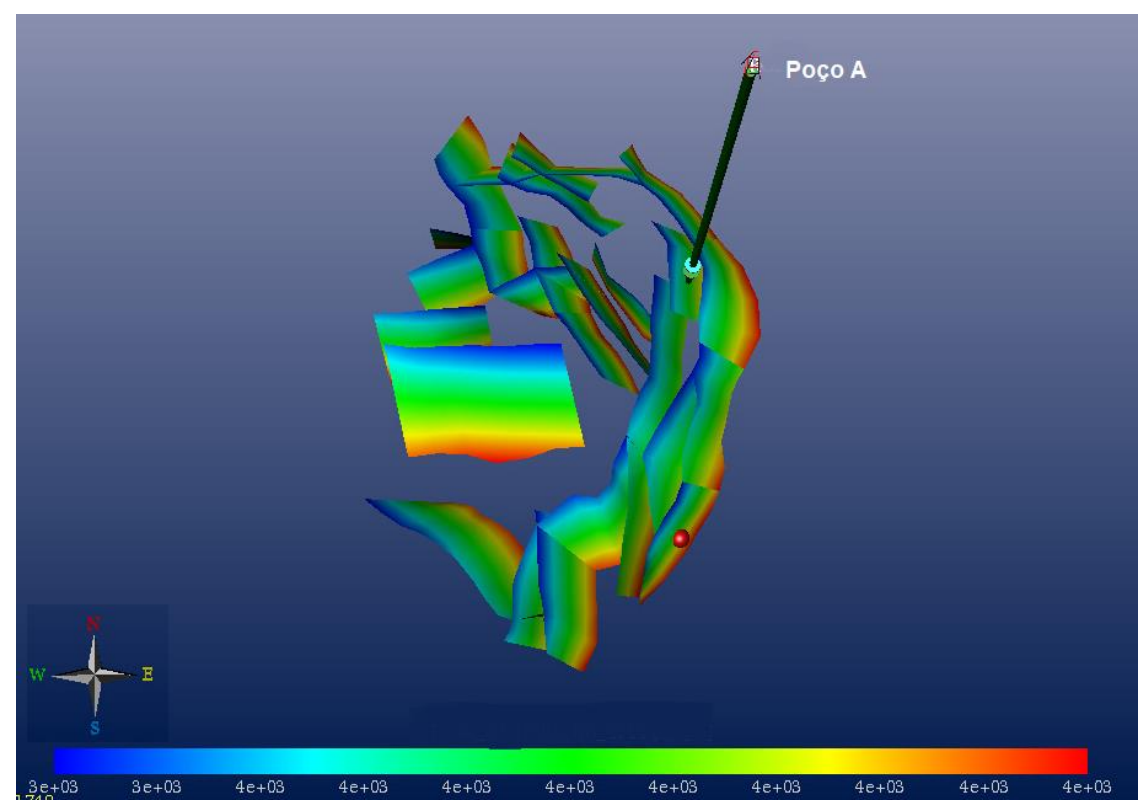

Figura 32 - Superfícies de falhas próximas ao poço A utilizadas para a inversão de descontinuidades

A aplicação do método de inversão nas falhas mostrou que entre 30 a 60 Ma o regime de falha era normal, as magnitudes das tensões horizontais tinham pouca diferença e o ângulo de atrito interno ficava na faixa de $12^{\circ}$ a $21^{\circ}$. O método não conseguiu uma direção única para o $\sigma_{H}$, possivelmente resultante da atuação de um estado de tensão aproximadamente isotrópico (i.e sem direção definida).

O método de inversão de descontinuidades também foi aplicado nas quatro superfícies de BD interpretadas em perfil imagem da Figura 23.

Em contraste às falhas, a inversão das $\mathrm{BD}$ resultou na possibilidade de todos os regimes, com grande predominância de falha reversa a transcorrente, direção de $\sigma_{H}$ por volta de $100^{\circ}$ e tendência para ângulos de atrito interno entre $-25^{\circ} \mathrm{e}$ $35^{\circ}$.

De acordo com estas informações, elaborou-se alguns cenários para as tensões horizontais e regimes de falhamento por unidade estratigráfica, descritos na Tabela 7. 
Tabela 7 - Cenários para as tensões horizontais e regimes de falhamento

\begin{tabular}{|c|c|c|c|c|c|c|}
\hline \multirow{3}{*}{ Cronoestratigrafia } & \multirow{3}{*}{$\begin{array}{l}\text { Regime } \\
\text { de Falha }\end{array}$} & \multicolumn{4}{|c|}{ Cenários } & \multirow{3}{*}{ Estruturas Formadas } \\
\hline & & 1 & 2 & 3 & 4 & \\
\hline & & $K_{H} \mid K_{h}$ & $K_{H} \mid K_{h}$ & $K_{H} \mid K_{h}$ & $K_{H} \mid K_{h}$ & \\
\hline Soterramento Final & $\mathbf{n}$ & $0,94 \mid 0,91$ & $0,94 \mid 0,92$ & $0,95 \mid 0,93$ & $0,98 \mid 0,95$ & - \\
\hline Oligoceno Superior & $n$, rou t & $0,8 \mid 0,8$ & $0,85 \mid 0,85$ & $1,2 \mid 0,95$ & $1,3 \mid 1,1$ & BD \\
\hline Oligoceno Médio/Inferior & $\mathbf{n}$ & $0,8 \mid 0,8$ & $0,85 \mid 0,85$ & $0,9 \mid 0,9$ & $0,95 \mid 0,95$ & falhas normais \\
\hline Eoceno & $\mathbf{n}$ & $0,8 \mid 0,8$ & $0,85 \mid 0,85$ & $0,9 \mid 0,9$ & $0,95 \mid 0,95$ & falhas normais \\
\hline Paleoceno & $\mathbf{n}$ & $0,8 \mid 0,8$ & $0,85 \mid 0,85$ & $0,9 \mid 0,9$ & $0,95 \mid 0,95$ & falhas normais \\
\hline Maastrichtiano - Res 1 & $\mathbf{n}$ & $0,8 \mid 0,8$ & $0,85 \mid 0,85$ & $0,9 \mid 0,9$ & $0,95 \mid 0,95$ & - \\
\hline Maastrichtiano - Res 2 & $\mathbf{n}$ & $0,98 \mid 0,98$ & $0,99 \mid 0,99$ & $1 \mid 1$ & $1 \mid 1$ & - \\
\hline
\end{tabular}

Os cenários foram definidos por intervalos de tempo geológico, com base nas seguintes informações:

- No Soterramento Inicial (Maastrichtiano - Res 2) o modelo mostrou um estado de tensões praticamente isotrópico (de caráter hidostático). Portanto, optou-se por uma pequena variação de $K_{H}=K_{h}$ entre 0,98 e 1.

- Pelo modelo geomecânico atual sabe-se que o regime de tensões no Soterramento Final é normal. Dessa forma, fixou-se o regime nessa idade geológica, com variações pequenas de $K_{H}$ e $K_{h}$ em relação ao valor que temos hoje, $K_{H}=0,94$ e $K_{h}=0,92$.

- Partindo do conhecimento que as falhas mapeadas próximas ao poço $\mathrm{A}$ foram formadas em regime normal (informação resultante da inversão das superfícies das falhas) no período que vai do Paleoceno até o Oligoceno Médio/Inferior, considerou-se nesse intervalo temporal as magnitudes das tensões horizontais sendo iguais, variando apenas os valores de $K_{H}=K_{h}$ dentro do regime de falhamento normal.

- No Maastrichtiano - Res 2 considerou-se pouco provável o regime de falhamento não ser normal, devido à proximidade da fase de soterramento inicial, ainda com pouca compressão lateral, repetindo o cenário anterior.

- Com a intenção de simular outros regimes de falhamento, retratando um possível tectonismo e, sabendo que a inversão das superfícies de BD resultou na possibilidade de qualquer regime de falhamento, por eliminação, traçou-se cenários com os regimes de falhamento normal, transcorrente e reverso no único intervalo livre, o Oligoceno Superior.

- O valor mínimo de $K_{H}$ e $K_{h}$ igual a 0,8 vem do fato de que nos primeiros tempos deposicionais, valores menores que 0,8 levam a trajetória de tensões para um estado inconsistente, fora do quadrante positivo do espaço $p^{\prime} \times q$. 


\section{4.}

\section{Trajetória de Tensões e Plastificação}

Para modelar o caminho de tensões aplicado à formação na profundidade $3.355,00 \mathrm{~m}$ do Poço A é necessário a tensão média efetiva ( $p$ '), a tensão diferencial $(q)$, o ângulo de atrito interno $(\varphi)$ e a pressão de colapso $\left(P^{*}\right)$ nos diferentes tempos geológicos.

Os parâmetros $p$ e $q$ são necessários para representar o estado de tensão no espaço $p \times q$ na forma [Davis e Selvadurai (2002)]

$$
\begin{gathered}
p=\frac{I_{1}}{3}=\frac{\sigma_{1}+\sigma_{2}+\sigma_{3}}{3} \\
q=\sqrt{I_{1}^{2}-3 I_{2}}=\frac{1}{\sqrt{2}}\left[\left(\sigma_{1}-\sigma_{2}\right)^{2}+\left(\sigma_{2}-\sigma_{3}\right)^{2}+\left(\sigma_{3}-\sigma_{1}\right)^{2}\right]^{1 / 2}
\end{gathered}
$$

Para se trabalhar com rochas porosas, que normalmente armazenam fluidos, é fundamental a representação do estado de tensões levando em consideração as tensões efetivas, ou seja, valendo-se do espaço $p$ ' $x q$. Definese, então, o parâmetro p' como a tensão média efetiva na forma [Moraes (2016)]

$$
p^{\prime}=\frac{I_{1}}{3}=\left(\frac{\sigma_{1}+\sigma_{2}+\sigma_{3}}{3}\right)-\alpha P_{p}
$$

onde $\alpha$ é o coeficiente de Biot.

A pressão efetiva do início do quebramento do grão / poro é obtida por ensaio de compactação hidrostática. Como nesse estudo não foi possível a realização de tal teste, inferiu-se a magnitude da pressão de colapso pela relação de Zhang et al. (1990b) - eq. (7), dependente da porosidade e do raio do grão.

No cômputo de $P^{*}$ para o tempo atual utilizou-se a magnitude de 29 \% para porosidade e os valores $1 ; 0,5 ; 0,25$ e $0,125 \mathrm{~mm}$ para o raio do grão.

Como essa relação exige um fator de proporcionalidade $\left(k_{p}\right)$, aplicou-se primeiramente uma regressão linear (Figura 33A) nos dados da Tabela 1. Porém, a reta de tendência não obteve uma boa correlação com os dados $\left(R^{2}=0,2281\right)$. Sendo assim, experimentou-se outras duas regressões distintas, uma sem os arenitos 3 e 6 da Tabela 1 (Figura 33B), que resultou na relação $K_{p}=1,9647 *$ $(\Phi R)+0,3125$, com valores resultantes variando entre 0,384 e 1,191; e uma outra regressão, sem os arenitos 1 e 2 da Tabela 1 (Figura 33C), que resultou na relação $K_{p}=14,834 *(\Phi R)-0,0903$, com magnitudes resultantes oscilando entre 0,447 e 6,54. 


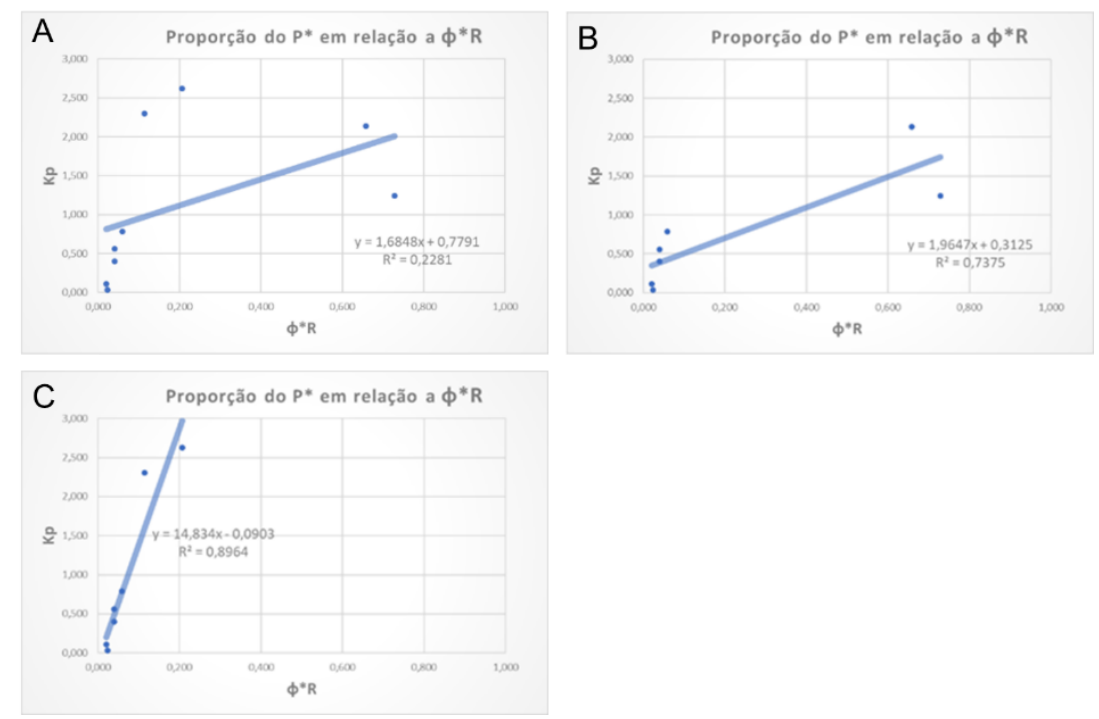

Figura 33 - Regressão linear para o fator de proporcionalidade $\left(\boldsymbol{K}_{\boldsymbol{p}}\right)$ para estimativa da pressão de colapso $\left(P^{*}\right)$

\section{5.}

\section{Simulação e Resultados}

Para a simulação definiu-se cenários com a variação dos parâmetros $K_{p}, K_{H}$, $K_{h}$ e $R$ (raio do grão).

Como o fator $K_{p}=14,834 *(\Phi R)-0,0903$ apresentou o valor máximo $(6,54)$ bem acima do valor máximo de $K_{p}$ da Tabela $1(2,623)$ e resultou em magnitudes de $P^{*}$ na faixa entre $21,89 \mathrm{MPa}$ e $64,83 \mathrm{MPa}$, o que não é suficiente para a localização de uma BD com algum componente de compactação, decidiuse mostrar somente os resultados referentes ao fator de proporcionalidade $K_{p}=$ $1,9647 *(\Phi R)+0,3125$, que possibilita a nucleação de BD.

As superfícies de cap formadas a partir dos raios do grão 0,250 mm e 0,125 $\mathrm{mm}$ também ficaram distantes dos estados de tensões nos diferentes tempos geológicos (Figura 34). Como se sabe que há $\mathrm{BD}$, possivelmente os tamanhos dos raios de hoje em dia não correspondem necessariamente ao passado supondo que a relação de Zhang et al. (1990b) - eq. (7) esteja de fato correta. Para uma melhor visualização dos resultados, decidiu-se eliminar esses cenários dos resultados finais. Um condensado com todos os resultados do fluxo de trabalho é mostrado na Tabela 8. 


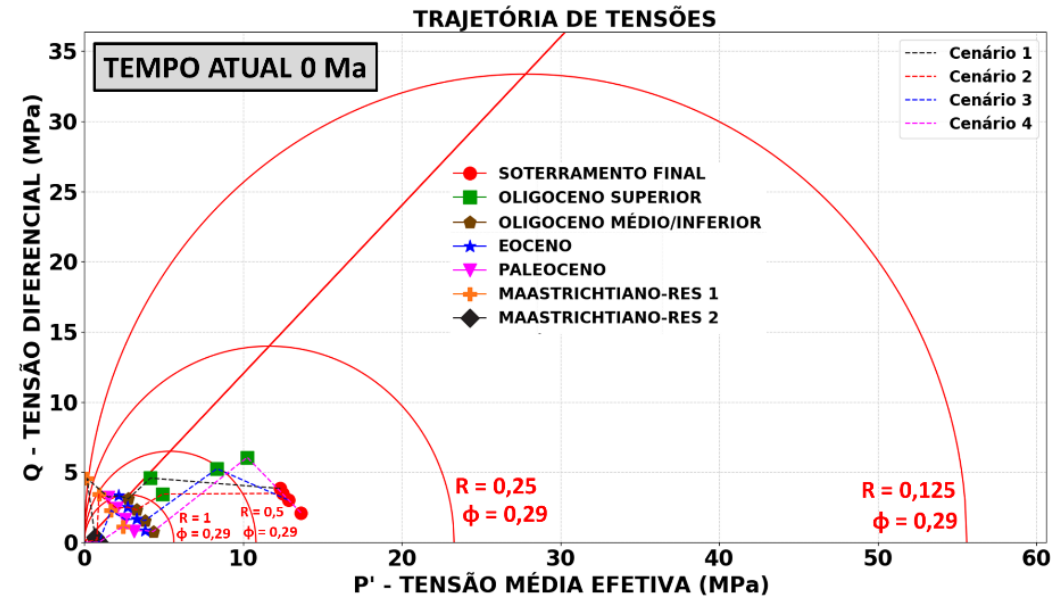

Figura 34 - Trajetória de tensões no tempo atual (0 Ma)

\section{Tabela 8: Compilação dos resultados}

\begin{tabular}{|c|c|c|c|c|c|c|c|}
\hline Tempo (Ma) & 0 & $25 \mathrm{Ma}$ & $35 \mathrm{Ma}$ & $50 \mathrm{Ma}$ & $60 \mathrm{Ma}$ & $65 \mathrm{Ma}$ & $70 \mathrm{Ma}$ \\
\hline Soterramento (m) & 1465,00 & 779,96 & 566,10 & 523,74 & 433,30 & 383,35 & 113,80 \\
\hline Lâmina d'água (m) & 1890,00 & 820,00 & 518,00 & 730,00 & 840,00 & 1610,00 & 1610,00 \\
\hline Prof. Vertical (m) & 3355,00 & 1599,96 & 1084,10 & 1253,74 & 1273,30 & 1993,35 & 1723,80 \\
\hline Subs. Embas. (m) & 2739,91 & 1283,53 & 872.77 & 1061,96 & 1114.17 & 1854.11 & 1683.1 \\
\hline$\sigma_{v}(\mathrm{Mpa})$ & 48,32 & 22,91 & 15,49 & 16,71 & 16,16 & 22,77 & 17,83 \\
\hline $\mathrm{K}_{\mathrm{H}}$ & {$[0,94 ; 0,94 ; 0,95 ; 0,98]$} & {$[0,8 ; 0,85 ; 1,2 ; 1,3]$} & {$[0,8 ; 0,85 ; 0,9 ; 0,95]$} & {$[0,8 ; 0,85 ; 0,9 ; 0,95]$} & {$[0,8 ; 0,85 ; 0,9 ; 0,95]$} & {$[0,8 ; 0,85 ; 0,9 ; 0,95]$} & {$[0,98 ; 0,99 ; 1 ; 1]$} \\
\hline$\sigma_{\mathrm{H}}(\mathrm{Mpa})$ & 45,42 & 18,33 & 12,39 & 13,37 & 12,93 & 18,22 & 17,47 \\
\hline$\sigma_{\mathrm{H}}(\mathrm{Mpa})$ & 45,42 & 19,47 & 13,17 & 14,20 & 13,74 & 19,35 & 17,65 \\
\hline$\sigma_{\mathrm{H}}(\mathrm{Mpa})$ & 45,90 & 27,49 & 13,94 & 15,04 & 14,54 & 20,49 & 17,83 \\
\hline$\sigma_{\mathrm{H}}(\mathrm{Mpa})$ & 47,35 & 29,78 & 14,72 & 15,87 & 15,35 & 21,63 & 17,83 \\
\hline $\mathrm{K}_{\mathrm{h}}$ & {$[0,91 ; 0,92 ; 0,93 ; 0,95]$} & {$[0,8 ; 0,85 ; 0,95 ; 1,1]$} & {$[0,8 ; 0,85 ; 0,9 ; 0,95]$} & {$[0,8 ; 0,85 ; 0,9 ; 0,95]$} & {$[0,8 ; 0,85 ; 0,9 ; 0,95]$} & {$[0,8 ; 0,85 ; 0,9 ; 0,95]$} & {$[0,98 ; 0,99 ; 1 ; 1]$} \\
\hline$\sigma_{\mathrm{h}}(\mathrm{Mpa})$ & 43,97 & 18,33 & 12,39 & 13,37 & 12,93 & 18,22 & 17,47 \\
\hline$\sigma_{h}(\mathrm{Mpa})$ & 44,45 & 19,47 & 13,17 & 14,20 & 13,74 & 19,35 & 17,65 \\
\hline$\sigma_{h}(\mathrm{Mpa})$ & 44,94 & 21,76 & 13,94 & 15,04 & 14,54 & 20,49 & 17,83 \\
\hline$\sigma_{\mathrm{h}}(\mathrm{Mpa})$ & 45,90 & 25,20 & 14,72 & 15,87 & 15,35 & 21,63 & 17,83 \\
\hline $\mathrm{P}_{\mathrm{P}}(\mathrm{MPa})$ & 33,54 & 15,69 & 10,64 & 12,31 & 12,50 & 19,55 & 16,91 \\
\hline peso de lama (MPa) & 34,53 & - & - & - & - & - & - \\
\hline ucs (MPa) & 14,35 & - & - & - & - & - & - \\
\hline$\rho_{\text {média coluna }}\left(\mathrm{g} / \mathrm{cm}^{3}\right)$ & 1,98 & 1,94 & 1,87 & 1,86 & 1,86 & 1,85 & 1,83 \\
\hline $\mathbf{K}$ & 486,20 & - & - & - & - & - & - \\
\hline$\varphi\left({ }^{\circ}\right)$ & 30,00 & 30,00 & 30,00 & 30,00 & 30,00 & 30,00 & 30,00 \\
\hline$\phi$ & 0,290 & 0,332 & 0,365 & 0,373 & 0,387 & 0,396 & 0,447 \\
\hline \multicolumn{8}{|c|}{$K_{p}=1,9647 *(\phi R)+0,3125$} \\
\hline$R_{\text {grão }}(\mathrm{mm})$ & 1,000 & 1,000 & 1,000 & 1,000 & 1,000 & 1,000 & 1,000 \\
\hline$K_{p}$ & 0,882 & 0,965 & 1,030 & 1,045 & 1,073 & 1,091 & 1,191 \\
\hline P* (MPa) & 5,65 & 5,04 & 4,67 & 4,59 & 4,46 & 4,38 & 3,98 \\
\hline$R_{\text {grão }}(\mathrm{mm})$ & 0,500 & 0,500 & 0,500 & 0,500 & 0,500 & 0,500 & 0,500 \\
\hline$K_{p}$ & 0,597 & 0,639 & 0,671 & 0,679 & 0,693 & 0,702 & 0,752 \\
\hline $\mathrm{P*}(\mathrm{MPa})$ & 10,82 & 9,44 & 8,61 & 8,43 & 8,14 & 7,96 & 7,11 \\
\hline$R_{\text {grão }}(\mathrm{mm})$ & 0,250 & 0,250 & 0,250 & 0,250 & 0,250 & 0,250 & 0,250 \\
\hline $\mathrm{K}_{\mathrm{p}}$ & 0,455 & 0,476 & 0,492 & 0,496 & 0,503 & 0,507 & 0,532 \\
\hline $\mathrm{P}^{*}$ (MPa) & 23,30 & 19,89 & 17,84 & 17,41 & 16,70 & 16,28 & 14,24 \\
\hline$R_{\text {grão }}(\mathrm{mm})$ & 0,125 & 0,125 & 0,125 & 0,125 & 0,125 & 0,125 & 0,125 \\
\hline Kp & 0,384 & 0,394 & 0,402 & 0,404 & 0,408 & 0,410 & 0,422 \\
\hline P* (MPa) & 55,60 & 46,61 & 41,26 & 40,14 & 38,30 & 37,21 & 31,97 \\
\hline \multicolumn{8}{|c|}{$K_{p}=14,834 *(\phi R)-0,0903$} \\
\hline$R_{\text {grão }}(\mathrm{mm})$ & 1,000 & 1,000 & 1,000 & 1,000 & 1,000 & 1,000 & 1,000 \\
\hline $\mathrm{K}_{\mathrm{p}}$ & 4,212 & 4,835 & 5,324 & 5,443 & 5,650 & 5,784 & 6,540 \\
\hline P* (MPa) & 26,97 & 25,27 & 24,14 & 23,89 & 23,47 & 23,21 & 21,89 \\
\hline $\mathbf{R}_{\text {grão }}(\mathrm{mm})$ & 0,500 & 0,500 & 0,500 & 0,500 & 0,500 & 0,500 & 0,500 \\
\hline $\mathbf{K}_{\mathrm{p}}$ & 2,061 & 2,372 & 2,617 & 2,676 & 2,780 & 2,847 & 3,225 \\
\hline P* (MPa) & 37,32 & 35,07 & 33,57 & 33,23 & 32,66 & 32,31 & 30,52 \\
\hline $\mathbf{R}_{\text {grão }}(\mathrm{mm})$ & 0,250 & 0,250 & 0,250 & 0,250 & 0,250 & 0,250 & 0,250 \\
\hline $\mathrm{K}_{\mathrm{p}}$ & 0,985 & 1,141 & 1,263 & 1,293 & 1,345 & 1,378 & 1,567 \\
\hline $\mathrm{P}^{*}$ (MPa) & 50,47 & 47,71 & 45,83 & 45,41 & 44,69 & 44,25 & 41,96 \\
\hline$R_{\text {grão }}(\mathrm{mm})$ & 0,125 & 0,125 & 0,125 & 0,125 & 0,125 & 0,125 & 0,125 \\
\hline Кр & 0,447 & 0,525 & 0,587 & 0,601 & 0,627 & 0,644 & 0,739 \\
\hline P* (MPa) & 64,83 & 62,14 & 60,18 & 59,73 & 58,96 & 58,47 & 55,92 \\
\hline
\end{tabular}


Após a simulação, pode-se listar algumas considerações:

(i) na primeira fase do Maastrichtiano ( 70 Ma) (Figura 35), devido, talvez, à extensa lâmina d'água $(1.610 \mathrm{~m})$, a magnitude da $P_{p}(16,91$ $\mathrm{MPa})$ se aproxima da $\sigma_{v}(17,83 \mathrm{MPa})$ resultando em um regime praticamente hidrostático;

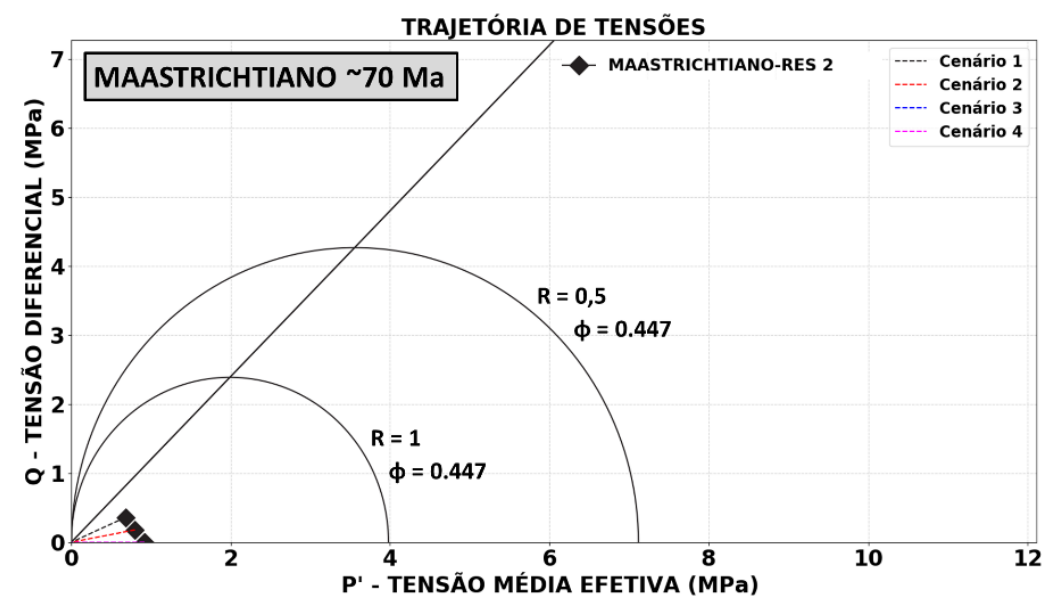

Figura 35 - Trajetória de tensões no tempo $70 \mathrm{Ma}$ (Maastrichtiano)

(ii) na segunda fase do Maastrichtiano ( 65 Ma) (Figura 36) quanto maior a tensão diferencial, mais o estado de tensões se aproxima ou ultrapassa o limite para plastificação por tração induzida por cisalhamento, conforme o esquema conceitual de Schultz e Siddharthan (2005);

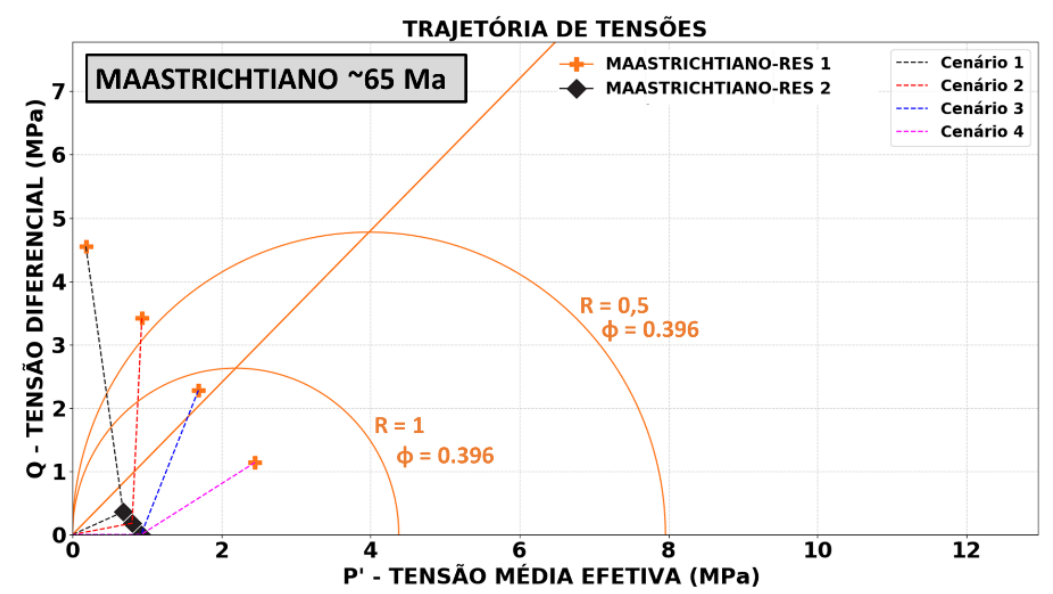

Figura 36 - Trajetória de tensões no tempo $\sim 65 \mathrm{Ma}$ (Maastrichtiano)

(iii) no Paleoceno ( 60 Ma) (Figura 37) percebe-se uma tendência de diminuição da tensão diferencial e aumento da tensão média, o que 
torna a porção do reservatório mecanicamente mais estável, i.e., mais distante de uma deformação inelástica, com exceção do cenário $K_{H}=K_{h}=0,8$ que se encontra acima da CSL;

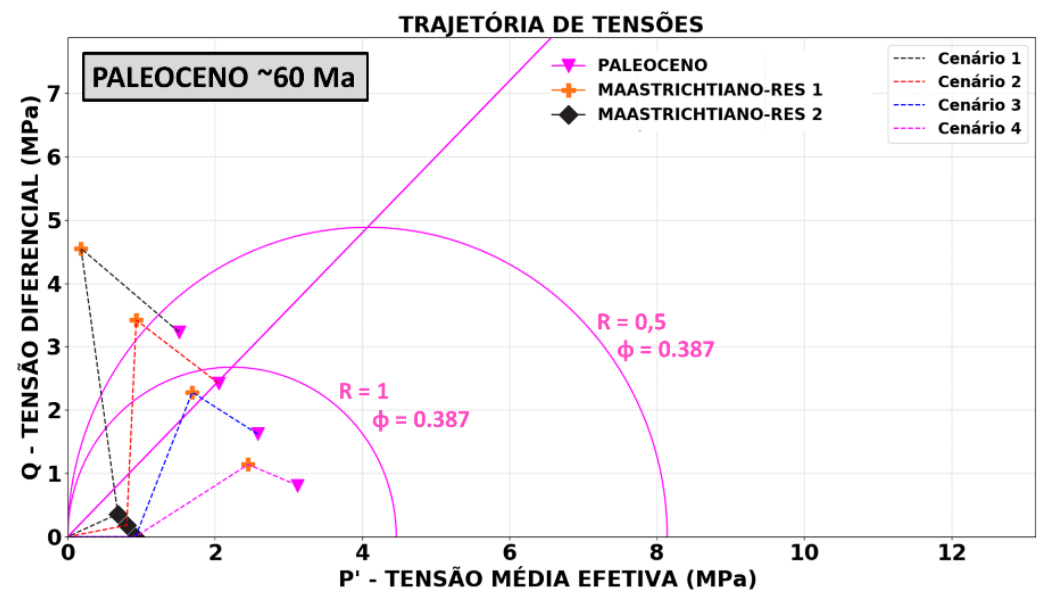

Figura 37 - Trajetória de tensões no tempo 60 Ma (Paleoceno)

(iv) no Eoceno ( 50 Ma) (Figura 38) vê-se uma aproximação maior do cap para grãos mais grossos $(R=1 \mathrm{~mm})$, podendo-se até afirmar que se a $P_{p}$ fosse um pouco menor seria possível a nucleação de uma BD com um forte componente de compactação. Porém, no cenário $K_{H}=K_{h}=0,8$ o estado de tensões continua acima da CSL;

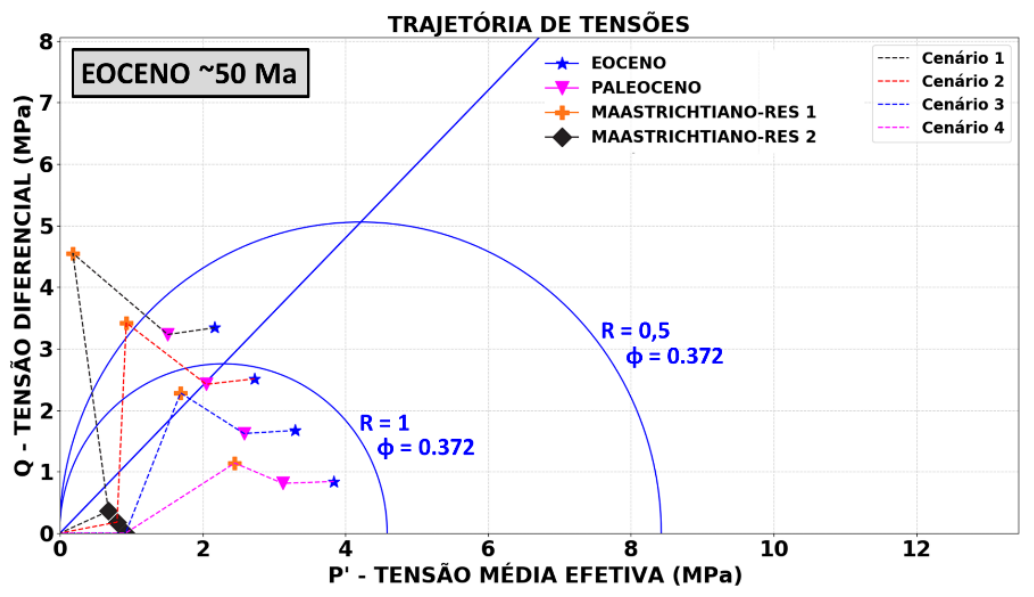

Figura 38 - Trajetória de tensões no tempo 50 Ma (Eoceno)

(v) no Oligoceno Médio/Inferior ( 35 Ma) (Figura 39) observa-se o mesmo comportamento da idade anterior. Entretanto, para o cenário $\left(K_{H}=0,8, K_{h}=0,8\right)$ o estado de tensões ultrapassa 0 limite de 
plastificação dúctil para o cap de $R=1 \mathrm{~mm}$, o que caracterizaria uma CSB (banda de cisalhamento com compactação associada);

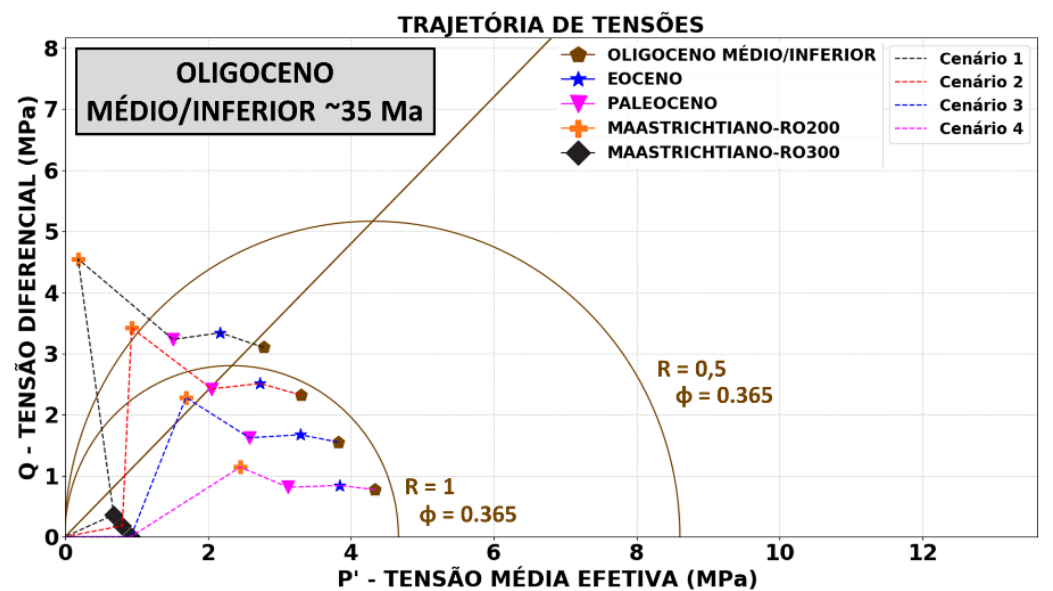

Figura 39 - Trajetória de tensões no tempo $\sim 35$ Ma (Oligoceno Médio/Inferior)

(vi) no Oligoceno Superior ( 25 Ma) (Figura 40) vê-se uma alta probabilidade da localização das BD vistas no testemunho do poço A (Figura 23) na profundidade aproximada de 3.355,00 m. Em todos os cenários o caminho das tensões resultam em deformações hardening para o cap de $\mathrm{R}=1 \mathrm{~mm}$, sendo que nos cenários de regimes transcorrente e reverso a trajetória de tensões também ultrapassa o cap de $\mathrm{R}=0,5 \mathrm{~mm}$;

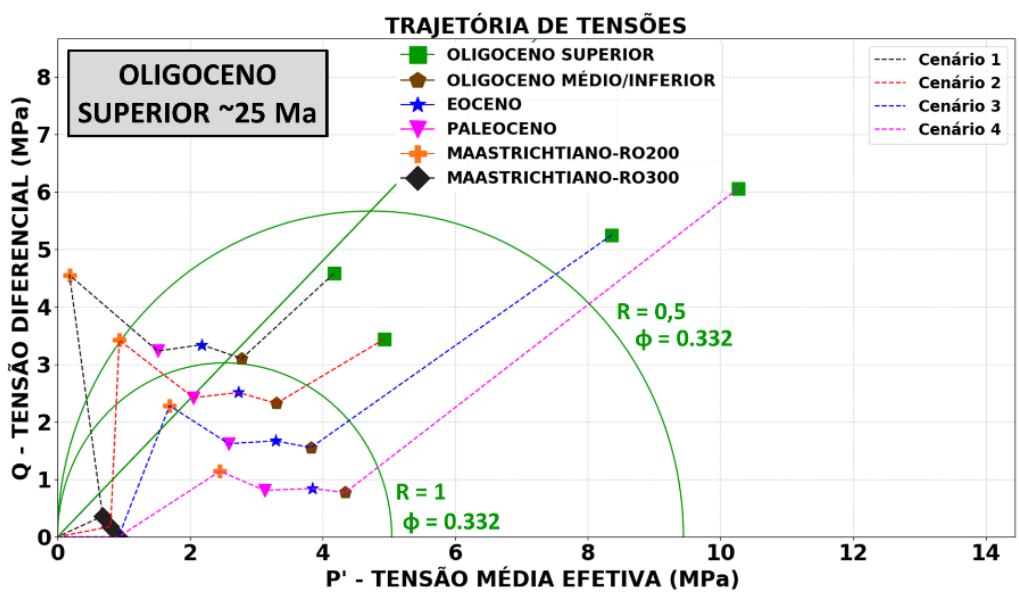

Figura 40 - Trajetória de tensões no tempo 25 Ma (Oligoceno Superior) 
(vii) no tempo atual (0 Ma) (Figura 41$)$ tem-se a situação mais provável para a nucleação de BD com forte grau de compactação para ambos os $\operatorname{caps}(R=1 \mathrm{~mm}$ e $R=0,5 \mathrm{~mm})$.

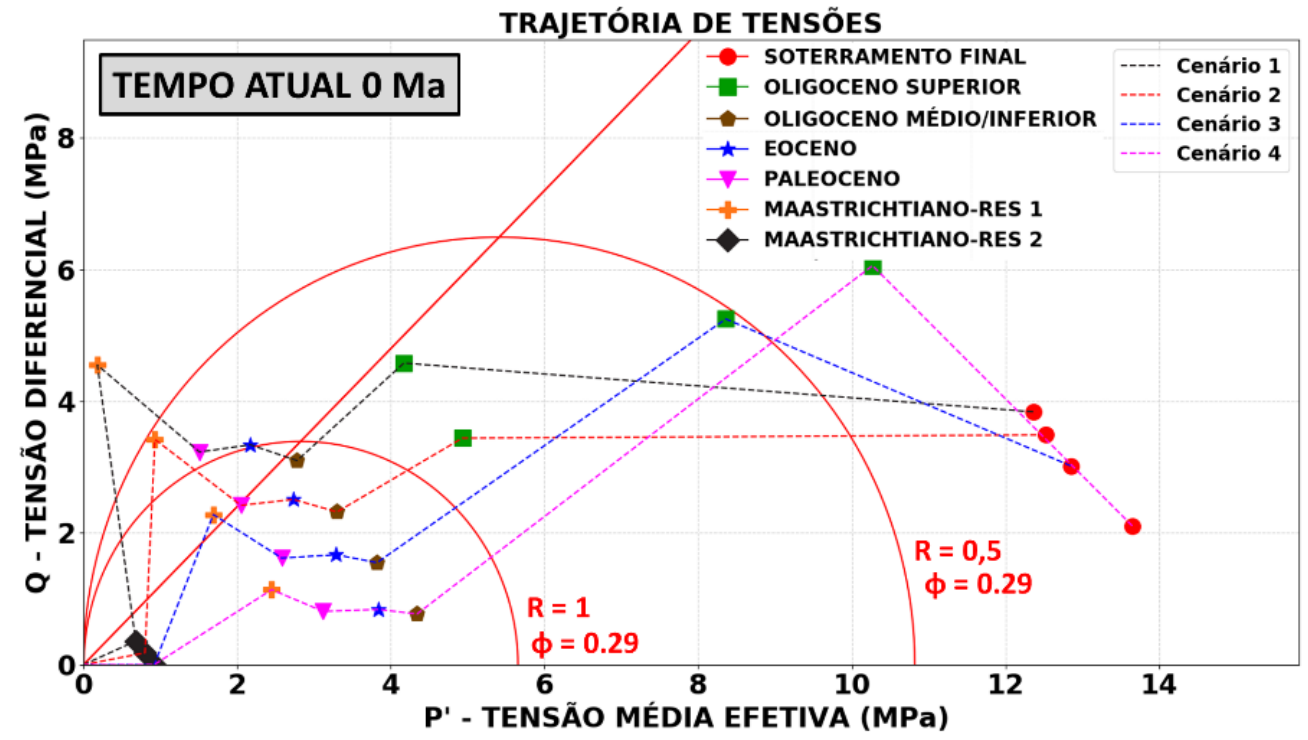

Figura 41 - Trajetória de tensões no tempo atual

De acordo com o que foi postulado, observa-se uma probabilidade crescente da formação das BD visualizadas em testemunho do Poço A a partir do Oligoceno ( 23 a $35 \mathrm{Ma}$ ). Nesse período, as feições seriam localizadas nos cenários de regime de falhamento transcorrente e reverso em grãos de raios $1 \mathrm{~mm}$ e $0,5 \mathrm{~mm}$ e em cenários de regime de falha normal em grãos de raio $1 \mathrm{~mm}$. Um regime transcorrente ou reverso aumentaria o potencial da nucleação de BD nessa idade geológica. O tempo presente reafirma as condições para a gênese dessas estruturas, porém, em regime normal. 


\section{5 \\ Considerações Finais}

O presente trabalho teve como objetivo propor um modelo analítico para a mecânica da gênese de BD baseado na teoria do estado crítico da mecânica dos solos e avaliar sua aplicabilidade por um estudo de caso. Neste capítulo são apresentadas as conclusões e sugestões para trabalhos futuros.

\section{1.}

\section{Conclusões}

Nesta pesquisa verificou-se a existência de uma série de estudos sobre BD contendo observações de afloramentos com medições de permeabilidade, propostas de modelos conceituais para a nucleação das BD [e.g. Soliva et al. (2013)], ensaios triaxiais para o entendimento da transição entre as deformações rúptil e dúctil e a elucidação de fatores que favorecem a intensidade de catáclase nessas estruturas, processo responsável por uma forte redução de permeabilidade em rochas porosas.

Contudo, notou-se uma ausência de aplicações reais dos modelos conceituais da mecânica de geração de BD em rochas naturalmente deformadas e, consequentemente, uma falta de aplicabilidade na indústria do petróleo. Isso acontece, em grande parte, devido à dificuldade de se obter informações do passado geológico, tais como o regime de falhamento, o estado de tensões e as propriedades das rochas.

Objetivando o preenchimento dessa lacuna, este trabalho propôs uma metodologia integrada de algumas técnicas da geomecânica do petróleo, mecânica dos solos, geologia estrutural e modelagem de bacias para a obtenção de paleomodelos geomecânicos e um posterior estudo de caso com a aplicação dos conceitos em uma porção de um reservatório de hidrocarbonetos em subsuperfície rico em BD para avaliação desta metodologia.

Identificou-se uma grande incerteza em alguns parâmetros do fluxo de trabalho como por exemplo a altura da lâmina d'água nas idades geológicas, que exerce uma forte influência nos paleomodelos geomecânicos por Backstripping, 
relação direta com a sobrecarga e pressão de poros. Daí a necessidade da realização de análises de sensibilidade com diversos cenários.

A metodologia integrada foi uma boa maneira de restringir aspectos interpretativos e contribuir na definição dos cenários para reduzir a incerteza dos parâmetros.

Porém, a maior dificuldade na modelagem se deu na definição da pressão efetiva crítica de colapso $\left(P^{*}\right)$, que estabelece o limite da envoltória de plastificação (cap) na ausência de cisalhamento. Na falta de ensaios hidrostáticos, a relação de Zhang et al. (1990b) possibilitou a inferência da $P^{*}$ nos diferentes tempos geológicos via porosidade e raio do grão. Contudo, observou-se que essa relação empírica não encerra a magnitude de $P^{*}$, pois há uma grande variação no fator de proporcionalidade devido as diferenças composicionais dos arenitos e da existência restrita de resultados de ensaios hidrostáticos na literatura.

Os resultados confirmaram a aplicabilidade prática da metodologia, mostrando uma alta probabilidade da nucleação das BD existentes nos testemunhos do poço A terem acontecido a partir do Oligoceno ( 23 a $35 \mathrm{Ma}$ ) para regime de falha transcorrente e reverso em grãos de raios $1 \mathrm{~mm}$ e $0,5 \mathrm{~mm}$ e em cenários de regime de falha normal em grãos de raio $1 \mathrm{~mm}$. Um regime transcorrente ou reverso aumentaria o potencial da localização de BD nessa idade geológica. O cálculo da pressão de colapso considerando todos os tempos geológicos resultou em magnitudes na faixa entre 3,98 MPa e 55,60 MPa.

\section{2.}

\section{Sugestões para Trabalhos Futuros}

Constatou-se que o trabalho pode ser aperfeiçoado com a realização de ensaios de compressão hidrostática em arenitos e uma modelagem de proporcionalidade $\left(K_{p}\right)$ da relação de Zhang et al. (1990b) mais acurada, por classificações mineralógicas e granulométricas das rochas. Para diminuir a incerteza do modelo sugere-se também uma modelagem real do parâmetro $C$ (coeficiente de decaimento da compactação) do Backstripping ao invés de utilizar correlações da literatura.

Uma contribuição bastante relevante para a caracterização de reservatórios areníticos seria a modelagem de distribuição de BD e intensidade de catáclase baseada nos padrões existentes na literatura a partir de feições interpretadas na sísmica, em perfis de imagem e em testemunhos de poços de um campo de petróleo em sua integralidade. 
Por fim, sugere-se também, como evolução do trabalho, uma predição quantitativa da redução da permeabilidade devido à presença de BD baseada na metodologia proposta e um estudo similar para reservatórios de carbonatos. 
6

\section{Referências Bibliográficas}

ALLEN, P.A.; ALLEN, J.R. Basin Analysis: Principles and Applications. $2^{2}$ ed., Blackwell Publishing (2005), p. 351, 359-366.

ANTONELLINI, M.A.; AYDIN, A.; POLLARD, D.D. Microstructure of deformation bands in porous sand-stones at Arches National Park, Utah. Journal of Structural Geology, 16 (1994) 941-959, 1994.

AYDIN, A. Small faults formed as deformation bands in sandstones. Pure and Applied Geophysics (1978), 116: 913-930.

BALLAS, G.; FOSSEN, H.; SOLIVA, R. Factors controlling permeability of cataclastic deformation bands and faults in porous sandstone reservoirs. Journal of Structural Geology 76 (2015) 1-21.

BALLAS, G.; SOLIVA, R.; BENEDICTO, A.; SIZUN, J.P. Control of tectonic setting and large-scale faults on the basin-scale distribution of deformation bands in porous sandstone (Provence, France). Marine and Petroleum Geology 55 (2014) 142-159.

BALSAMO, F.; STORTI, F. Grain size and permeability evolution of softsediment extensional sub-seismic and seismic fault zones in high-porosity sediments from the Crotone basin, southern Apennines, Italy. Marine and Petroleum Geology 27 (2010) 822-837.

BAUER, J.F.; MEIER, S.; PHILIPP, S.L. Architecture, fracture system, mechanical properties and permeability structure of a fault zone in Lower Triassic sandstone, Upper Rhine Graben. Tectonophysics 647-648 (2015) $132-145$.

BENSE, V.F.; GLEESON, T.; LOVELESS, S.E.; BOUR, O.; SCIBEK, J. Fault zone hydrogeology. Earth-Science Reviews 127 (2013) 171-192

BORJA, R.I. Plasticity Modeling \& Computation. 1를 ed., Springer (2013), p. 122. 
BOTT, M. The mechanics of oblique slip faulting. Geological Magazine (1959), 96:109-117.

BOUTÉCA, M.J. Constitutive Law for Permeability Evolution of Sandstones During Depletion. SPE International Symposium on Formation Damage Control held in Lafayette, Louisiana (February 2000).

CAINE, J.S.; EVANS, J.P.; FORSTER, C.B. Fault zone architecture and permeability structure. Geology (1996) 1025-1028.

CHILDS, C., MANZOCCHI, T., WALSH, J.J., BONSON, C.G., NICOL, A., SCHOPFER, M.P.J. A geometric model of fault zone and fault rock thickness variations. Journal of Structural Geology 31 (2), (2009), 117-127.

CRAWFORD, B.R. Constitutive Modeling of Deformation and Permeability: Relationships Between Critical State and Micromechanics. SPE/ISRM Rock Mechanics Conference held in Irving, Texas (2002).

CUSS, R.J.; RUTTER, E.H.; HOLLOWAY, R.F. The application of critical state soil mechanics to the mechanical behaviour of porous sandstones. International Journal of Rock Mechanics \& Mining Sciences 40 (2003) 847-862.

DAVIS, R.O.; SELVADURAI. A.P.S. Plasticity and Geomechanics. $1^{\underline{a}}$ ed., Cambridge University Press (2002), p. 56-57.

FAULKNER, D.R.; JACKSON, C.A.L.; LUNN, R.J.; SCHLISCHE, R.W.; SHIPTON, Z.K.; WIBBERLEY, C.A.J.; WITHJACK, M.O. A review of recent developments concerning the structure, mechanics and fluid flow properties of fault zones. Journal of Structural Geology 32 (2010) 1557-1575.

FJÆER, E.; HOLT, R.M.; HORSRUD, P.; RAAEN, A.M.; RISNES, R. Petroleum Related Rock Mechanics. 2ª ed., Elsevier (2008), p. 298-306, 418-424, 439.

FLORNES, O. Stress dependent fluid flow in porous rock: Experiments and network modelling. PhD Thesis NTNU (2005):207, 119 pp.

FOSSEN, H.; SCHULTZ, R.A.; SHIPTON, Z.K.; MAIR, K. Deformation bands in sandstone: a review. Journal of the Geological Society (2007) 164 (4), 755-769.

FOSSEN, H.; SOLIVA, R.; BALLAS, G.; TRZASKOS, B.; CAVALCANTE, C.; SCHULTZ, R.A. A review of deformation bands in reservoir sandstones: 
geometries, mechanisms and distribution. Geological Society, London, Special Publications, 459 (2017) 9-33.

FOSSEN H. Structural Geology. $2^{\underline{a}}$ ed., Cambridge University Press (2011), p. 192-196.

HERTZ, H. Über die Berührung fester elastischer Körper. J. Reine Angew. Math., 92 (1882), p. 156.

HANTSCHEL T.; KAUERAUF, A. I. Fundamentals of Basin and Petroleum Systems Modeling. $1^{\text {a }}$ ed., Springer (2009), p. 406-408.

ISSEN, K.A.; RUDNICKI, J.W. Conditions for compaction bands in porous rock. Journal of Geophysical Research (2000) 105, 21,529-21,536.

ISSEN, K.A.; RUDNICKI, J.W. Theory of compaction bands in porous rock. Physics and Chemistry of the Earth (2001) (A) 26, 95-100.

JAEGER, J.C; COOK, N.G.W. Fundamentals of Rock Mechanics. $2^{\mathrm{a}}$ ed., Chapman and Hall (1979).

MATSUMOTO, N.; SHIGEMATSU, N. In-situ permeability of fault zones estimated by hydraulic tests and continuous groundwater-pressure observations. Earth, Planets and Space (2018) 70-13.

MORAES, A. Comportamento mecânico de zonas de falhas. Instituto de Geociências - UFRJ, Doutorado, Programa de Pós-graduação em Geologia, (2004), XIX, 300p.

MORAES, A.; RICCOMINI, C. Inversão de paleotensões em bacias sedimentares utilizando condicionantes da geomecânica aplicada à indústria do petróleo. 47ํㅡㄹ Congresso Brasileiro Geologia (2014), Salvador, PAP15206.

MORAES, A. Estimativa de Paleomodelos Geomecânicos em Bacias Sedimentares. I Simpósio de Geologia (2018), Petrobras.

MORAES, A. Mecânica do Contínuo para a Geologia Estrutural. $2^{\underline{a}}$ ed., PerSe (2016), p. 69. 
NGUYEN, V.H.; GLAND, N.; DAUTRIAT, J.; DAVID, C.; WASSERMANN, J.; GUÉLARD, J. Compaction, permeability evolution and stress path effects in unconsolidated sand and weakly consolidated sandstone. International Journal of Rock Mechanics \& Mining Sciences 67 (2014) 226-239.

NIKOLAEVSKIY, V.N. Geomechanics and Fluidodynamics With Applications to Reservoir Engineering. Springer Science+Business Media Dordrecht (1996), p. $65-66$.

ROCHA, L.A.S.; AZEVEDO, C.T. Projetos de poços de petróleo: geopressões e assentamento de colunas de revestimentos. $1^{\underline{a}}$ ed., Editora Interciência: Petrobras (2007), p. 76-95, 283-312.

ROSCOE, K.H., BURLAND, J.B. On the generalized stress-strain behaviour of 'wet' clay. In: Engineering Plasticity. Cambridge University Press (1968), p. 535609.

ROSCOE, K.H.; SCHOFIELD, A.N.; THURAIRAJAH, A. Yielding of clays in states wetter than critical. Géotechnique 13 (1963), 211-240.

ROTEVATN, A; FOSSEN, H. Simulating the effect of subseismic fault tails and process zones in a siliciclastic reservoir analogue: Implications for aquifer support and trap definition. Marine and Petroleum Geology 28 (2011) 16481662.

RUTTER, E.H.; GLOVER, C.T. The deformation of porous sandstones; are Byerlee friction and the critical state line equivalent? Journal of Structural Geology 44 (2012) 129-140.

SCHOLZ, C.H. Wear and Gouge formation in brittle faulting. Geology 15 (6), (1987), 493-495.

SCHULTZ, R.A.; SIDDHARTHAN, R. A general framework for the occurrence and faulting of deformation bands in porous granular rocks. Tectonophysics 411 (2005) 1-18.

SOLIVA, R.; SCHULTZ, R.A.; BALLAS, G.; TABOADA, A.; WIBBERLEY, C.; SAILLET, E.; BENEDICTO, A. A model of strain localization in porous sandstone as a function of tectonic setting, burial and material properties; 
new insight from Provence (southern France). Journal of Structural Geology 49 (2013) 50-63.

SPERREVIK, S.; GILLESPIE, P.A.; FISHER, Q.J.; KNIPE, R.J. Empirical Estimation of Fault Rock Properties. In: Koestler, A.G., Hunsdale, R. (Eds.), Hydrocarbon Seal Quantification. NPF Special Publications, (2002), vol. 11, p. 109-125.

TORABI, A.; BERG, S.S. Scaling of fault attributes: a review. Marine and Petroleum Geology 28, (2011), 1444-1460.

TUECKMANTEL, C.; FISHER Q.J.; GRATTONI C.A.; APLIN, A.C. Single-and two-phase fluid flow properties of cataclastic fault rocks in porous sandstone. Marine and Petroleum Geology 29 (2012) 129-142.

WALLACE, R. Geometry of shearing stress and relation to faulting. The Journal of Geology (1951), 59:118-130.

WONG, T.; DAVID, C.; ZHU, W. The transition from brittle faulting to cataclastic flow in porous sandstones: Mechanical deformation. Journal of Geophysical Research 102 (B2) (1997) 3009-3025.

WONG, T.; BAUD, P. The brittle-ductile transition in porous rock: A review. Journal of Structural Geology 44 (2012) 25-53.

ZHANG, J.; WONG, T.; DAVIS, D.M. Micromechanics of Pressure-Induced Grain Crushing in Porous Rocks. Journal of Geophysical Research, 95 (B1) (1990) 341-352.

ZHU, W.; MONTESI, L.G.J.; WONG, T. Shear-enhanced compaction and permeability reduction: Triaxial extension tests on porous sandstone. Mechanics of Materials 25 (1997) 199-214.

ZOBACK, M.D. Reservoir Geomechanics. $2^{\underline{a}}$ ed., Cambridge University Press (2010), p. 222-223.

ZOBACK, M.D. Reservoir Geomechanics - In situ stress and rock mechanics applied to reservoir processes. Notas de aula. Stanford University Online (2016), gp202.class.stanford.edu, lecture 9 - Minifracs Shmin and Constraining Shmax, p. 23. 